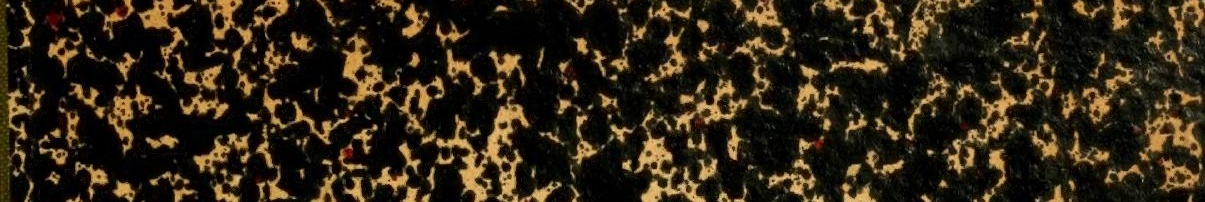

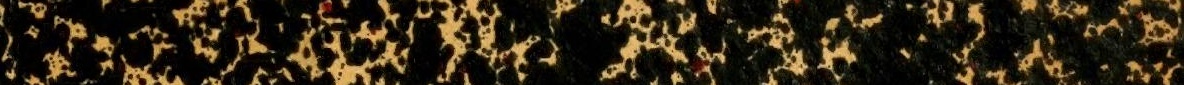

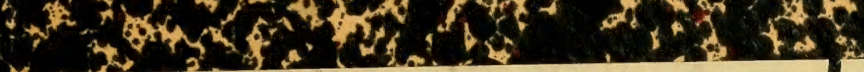

3

\title{
LABORATORY MANUAL
}

$O F$

CEREALS and FORAGE CROPS

(1)

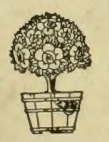

LIVINGSTON \& STEMPLE

10.

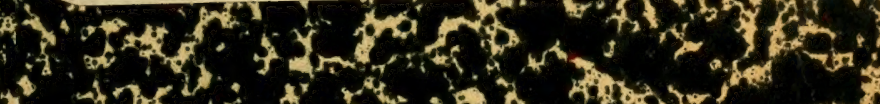

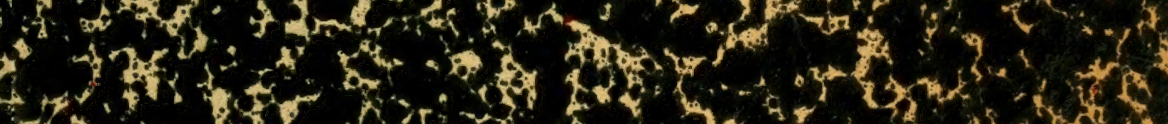

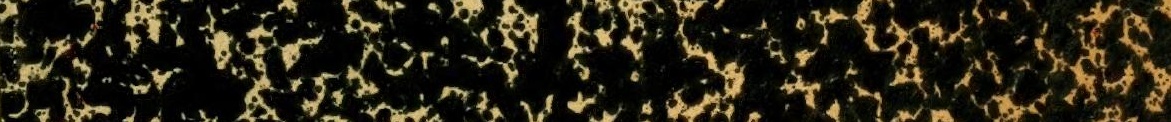

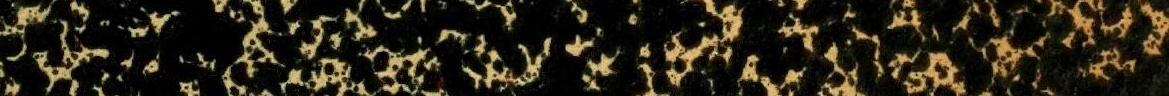

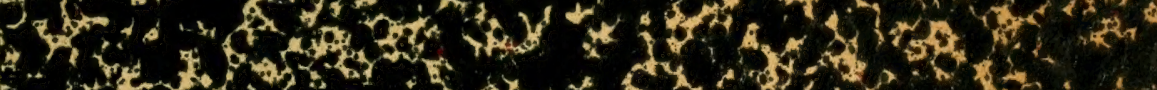

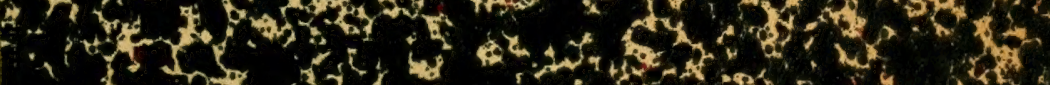

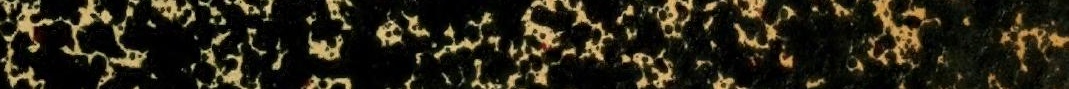

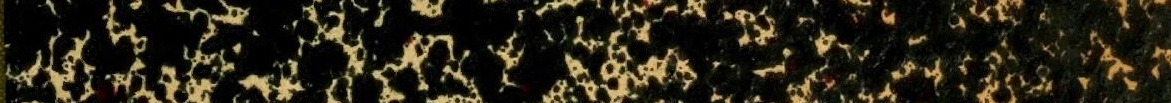

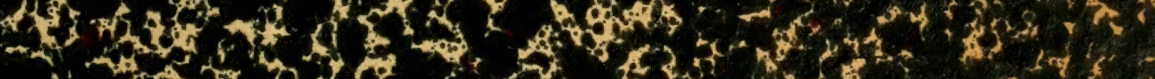

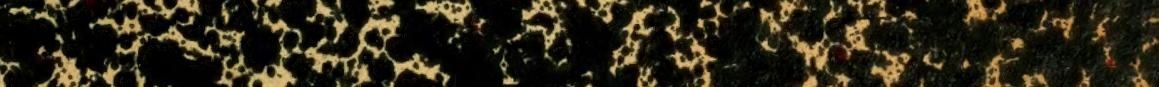

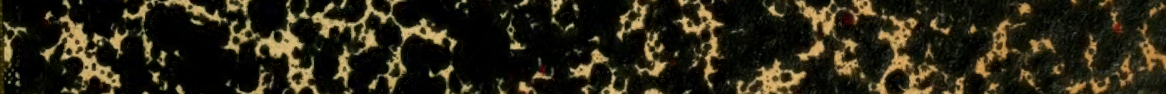

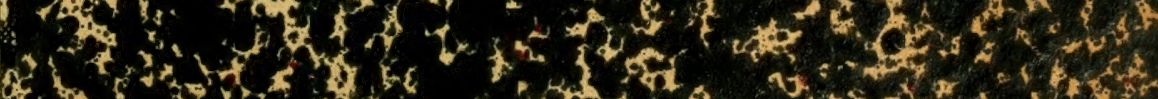

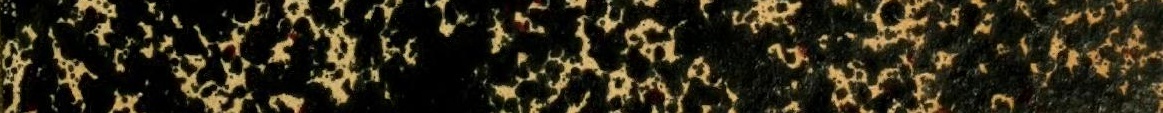

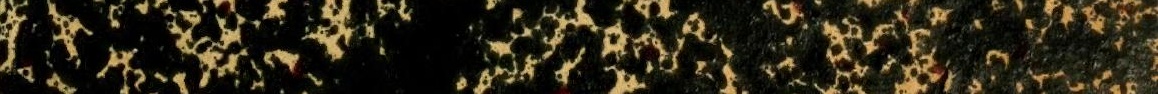
\& ${ }^{2}$ 


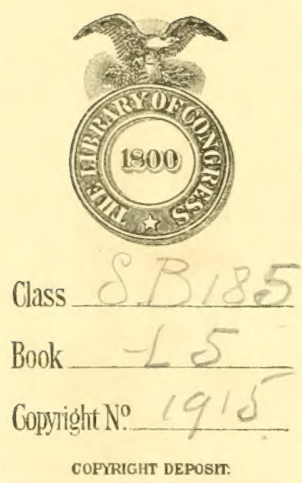





\title{
Laboratory Manual
}

\section{Of \\ CEREALS and FORAGE CROPS}

\author{
By \\ Geo. Livingston \\ Formerly Assistant Professor of Agronomy in the Ohio State University \\ And \\ F. W. Stemple \\ Instructor in Agronomy in Ohio State University
}

R. G. ADAMS \& COMPANY

COLUMBUS, OHIO

1915 


$$
\begin{gathered}
S B 185 \\
15 \\
1915
\end{gathered}
$$

COPYRIGHT 1915

BY THE

AUTHORS

$\therefore \vdots$

\& 0.90

NOV $-5 / y \mid 5$

(C) C. A416:295

no. 1 . 


\section{PREFACE}

A large number of the exercises contained in this manual have been used during the past four years as laboratory exercises in connection with the regular Cereal and Forage Crop courses at the Ohio State University. During that time it has become evident that, to make the courses as valuable as possible, and at the same time as full of interest and pleasure as other scientific courses, that several changes and additions needed to be made.

The botanical study of the plants has been considerably increased, giving the student a more complete idea of the plants, both as a matter of general knowledge and as a preparation for future work in plant improvement. In the matter of corn judging, the authors have tried to keep within the bounds of genetic knowledge, feeling that there is a place in this sort of work for a better idea of future corn improvement. As most instructors know, the score cards are only used as a means to bring more closely to the student's attention the things that are important in the consideration of the quality of the material to be scored. Just as the stockman shows by means of his score card what things he considers essential in an animal so the crop man shows what he considers essential in the plant. After the student has these things well in mind the score card should be dropped, for at best the values on it are only arbitrary. References are given to various score cards and from them the student will readily see that the aim of all is the same, but the values used are somewhat different means of attaining the same end.

Several new exercises have been added because we have felt that a general laboratory outline should contain everything of a general nature possible that belongs to the realm of general field crops study. More than one laboratory period of two hours per week will be required to complete all of the exercises, but when no more time is available, such exercises as are deemed most important may be selected for study.

The use of references in making assignments for written reports we feel is one of the most valuable parts of this work. For the most part these references are of late date and worth while. However, as a matter of advice we think that the instructor would do well to look these all up himself before making assignments in order that the student will not be given something too technical or too difficult for an intelligent report. The use of blank leaves placed at intervals in this book will be valuable in taking notes on instructor's recommendations, explanations and so on.

Many suggestions have been gained from various sources, especially from Hunt's "Cereals in America" and "Forage and Fiber Crops," Shoesmith's "The Study of Corn," Lyon and Montgomery "The Grading of Grain" and Call and Schaefer's "Agricultural Laboratory Guide." To J. F. Courcier, Secretary of the Grain Dealers' National Association, to J. C. F. Merrill, Secretary of the Chicago Board of Trade, to J. W. T. Duvel, U. S. Crop Technologist, and to J. W. McCord, Secretary of Ohio Grain Dealers' Association we are much indebted for information in regard to the grading of grain. To Malon Yoder, formerly Assistant, and to Adolph Waller and Max Abell, at present Assistants in Agronomy in Ohio State University, for the many suggestions, just criticisms, and helpful advice obtained from them we are especially grateful. 



\section{TABLE OF CONTENTS.}

Corn.

Exercise 1. Corn Botany.

Exercise 2. Selecting of Seed in the Field.

Exercise 3. Storing Seed Corn.

Exercise 4. Judging Corn.

Exercise 5. Placing of Corn Ears.

Exercise 6. Placing of Five-ear Samples.

Exercise 7. Field Study-Ear-row work.

Exercise 8. Field Study of Varieties.

Exercise 9. Germination Tests.

Exercise 10. Moisture Tests.

Exercise 11. Final Selection of Seed Corn.

Wheat.

Exercise 12. Wheat Botany.

Exercise 13. Field Study of Varieties. (Early Growth.)

Exercise 14. Laboratory Study of Varieties.

Exercise 15. Field Study of Varieties. (Late Growth.)

Exercise 16. Field Study of Head-row Work.

Exercise 17. Judging.

Exercise 18. Scoring.

Exercise 19. Study of Market Classes.

Oats.

Exercise 20. Botany of Oats.

Exercise 21. Laboratory Study of Varieties.

Exercise 22. Field Study of Newly Sown Oat Field.

Exercise 23. Field Study of Varieties.

Exercise 24. Weeds Found in Oat Seed.

Exercise 25. Judging.

Exercise 26. Scoring.

Exercise 27. Treatment for Smut of Grains.

Barley.

Exercise 28. Botany of Barley.

Exercise 29. Laboratory study of Varieties.

Exercise 30. Judging.

Exercise 31. Scoring.

Exercise 32. Germination. 
Rye.

Exercise 33. Botany and Scoring of Rye.

General.

Exercise 34. Comparison of Oats, Wheat, Corn, Barley, and Rye.

Exercise 35. Keeping Record of Market Prices.

Exercise 36. Distribution of Farm Crops.

Exercise 37. Grading Grain.

Exercise 38. Grading Grain.

Exercise 39. Grading Grain.

\section{Legumes.}

Exercise 40. Inoculation for Legumes.

Exercise 41. Botany of Legumes.

Exercise 42. Laboratory Study of Beans and Peas.

Exercise 43. Study of Weed Seeds Found in Forage Crops.

Exercise 44. Study of Weed Plants.

Exercise 45. Study of Legume Seeds. (Alfalfa, etc.)

Exercise 46. Identification of Seeds.

Exercise 47. Purity Test of Seeds.

Exercise 48. Germination Test of Seeds.

Exercise 49. Laboratory Study of Leguminous Plants.

Exercise 50. Field Study of Leguminous Plants.

Grasses.

Exercise 51. Study of Grass Seeds.

Exercise 52. Identification of Grass Seeds.

Exercise 53. Purity Test of Grass Seeds.

Exercise 54. Germination Test of Grass Seeds.

Exercise 55. Collecting and Mounting Grass, Grain, and Legume Specimens.

Exercise 56. Laboratory Study of Grasses.

Sorghums and Millets.

Exercise 57. Study of Sorghums and Millets.

Potatoes:

Exercise 58. Field and Laboratory Study of Varieties.

Exercise 59. Scoring.

Appendix.

Table of Seed Weights and Quantity to Use in Seeding. 
Note.

Exercises 1, 12, 20, 34, and 41 require both seedlings and plants at the stage of bloom. The instructor needs pay attention to this that he may have material ready at time to give the work. To get the plants to the stage of bloom requires some green house space. Exercise 40 will require ten weeks to complete. Hence this needs to be started sufficiently early in the Semester. 


\section{PRELIMINARY NOTICE.}

(1) Label all parts that are to be shown in each drawing.

(2) Use a hard pencil $(4 \mathrm{H})$ in making the drawings, and ink them in at your convenience.

(:) Use Standard Engineers' Note Book $(8 \times 10)$ which should be supplied with hoary palper for the drawings, and lighter paper for the notes and reports.

(1) Do not malie the drawings too small, usually about one-half page. Use one side of the paper only.

(5) Make the notes brief and concise. Use one side of the paper. Write with ink.

(6) The following are reference books used in this course. Further reference to these works in the book will be to the name of the authors only and not to the title.

THE BOOK OF CORN Bowman and Crossley.

THE BOOK OF CORN Myrick.

THE STUDY OF CORN

THE CORN PLANT. Shoesmith.

PRACTICAL BOTANY Sargent.

AGRICULTURAL BOTANY Bergen and Caldwell.

THE GRADING OF GRAIN

FIELD CROPS. Percival. Lyon and Montgomery.

FIELD CROP PRODUCTION Wilson and Warburton.

SOUTHERN FIELD CROPS Livingston.

CEREALS IN AMERICA. Duggar.

THE BOOK OF WHEAT Hunt.

MIANUAL OF WEEDS Dondlinger.

A TEXT BOOK OF GRASSES Ada Georgia.

MEADOWS AND PASTURES Hitcheock.

THE POTATO Wing.

THE POTATO. Fraser. Guilford and Grubb.

(7) A report on any reference should consist of not less than 500 words. 
INSTRUCTOR'S NOTICES, EXPLANATIONS, ETC. 
Laboratory Manual of Cereals and Forage Crops.

INSTRUCTOR'S NOTICES, EXPLANATIONS, ETC. 
CORN.

LABORATORY EXERCISE.

(Label all parts in each drawing.)

1. Draw a kernel of each of the following types of corn:

(Germ side up.)
1. Dent
2. Flint
3. Soft
4. Pop
5. Sweet
6. Pod

In doing the following best results can be obtained if the kernel be soaked in hot water for fifteen to twenty minutes before cutting.

2. Make a longitudinal section of each of the above, showing:

1. Hull

2. Endosperm
a. Hard or horny
b. Soft or white starch

3. Germ
a. Scutellum
b. Plumule
c. Radicle

4. Tip cap

3. Make a cross section of the same and draw with the germ side up, showing all the parts.

1. Does the thickness of the horny gluten vary markedly in different kernels?

5. Does the percentage of tip starch vary materially in different kernels?

6. Which has the greater value for flesh production, a kernel with a large percentage of horny starch or one which is largely white starch?

7. A large germ denotes what in regard to feeding value? 
8. Make a drawing of a newly germinated kernel of corn, showing:

1. Plumule

2. Radicle

9. Make a drawing of a corn plant eight or ten days old, showing:

1. Kernel

2. Plantlet with unfolding leaves

3. Roots

a. Primary

b. Secondary

10. Make a drawing of a single root. (Enlarge.)

Indicate:

1. The root hairs

2. The root cap

3. The growing point

11. (a) What part of a root takes in food?

(b) What uses has the root cap?

(c) Where on a root are most of the root hairs?

(d) What effect will a wet spring have on the depth of roots and the number of root hairs?

12. Make a drawing of the roots of a mature plant showing:

1. The general direction of the roots and the points of attachment

2. Primary roots

3. Secondary roots

4. Brace roots

5. Base of stalk

13. Describe in a general way the evolution of the root system of the corn plant from the time of germination to the ripened plant.

14. (a) What is the comparative length of root and stem?

(b) If kernels are planted deeply early in the spring and the ground remains cold, where will the first permanent root appear?

(c) Name two reasons why a corn sprout which comes from a kernel which has been planted too deeply is always long and slender? 
15. (a) What causes the green color in the growing plant?

(b) Is there any assimilation of food by the plant until the green appears?

(c) In a cold spring, which kernel will be surer of putting its sprout above ground, one that is starchy or one that is horny?

(d) Why?

16. Are nodes and internodes present on the roots?

17. Describe in a general way the evolution of the root system of the corn plant from the time of germination to the ripened plant.

18. (a) Does the corn plant have a tap root?

(b) What is a fibrous root system?

(c) What physical factors might affect the root system?

19. (a) Would you call corn a surface, medium, or deep feeder?

(b) Differentiate between annual, biennial, and perennial root systems.

(c) To what class does corn belong?

(d) Do the brace roots come out equally on all sides?

(e) What conditions or factors influence this?

(f) At how many nodes do these brace roots appear?

$(\mathrm{g})$ What offices do the brace roots have?

20. (a) Describe the arrangement of the leaves in the young plant.

(b) Is corn a monocotyledon or a dicotyledon?

(c) What is the distinction between them?

21. Draw a portion of a corn stalk bearing a leaf showing: (Sketch and cross section.)
1. Leaf sheath
2. Leaf blade
3. Ligule
4. Auricle
5. Rain guard
6. Mid-rib
7. Epidermis
8. Woody portion
9. Pith
10. Fibro-vascular bundles.
11. Formative grooves. 
22. (a) What is the nature of the epidermis?

(b) How thick is the woody portion?

(c) Of what use is the epidermis?

(d) What are the differences in structure of the stem of a wheat plant and a corn plant?

23. (a) Define node and inter-node.

(b) Are the inter-nodes the same length throughout the stalk? Why?

(c) Discuss the fibro-vascular bundles as to their location, structure and function.

(d) What is the structure of the pith? Its function?

(e) Where does growth take place in the corn plant?

24. (a) What is the arrangement of the leaves on the stalk?

(b) Where does the leaf grow from?

(c) Discuss the purpose of the leat sheath, ligule, auricle and rain guard.

(d) What gives the wavy effect to the leaf blade?

(e) What is the purpose of the mid-rib?

25. Make a drawing of a corn tassel.

26. From a part of a corn tassel remove all except one pair of spikelets. Make an enlarged drawing of this pair in place. Are the two spikelets sessile or pedicelled?

27. Make a drawing of the dissected pair showing the following in their relative positions and properly labeled:
1. Outer glumes
2. Lemmas
3. Stamens
4. Paleas

28. (a) Why is the corn flower called unisexual?

(b) How many stamens are there to each spikelet?

29. With a compass pen show in a diagram the relative positions of the various parts of a tassel flower.

Why is this called a staminate flower? 
30. Make a drawing of a young corn ear with silks attached.

Note: Each silk is a stigma and style and each kernel an enlarged ovary all forming the pistil of the corn.

Are there any stamens present?

If the tassel is called a staminate flower, what should the silk be called?

31. Remove two or three kernels from an ear taking chaff with them.

Make a drawing of this showing:

1. Silk (stigma and style).

2. Kernel (Enlarged ovary).

3. Glumes (Outer glumes and lemma and palea).

What is the shuck?

32. Make a diagram representing the parts of the pistillate flower of a corn plant in their relative positions.

33. (a) If a paper sack is tied over an ear of corn in a field just before it begins to silk and left there two or three weeks, what will result?

(b) If the tassel is covered, what will result?

(c) Is corn self fertilized or cross fertilized?

34. Examine an ear of pod corn. Do you find the pistillate flowers more or less like those of other grasses than is the case with common corn?

Note: You will be able after studying wheat to observe that there is a strong similarity in the flowers of corn, grains, and grasses. All belong to the same family.

35. Make a cross section of an ear through the kernels. Make a drawing showing:

1. Kernels.

2. Fibro-vascular bundles.

3. Tip cap of kernels.

4. Portion of chaff.

5. Woody part.

6. Tubes.

7. Pith.

36. (a) How does each kernel receive its nourishment from the cob?

(b) Of what use are the little tubes between the woody part and the pith? 
(c) How are the rows of kernels arranged?

References: Sargent, pp. 11-68; Myrick, pp. 5-12; Duggar, pp. 78-97; Lyon and Montgomery, pp. 27-31; Wilson and Warburton, pp. 23-33; Bowman and Crossley, pp. 42-61; Kans. Bul. 139; Farmers' Bul. 409; Bureau of Plant Ind. Bul. 141; B. P. I. Bul. 278; B. P. I. Circ. 107; Bergen and Caldwell, pp. 5-23; Livingston, pp. 29-50.

EXERCISE 2.

DATE.

\section{SELECTION OF SEED CORN IN THE FIELD.}

From the rows assigned by the instructor, select twenty ears of corn that in your judgment will be desirable for seed. In making the selection. the following factors should be considered:

(1) Maturity

(2) Environment

(a) Rate of planting

(b) Abnormal conditions favorable to growth

(3) Vigor of the plant

(4) Ability to stand upright

(5) Height of the plant

(6) Height of the ear

(7) Angle of the ear

(8) Size of the ear

(9) Freedom from disease

In your notes tell how the above factors influenced your selection.

References: Ill. Bull. 132; Ohio Circ. 72; U. S. Bureau of Entomology Circ. 59 ; Shoesmith, pp. 86-94.

EXERCISE 3.

DATE

STORING OF SEED CORN.

Hang up the ears you have selected (employing the method indicated by the instructor) in the laboratory or store room. Label your selection with 
your name, date of selection and variety.

(1) What is the essential factor to be considered in the storing of seed corn?

(2) What methods other than the one you employed might be used?

(3) Discuss drying of seed corn by artificial heat.

References: Minn. Bul. 48; La. Bul. 118; Del. Bul. 77; Wis. Circ. 18; Farmers linlletins :31:, 405, 415; Bowman and (rostey, pr. 102-115; Wilsom and Warburton, pp. 121-123.

EXERCISE: 4.

DATE.

\section{CORN JUDGING.}

Before one is able to judge and select corn intelligently, he must be thoroughly familiar with all of the details of those factors which influence quality and seed condition in corn. Hatving once acquired a working knowledge of these details, it is necessary for him also to have a conception of the relative importance of the major points, such ats maturity and seed condition, uniformity of grain, etc., as means of determining the value of any ear or number of ears for seed purposes. Too much emphisis is commonly placed on those factors which have to do with the appearance of ears. Ears of excellent appearance often yield less than other's endowed with less beauty. Since, with our present linowledge of corn, yield camnot be associated with physical appearance with any degree of definiteness, more emphasis needs to be placed on the maturity, adaptability to local environment, and seed condition. These three factors are easily emphasized in the method of judging employed in exercise 4. Again, the continuous selection of desirable types will insure a greater chamee of getting pur lines for the quality desired than will the "scoop shovel" method of taking what comes with no regard to desirability.

There are two ways in which this judging sheet may be used. One is to use two cars, compare them according to points in the corn judging sheet (p. 21), and reeord the differences which you find. Express the degree of difference as slight, medium, or marked according to the method explained in 
Shoesmith, Chap. II., putting these terms in the column under the better ear. The other method is to record one's idea of how nearly the ear being judged comes to the ideal as explained by the instructor.

\section{Explanation of Corn Judging Sheet.}

A. Maturity and seed condition is of first importance in the selection of seed corn. The assurance of a crop of corn, insofar as the selection of seed is concerned, is first determined by the vitality of the seed used and secondly by the earliness or lateness of the corn. Immaturity means not only lower yields, but also poor seed condition.

Maturity and seed condition are determined by:

1. Hardness of grain and cob. The grain should be firm so that it cannot be pressed into the cob. The ear should be firm and rigid when slightly twisted by the hands.

2. Weight of ear in proportion to size. An immature ear has a lower weight in proportion to its size, after it has thoroughly dried out, than one that is well matured.

3. Color of ear and kernels. Immature yellow corn has a dull mottled color of light and golden yellow. Many times the crown of the kernels are golden yellow with the tip of the hull showing a light color. Immature w] ite corn has a dull white color. Ears that have been exposed to moisture conditions are dull or bleached. The cobs of immature corn are often dull in color.

4. Color of kernels. The tip of the kernel should not be pale. The germ in cross section should not be pale, dull, nor brown. The color should be light creamy yellow. There should be no white spots or a light colored streak from the crown to the tip on the side opposite the germ.

5. Shape of kernels at tip. Thickness at the tip indicates a large germ and well matured corn. A wide tip insures a large germ, a pointerl tip, a small compressed germ.

6. Size of kernels. The kernels should be large, and quite thick, indicating a large germ and a plentiful food supply for the early life of the seedling:

7. Size of germs. A large germ indicates a vigorous embryo.

8. Freedom from mold and fungus disease. The presence of disease 
indicates not only poor seed condition of infected parts, but also susceptibility to rotting when planted, if inclement weather prevails.

9. Freedom from breaking off of the tip caps. Kernels from improperly stored or immature ears frequently leave the tip cap in the cob when shelled. The tip cap should remain on the grain to serve as a protection in case of unfavorable conditions in the soil. Breaking off of the tip cap is usually, though not always, associated with low vitality.

10. Freedom from insect attack. Any attack by insects reduces the vitality of the seed.

11. Freedom from blisters. Blisters on the kernels are due to the presence of an excess of moisture at harvest time or improper curing of the seed. They are associated with poor seed condition.

12. Freedom of tip cap from cob chaff. The presence of cob chaff on the tips of kernels after removal from the cob is an indication of immaturity.

13. Proportion of hard to soft endosperm. A high proportion of soft endosperm in the kernel is usually associated with immaturity.

Make a final placing of the ears for maturity and seed condition.

B. Uniformity of lernels is important as an indication of the purity of the grains in an ear of corn, and also of the accuracy of distribution by the planter.

Straight and uniform rows from butt to tip of ear insures the greatest possible uniformity in size and shape of kernels. Notice whether or not the indentation and color are uniform for all kernels in the ear.

Make a final placing for uniformity.

C. Amount and proportion of grain to $c o b$ not only influences the yield of sheller corn but also bears a direct relation to the feeding value of the corn. This point is of value in judging leeding classes. The proportion of grain to cob can be determined by:

1. The weight of ear in proportion to size. Other things being equal, the ear with the heavier weight in proportion to size has the higher percentage of grain.

2. Depth of lernels in proportion to size. The cob should not be too large, and the kernels should be fairly derp, the depth depending upon the type or variety and the latitude in which the corn was grown. 
3. Space between grains. Any space between kernels reduces the weight of grain and the proportion of grain to cob. The kernels should be full and strong at the tip; and there should not be much space between the kernels at the tip when viewed in the ear.

4. Filling out of butts and tips. Any uncovered part of the cob reduces the amount of grain. While covered tips are not indicative of higher yielding corn, from the standpoint of feeding value alone it is important to have well covered tips.

Make a final placing for amount of grain.

D. Shape of ears does not seem to be directly associated with high yield, but it is important in that it influences uniformity in type, and amount of grain.

The sides of the ear should be straight, and the width of the ear should be carried well towards the tip. Unless variety standards specify otherwise, the tip should have an abrupt taper and a well rounded outline. The butt should be full and well rounded forming a depression at the shank.

The circumference should be approximately three-fourths of the length of an ear. Too large a cob lowers the proportion of grain and lengthens the drying process. A slender ear frequently carries shallow grains. Make a final placing for shape.

E. Composition is important from the feeding standpoint. High protein content is associated with a high proportion of horny to soft endosperm. A large germ indicates a high content of oil.

F. Shank. The shank or place of attachment should be neither too large nor too small. Too large a shank makes harvesting more difficult; and one that is too small is likewise objectionable because of the weakness of attachment.

Make a final placing of the ears studied, taking into consideration all of the above points.

References: Myrick, pp. 70-82 ; Shoesmith, pp. 34-86 ; Duggar, pp. 98111; Lyon and Montgomery, pp. 33-47; Bowman and Crossley, pp. 406-423; Livingston, pp. 92-93; Wis. Circ. 8; Ohio Circ. 86; Ohio Bul. 212 and 282; Kans. Bul. 139; Ky. Bul. 145; Ind. Circ. 18. 


\section{EXERCISE 4.}

No. of Sample or No, of Ear

40. A. Maturity and seed condition

1. Hardiness of grain and cob.

2. Weight of ear in proportion to size

3. Color of ear and kernels

(1) Due to immaturity

(2) Due to moisture conditions

4. Color of kernels

1. At tip.

(2) Germ (cross section)

(3) Side opposite germ.

5. Shape of kernels at tip

(1) Thickness

(2) Width

6. Size of kernels

7. Size of germs

8. Freedom from mold and fungus disease.

9. Freedom from breaking off of tip caps...

10. Freedom of attack of insects

11. Freedom from blisters.

12. Freedom of tip caps from cob chaff

13. Proportion hard to soft endosperm

Total maturity and seed condition.

10. B. Uniformity of kernels in:
1. Size
2. Shape as viewed in ear
3. Color
4. Indentation
Total uniformity of kernels

20. C. Amount and proportion of grain to cob

1. Weight of ear in proportion to size

2. Depth of kernels in proportion to size of cobs

3. Space between kernels
(1) At tip.

(2) At crown

4. Filling out of butts and tips of ears

Total for amount of grain.

10. D. Shape of ears

1. Cylindricity.

(1) Shape of tip

(2) Shape of butt

(3) Fullness in middle portion

(4) Straightness of sides

2. 1.rngth and circumferenee of ear Total for shape

1.j. E. comprition

1. Protein - amount of horny endosperm

5. F. Shank

2. Oil size of germ

Total of all qualities

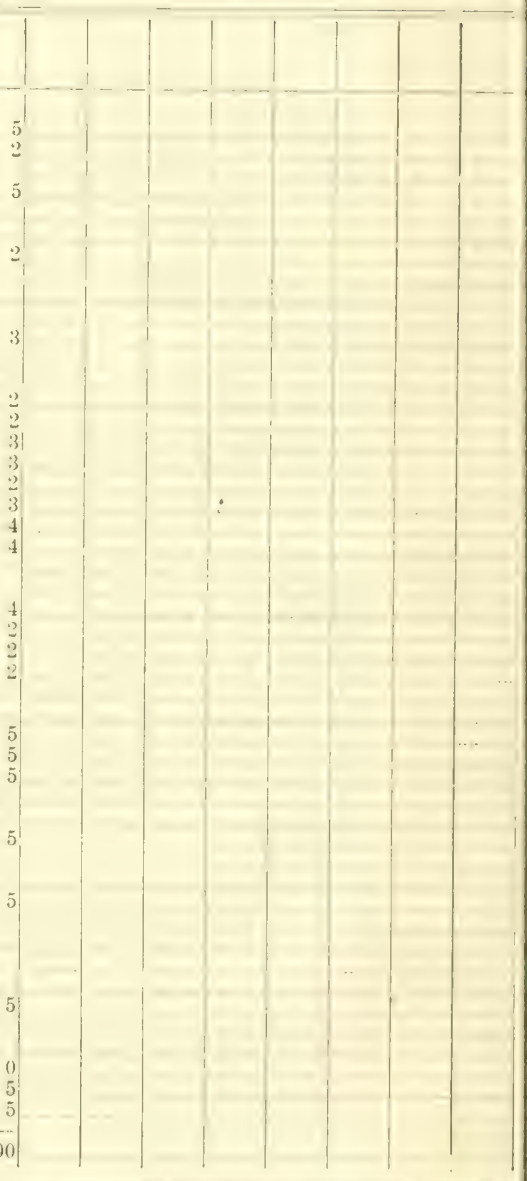


DATE

ING

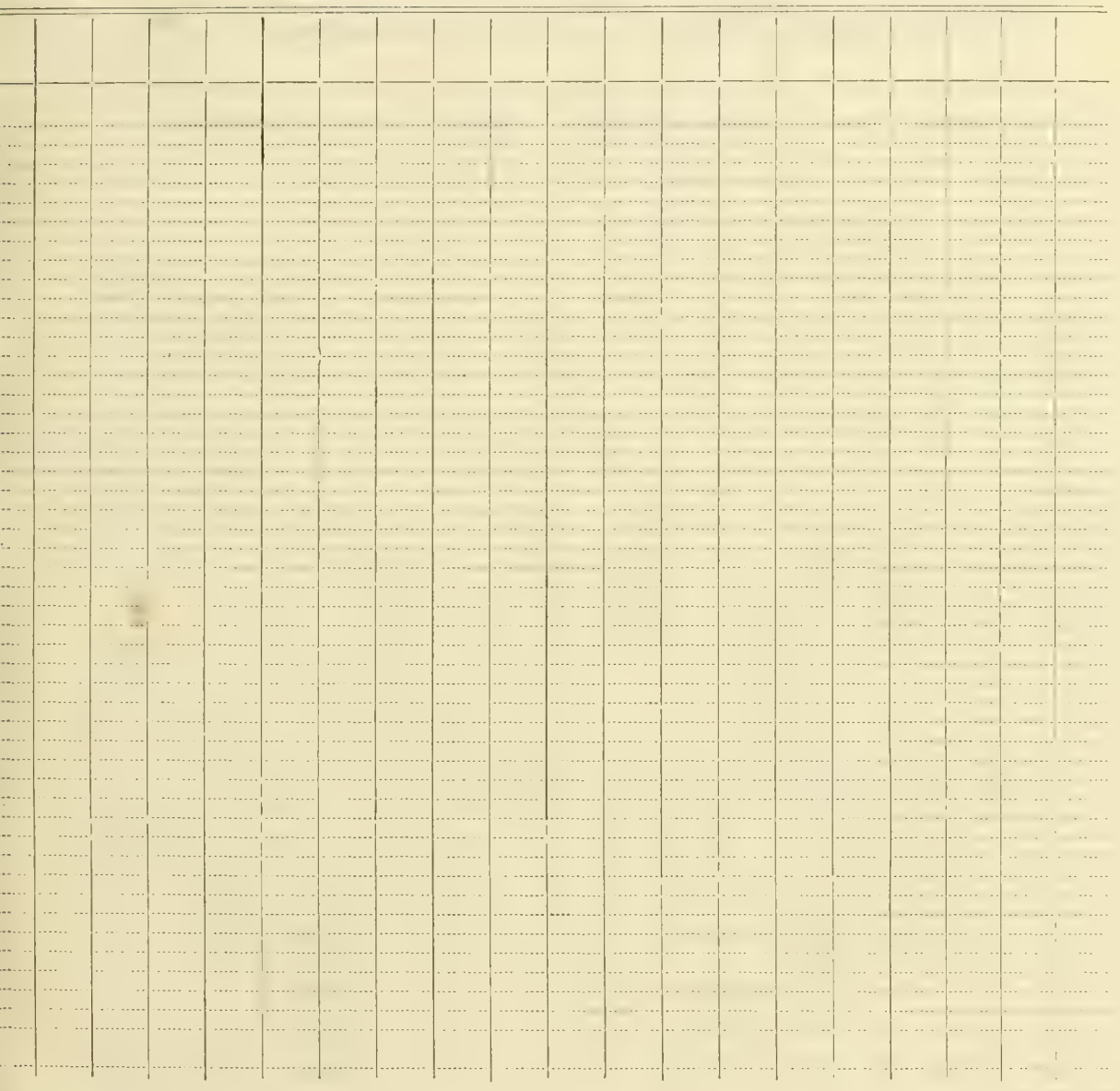


EXERCISE 5. DATE.

Corn Judging. (Placing of ears within five ear samples.)

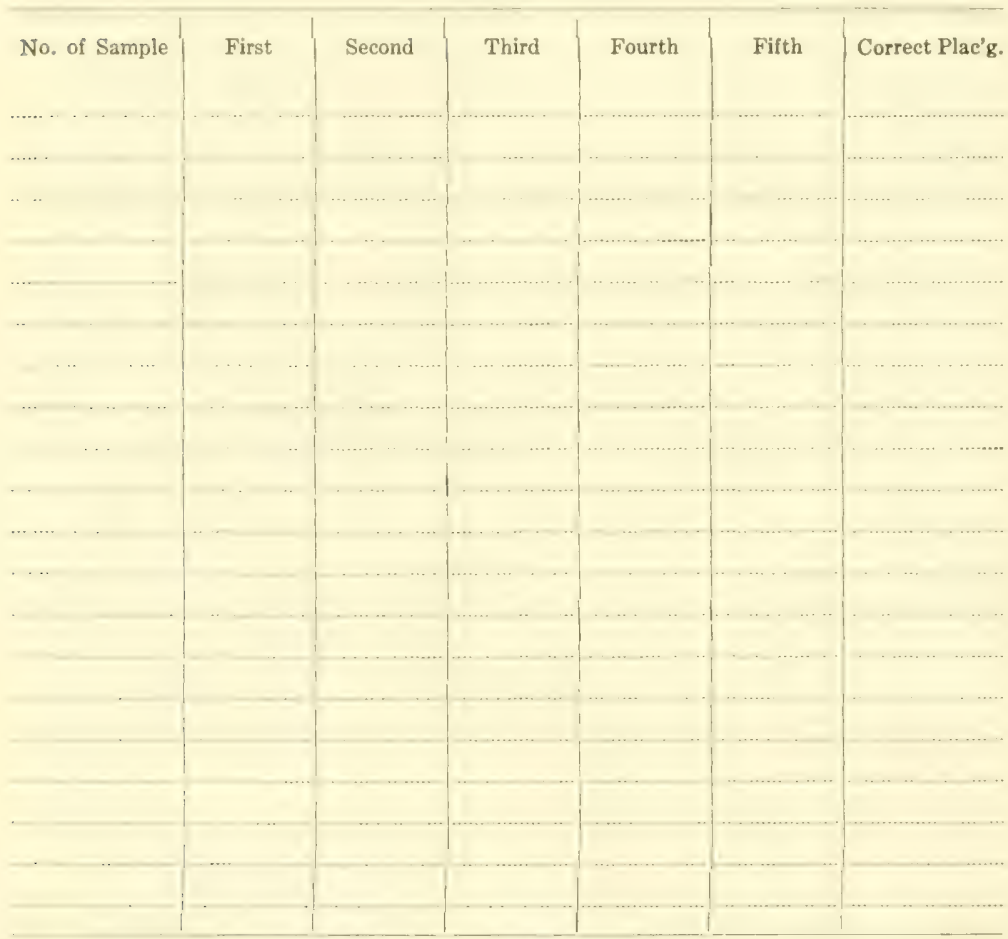


EXERCISE 6.

DATE

\section{CORN JUDGING.}

Placing of five-ear exhibits. (Five five-ear samples are placed on one table or in one section. The student will place these samples recording his placings in ink. Leave the book at end of period for instructor's examination.)

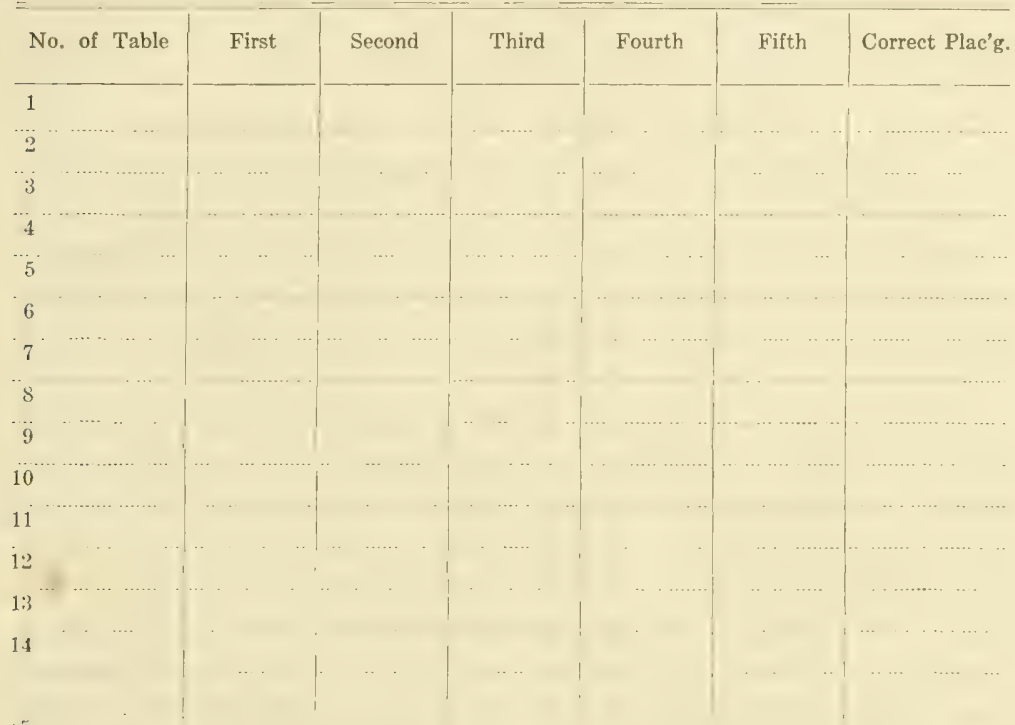

15

Reason for any unusual placing: State number of Exhibit and explain your reason for any unusual placing.

No. of exhibit.

No. of exhibit.

No. of exhibit

No. of exhibit

No. of exhibit.

No. of exhibit

No. of exhibit

No. of exhibit

No. of exhibit

No. of exhibit 
INSTRUCTOR'S NO'TICES, EXPLANATIONS, ETC. 
Iaboratory Manual of Cereals and forage Crops.

INSTRUCTOR'S NOTICES, EXPLANATIONS, ETC. 


\section{CORN RECORDS. EAR-TO-ROW AND VARIE'TY.}

Node Bearing Ear.

Count from first node visible above the ground. (Average of 10 hills.)

Leafiness of Plant.

Very leafy (V. L.) ; Leafy (L) ; Medium (M) ; Poor (P) ; Very Poor (V. P.)

Maturity.

Very early (V. E.) ; Early (E) ; Medium (M) ; Late (L) ; Very Late (V. L.).

Down Plants.

Plants standing at an angle of $30^{\circ}$ or less with the ground.

Broken Stalks.

Stalks broken at a point 24 inches or more below the base of the tassel.

Barren Stalks.

No kernels produced.

Useless Plants.

Extremely small ears, or less than a dozen kernels.

Suckers.

Plants that do not have an independent root system.

Angle of Ear.

Erect (E) ; Medium erect (M. E.) ; Medium (M) ; Medium drooping (M. D.) ; Drooping (D).

Height of Stalk.

Measure to top of tassel. (Average of 10 hills.)

Height of Ear.

Measure to node bearing ear. (Average of 10 hills.)

(When two ears are present measure height of lower one.)

Brace Roots.

Very good (V. G.) ; Good (G) ; Medium (MI) ; Poor (P) ; Very poor (V. P.). 
EXERCISE 7.

DATE.

FIELD STUDY OF CORN - EAR-TO-ROW.

Row No.

Total

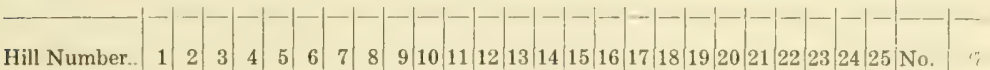

Stalks in hill

Suckers

Broken stalks

Barren stalks

Smutt'd pl'ts

No. 2-eared plants.

General qualities of row:

Maturity

Leafiness of plant

Height of plants

- Size of ear

Height of corn

Stiffiness of stalk

Adaptability

Row No,

Total

- ill Number

Stalks in hill

Suckers

Broken stalks

Barren stalks

Smutted pl'ts

No. 2-eared plants

General qualities of row:

Maturity

Leafiness of plant.

Height of plants.

Size of ear

Height of corn

Stiffness of stalk

Adaptability

Make a report of conclusions drawn from this study.

References: Ill. Bull. 132; N. C. Report 1912 (Suckers on Corn);

Ohio Bul. 282, pp. 83-84 and 91-101; Livingston, pp. 82-93. 
EXERCISE 8.

$\lim \mathrm{Xi}$.

No. hille jer low

Xo. mi sime litls:

No. hills having

I stilll:

2 stalks

i) stalli:-

1 stilli-

Suckers

I) rulien stalis:

simutted stalliz

liarren statlis.

Iterioht of stali:

Height of ear.

size of rar

No, of two-eared plants.

L.rifine of plant

Angle of ear.

Nerle hetrint rar

Brace root develonment

Incert injurie-s

Per cent. of

St:mu

Smutter stit!1-

Two-r..rut y)latut -

Brol.(e.1) $\leq 1: 11$.

Maturity. 
DATE

RN IN THE FIELD.

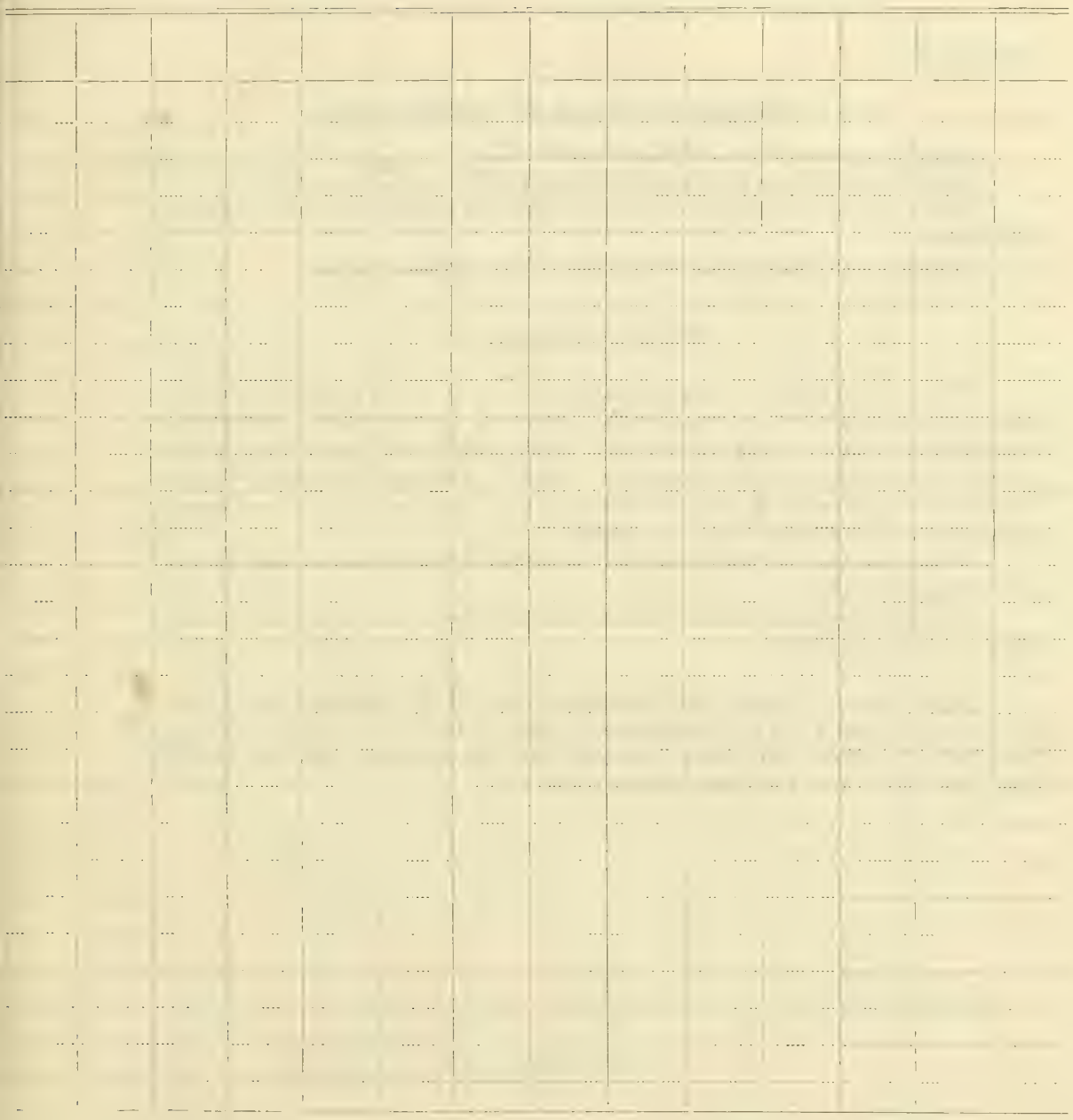

REFERENCES ON VARIETIES:

Bul. of nearly every state.

Shoesmith, pp. 11-13.

Duggar, pp. 112-149.

Myrick, pp. 12-36.

Bowman and Crossley, pp. 424-446. 
EXERCISE 9.

THE GERMINATION TEST OF SEED CORN.

Use the ears selected in Exercise No. 2.

With pins and tags number the ears from 1 to 20 , consecutively.

Examine several kernels from each ear, and estimate the percentage of germination.

Record your estimate in the proper column in the outline.

\section{MAKING THE TEST.}

Place in the bottom of a germination box from 1 to $11 / 2$ inches of moist sand. Cover this layer of sand with a piece of cotton cloth. Remove six kernels from various parts of each ear to be tested, and place them in the square corresponding to the number of the ear. Place another cloth over the kernels and cover with $1 / 2$ inch of moist sand. Examine the test and apply more moisture from day to day as needed.

When the test is completed make a careful examination of each kernel, and tabulate results.

Remove sand and cloths from germination box, and clean and return them to proper places.

References: Wilson and Warburton, pp. 66-70; Bowman and Crossley, pp. 61-77 and 115-146; Livingston, pp. 68-71; Ohio Bul. 282, pp. 103-10.4; Iowa Bul. 135; Kans. Bul. 136; Farmers' Bul. 253 and 428; Ill. Bul. 96; 111. Circ. 49; Wis. Circ. 18; Nebr. Exten. Bul. 3. 
DATE

RESULTS OF GERMINATION TEST.

\begin{tabular}{|c|c|c|c|c|c|}
\hline Ear No. & Strong & Weak & Dead & $\begin{array}{l}\text { Percentage of strong } \\
\text { germination }\end{array}$ & Estimated germination \\
\hline \multicolumn{6}{|l|}{$1 .}$. \\
\hline \multicolumn{6}{|l|}{2} \\
\hline \multicolumn{6}{|l|}{3.} \\
\hline \multicolumn{6}{|l|}{4} \\
\hline \multicolumn{6}{|l|}{5.} \\
\hline \multicolumn{6}{|l|}{$6 \ldots \ldots$} \\
\hline \multicolumn{6}{|l|}{7} \\
\hline \multicolumn{6}{|l|}{$8 \ldots$} \\
\hline \multicolumn{6}{|l|}{$9 \ldots$} \\
\hline \multicolumn{6}{|l|}{10.} \\
\hline \multicolumn{6}{|l|}{11.} \\
\hline \multicolumn{6}{|l|}{12.} \\
\hline \multicolumn{6}{|l|}{$13 \ldots$} \\
\hline \multicolumn{6}{|l|}{14} \\
\hline \multicolumn{6}{|l|}{15} \\
\hline \multicolumn{6}{|l|}{16} \\
\hline \multicolumn{6}{|l|}{17.} \\
\hline \multicolumn{6}{|l|}{18} \\
\hline \multicolumn{6}{|c|}{......... } \\
\hline $20 \ldots$ & & & & $\ldots \ldots$ & \\
\hline & & & & & \\
\hline
\end{tabular}

(1) Compare your estimate of the per cent of germination with the actual results obtained by the test.

(2) Write up a report of the test.

(3) Explain the importance of an accurate germination test.

(4) What factor may influence the reliability of the test? 
EXERCISE 10.

DATE

\section{THE MOISTURE TEST.}

By shelling a few kernels from each ear make a composite sample representing the twenty ears selected in Exercise 2.

From this sample weigh up 100 grams for the moisture test.

Transfer the 100 grams to the distillation flask of the Brown-Duval tester. Cover the corn in the flask with high grade machine oil. This will require about $150 \mathrm{cc}$. Only oil with a flash point above $200^{\circ} \mathrm{C}$. should be used. Connect the flask with the condensing tube and apply heat to the screen below the flask. So regulate the flame that it will require anout 2() minutes for the thermometer to read 190 C. When this point is reached, extinguish the flame. After the water ceases to drop from the condensing tule, read the test.

Run the test in duplicate.

\section{Results of Moisture Test.}

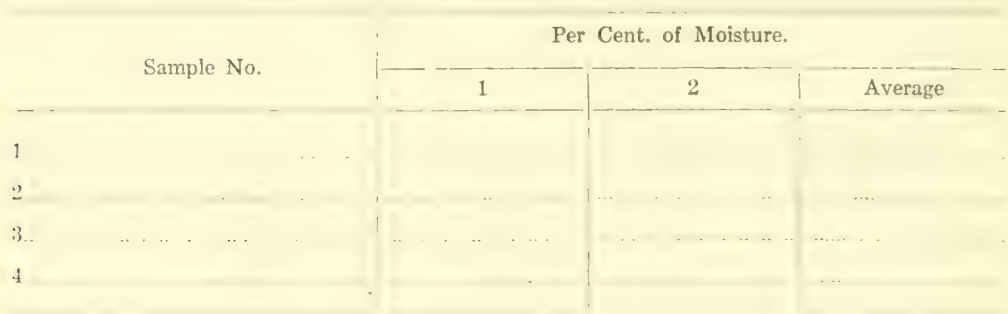

I. Explain the principle upon which this test is based.

II. What factors influence the moisture content of grain?

III. If corn with $15 \%$ of moisture is worth $50 \mathrm{c}$ per bushel, what is the value, upon this basis, of the corn you have tested?

IV. If eorn with $20 \%$ of moisture is selling at $60 \mathrm{c}$ per bushel, what is the value, upon this basis, of the corn you have tested?

V. Why should the farmer and feeder be interested in the moisture test? References: Ill Bul.. 113; Kans. Bul. 147; Mich. Bul. 191; Utah Bul. 130 ; Ohio Bul. 42, 57, 282 (pp. 105-107) ; N. D. Spec. Bul., Vol.2, No. 20 ; Farmers' Bul. 210 ; U. S. Department Bul. 317; B. P. I. Bul. 99 ; B. P. I. Circ. 72, 81; Bowman and Crossley, pp. 207-211. 
EXERCISE 11.

DATE

FINAL SELECTION OF SEED CORN.

From the twenty ears that you selected from the field, select what in your judgment are the ten best ears for planting. This selection should be based upon the germination test and the points brought out in Exercises 6, 7 and 8.

I. What are your objections to the ears discarded?

II. What criticism can you offer against the ten ears selected?

III. Do you consider "type" of much importance? Why?

IV. In a few paragraphs, tell what are the essential things to be considered in the final selection of seed corn.

References: Ky. Bul. 122; Ohio Bul. 282; Nebr. Bul. 91; Conn. Bul. 168; Farmers' Bul. 229, 329, 415; Ohio Cire. 71; Wis. Cire. 18; Mo. Circ. 50 ; Conn. State Report 1907-8, pp. 397-405. 
INSTRUCTOR'S NOTICES, EXPLANATIONS, ETC. 
Laboratory Manual of Cereals and forage Crops.

INSTRUCTOR'S NOTICES, EXPLANATIONS, ETC. 
EXERCISE 12.

DATE

WHEAT.

(Label all parts in each drawing.)

1. Make a drawing of a wheat spike as a whole.

2 . Remove all the spikelets but one (leave spikelet about midway of the rachis). Draw front view showing how spikelet is attached.

$\therefore$ Draw side view of the rachis with the one spikelet in position.

1. Draw a spikelet detached from the rachis.

5. Dissect one spikelet each from a smooth and a bearded variety.

Draw each part separately, arranging parts in proper relative position, showing:

1. Empty or outer glumes

2. Lemma

3. Palea

4. Awn

5. Sterile flower

6. Grain or kernel or enlarged ovary

(i. Draw a kemel of wheat showing:
1. Suture
2. Cheeks
3. Brush

. Make a longitudinal section of the wheat kernel through the suture, and draw, showing:

1. Germ

2. Bran

3. Endosperm

8. Malie a cross sectional drawing showing the same parts as in 7 , showing by shaded areas the differences in the physical characters.

?. Examine and make cross section drawings of red and white wheats. What is the difference between them?

10. From the study of the spike, what four factors would materially affect the yield of wheat?

11. Make a drawing of the dissected spolielet of the wheat plant showing in their relative positions:

1. Outer glumes

2. Two distinct and developed flowers with

(a) Flowering glumes or lemmas

(b) Palea

(c) Two stigmas each

(d) Three stamens each

3. Sterile flower 
12. (a) Are the flowers pedicelled or sessile? Is the spikelet pedicelled or sessile?

(b) Do you find any lodicules?

(c) What is the office of the lodicules?

13. Draw a circular diagram showing the parts of a wheat flower.

14. (a) Is the wheat plant a self fertilized or cross-fertilized plant?

(b) In what way does this flower differ from the flower of the corn plant?

(c) In what way is it alike?

(d) Are the glumes in the same relative positions as in the corn plant?

(e) Which glume bears the beard or awn and in what relative position?

1.. (a) What is a spikelet? How many outer glumes per spikelet?

(b) What is a sterile spikelet? A sterile flower?

16. Why is a long brush objectionable in milling wheat?

17. (a) Is the germ on the side of the kernel next to the palea or the flowering glume?

(b) Compared with corn, is the germ of wheat large or small in proportion to the size of the kernel?

18. How does the shriveled kernel compare in its physical composition to that of the plump kernel? Which is the more desirable for milling purposes?

19. What is the difference between the physical character of red winter and hard winter wheat? Red winter and spring? Red winter and durum? Red winter and white wheat?

20. Make a drawing of part of a stem showing:

1. Node

2. Internode

3. Leaf sheath

4. Ligule
5. Leaf blade

6. Rainguard

7. Auricle

8. Veins in leaf and stem.

21. (a) How many nodes in a stem?

(b) In what part of the stem are the nodes closest together and why?

(c) Farthest apart and why?

(d) What part of the stem is the largest in diameter?

(e) How are the leaves arranged on the stem?

(f) Is the stem hollow or full of pith?

(g) The veins of the leaf and the fibers of the wall of the stem are really what?

(h) On what part of the stem are the greatest number of leaves present?

References: Nebr. Bul. 32, pp. 100-114; Minn. Bul. 115; Wilson and Warburton, pp. 135-141; Livingston, pp. 99-113; Dondlinger, pp. 11-21 ; Percival; Bergen and Caldwell. 
EXERCISE 13.

DATE

VARIETY STUDY OF WHEAT IN THE FIELD. (Four or five weeks from date of seeding.)

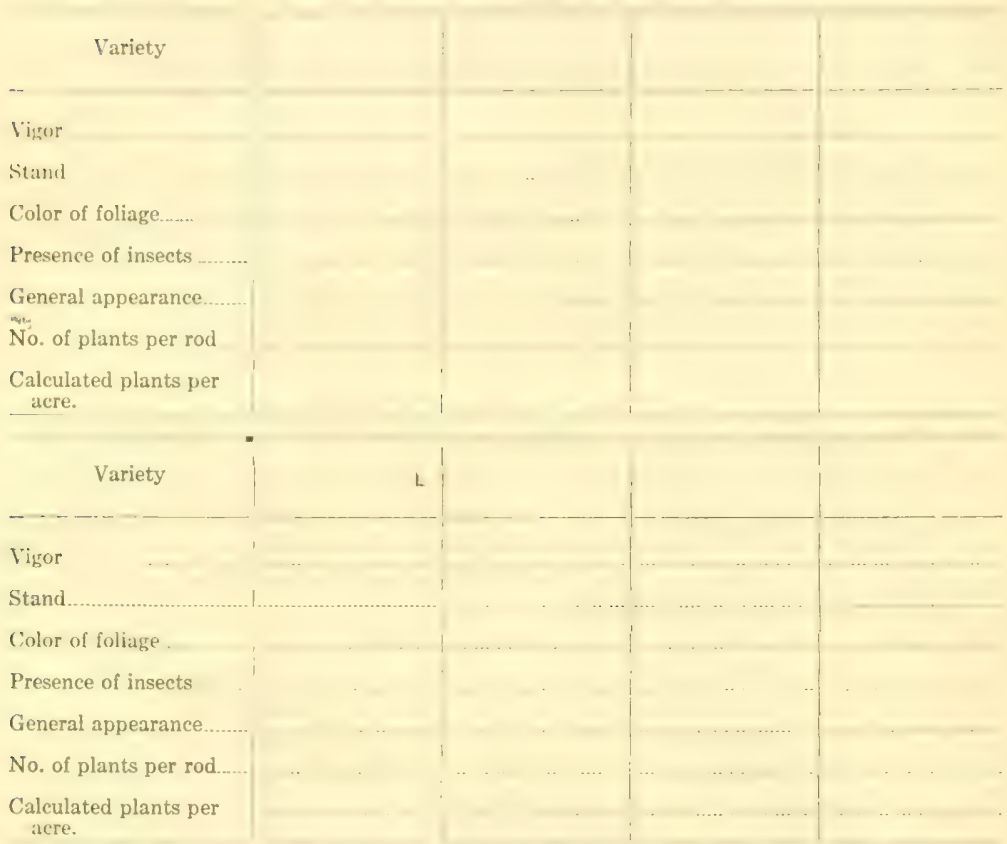

(In noting vigor, stand and general appearance, base the marking on 100 as perfect.)

I. In the strip along the edge of the plot carefully dig up a wheat plant. Locate the seed grain, temporary roots, permanent roots.

II. What influence has the depth of planting upon the location of the permanent root system? Is deeply planted wheat more likely to withstand a severe winter than that planted less deeply?

III. What varieties seem to be most vigorous? Was there anything else to show differences in varieties that might be used as a means of identification?

References: B. P. I. Bul. 47; Dondlinger, pp. 8-11.

Other field study might be made here on the rate, time, depth, etc., of seeding. 
I. Stool-

(1) No. of culms

II. Culm-

(1) Length (average of five plants)

(2) Foliage (scanty, medium, abundant)

(3) Color (light yellow, yellow, bronze, purple)

(4) Upper part of culm (solid, medium, hollow)

III. Spike-

(1) Position (erect, leaning, nodding)

(2) Length (iverage of ten,

(3) Shape (tapering to tip or butt, uniform, club, flattened across or with spikelets, square)

(4) Awn (bearded, partly bearded, beardless)

(5) Length of awn (average of 10 spikes)

(6) Compactness (very open, open, medium, compact)

IV. Spikelet-

(1) Shape (widely spreading, medium, narrow)

(2) Shattering (marked, medium, none).

(3) Outer glume (hairy, partly hairy, bald)

$1-$ Color (yellow, light yellow, bronze, black)

2-Width (wide, medium, narrow)

3-Beak (long, medium, short).

(4) Number of grains per spikelet (average of tive spikes)

(5) Number of sterile spikelets (average five spikes)

(6) Number of filled spikelets (average five spikes)

(7) Number of sterile flowers (average five spikes)

(8) Number of grains per spike (average five spikes)

V. Grain-

(1) Hardness (very hard, hard, medium, soft)

(2) Size-

1-Average weight of 100 grains

(2) Average length of 100 grains

(3) Average width of 100 grains

(3) Plumpness (plumn, medium, shriveled)

(4) Cheek (flat, plump, angular)

(5) Crease (deep, medium, shallow) wide, medium, narrow)

6) Lirush large area, small area, -lung hairs, short

(7) Color (white, yellow, amber, red).

*Use coordinate paper, page 85.

Hunt suggests that the class divide the varieties studied into a grouping like the following:

Light glumes: Grains red

Grains yellow

Grains white

Bearded:

Dark glumes: Grains red

Grains yellow

Grains white
Light Glumes: Grains red

Grains yellow

Beardless:

Grains white

Dark glumes: Grains red

Grains yellow

Grains white. 
EXERCISE 15.

D $A T E$

\section{VARIETY STUDY OF IVHEAT IN THE FIELD.}

(Exercise adapted for last of May or in June.)

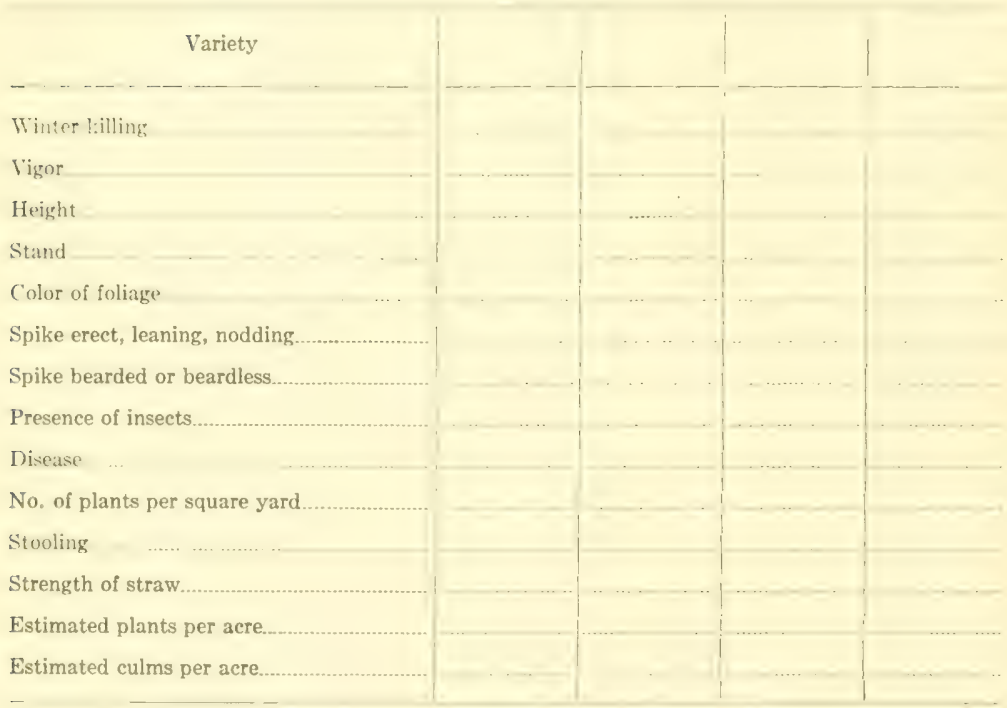




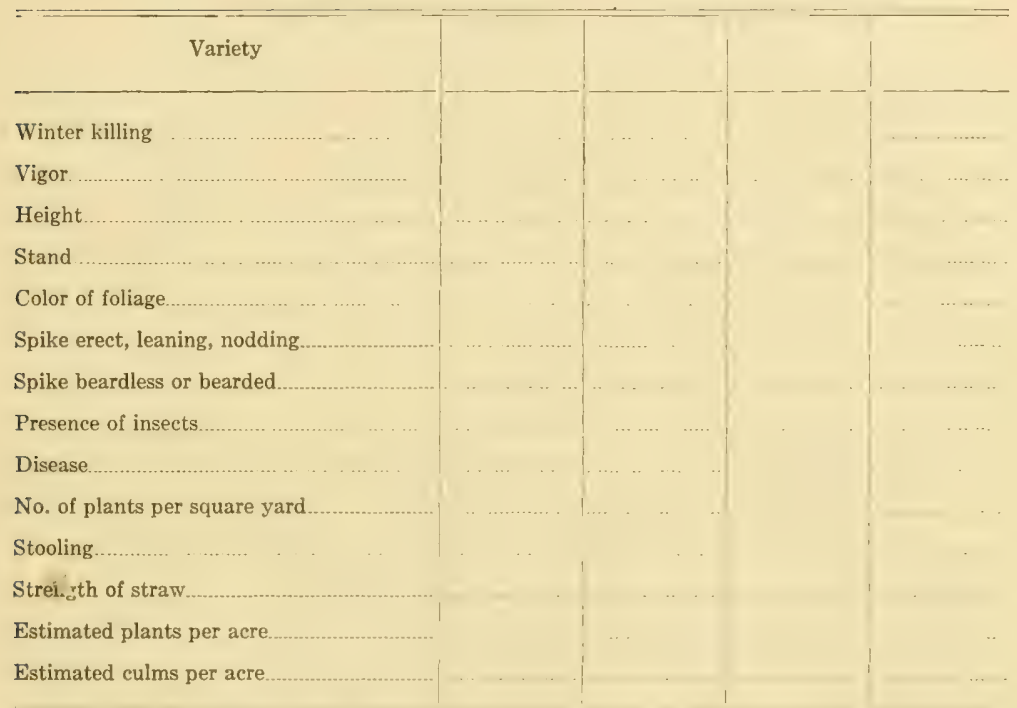

(In marking winter killing, vigor, strength of straw and stand use 100 as perfect in each case.) Write up a report of the exercise with special reference to the important variations that came to your attention.

References: Dondlinger, pp. 170-187; Ohio Circular 115 (Chinch Bug); Ohio Bul. 177 (Hessian Fly) ; Mich. Bul. 258 (Insects of field crops) ; Farmers' Bul. 657 (Chinch Bug); Bureatu of Entomology Circ. 66, 70, 113. 
Laromatori manual of Cereals and Forage Crops.

INSTRUCTOR'S NOTICES, EXPLANATIONS, ETC. 
laboratory manual of Cereals and Forage Crops.

INSTRUCTOR'S NOTICES, EXPLANATIONS, ETC. 
EXERCISE 16.

DATE.

HEAD-ROW STUDY OF WHEAT IN THE FIELD.

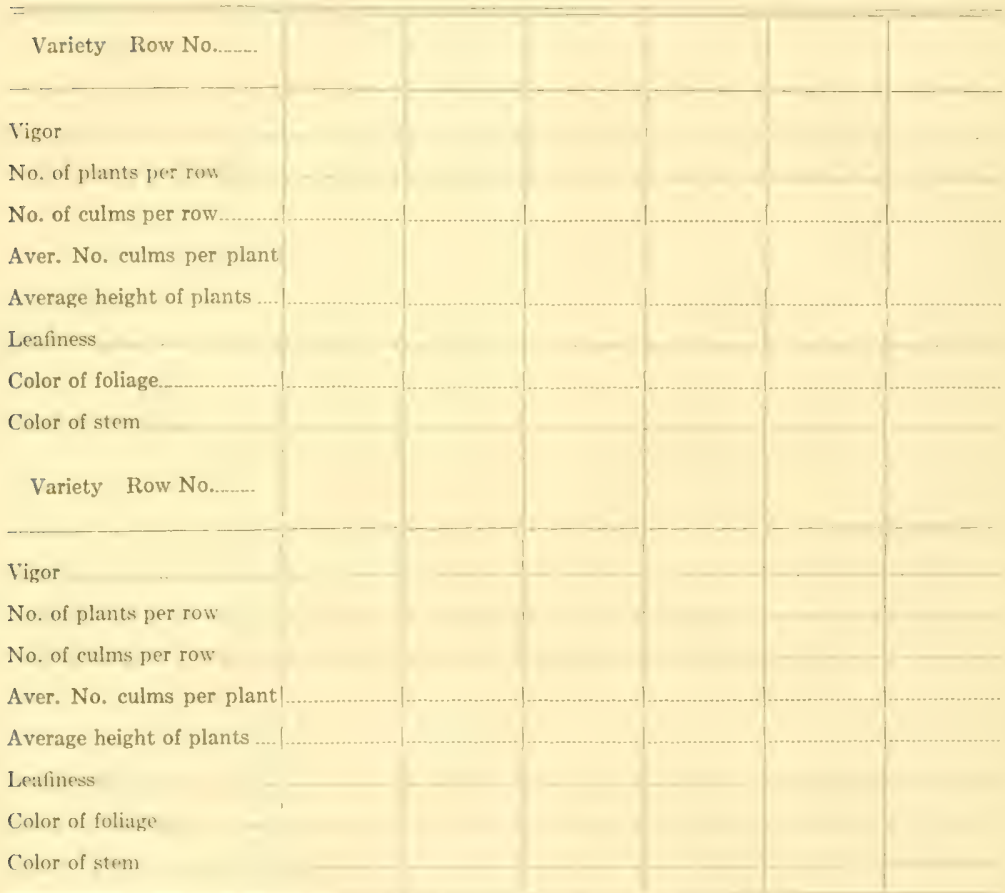

Write up a report of the exercise, with special reference to the important variations that came to your attention. 136-141.

References: Mich. Bul. 268; Dondlinger, pp. 33-57; Livingston, pp. 


\section{WHEAT JUDGING}

Before one can judge wheat quickly and accurately it is necessary to become familiar with the points that are of importance in determining the value of a sample. This familiarity can be gained by careful study or long experience. The student must necessarily, on account of limited time, gain his knowledge by careful study. This study should be such as to enable him to see quickly in a sample, both the good and bad points, and with both in view, to arrive at an accurate decision. The following exercise was inserted with that object in view. By carefully analyzing several samples, especially prepared for the exercise, experience will be gained that will enable the student to analyze a sample easily without making the actual separations.

\section{Wheat Judging-Detailed Study.}

Obtain 20 gram samples of good and poor grades of wheat, and separate each according to the accompanying outline. Weigh the foreign matter and determine the remaining parts of the sample either by wcirhing or counting. Record all results in percent. The total percent for each division (i. c. purity, soundness, etc.) should be 100.

Purity. Decide upon the class of wheat (red winter, hard winter, white winter, hard spring, durum) that constitutes the bulk of the sample. Separate all other classes and record under "other wheat." Record oats, rye, barley, etc., as "other grain." The foreign matter constitutes all dirt, chaff, weed seeds and inert materials.

Soundness. Discard all "other grain" and the "foreign matter," and study the remainder of the sample for soundness. Sound wheat should generally be bright and free from broken, shriveled and sprouted grains or grains otherwise injured, as from stack or bin burning, exposure, or insect injury. Grains injured from stack or bin burning usually have a dark, dull color at the hilum end of the grain. All bleached grains have been injured from exposure.

Separate the sample into sound and unsound lots, and classify the unsound grains as broken, shriveled, sprouted and otherwise damaged.

Color. Since color is associated with purity, soundness, and texture, it is important to distinguish the colors frequently met with in wheat. In a large degree color is dependent upon classes and varieties of wheat, but it is also influenced by the injuries which cause unsoundness. 
Separate the simple into lotis representing the different colors indicated in the outline, and keep the lots separate for the study of texture.

Texture. The darker colored (dark amber) wheats are generally harrler in texture (cxception, durum) than those that are lighter in color. Amber colored whoats consist largely of grains with a medium texture, while wheats of a light amber culnr are mostly soft in texture. One exception is the light amber, durum whoat, which has a flinty texture. All yellow or white wheat is soft in texture. Nake suctions of a few grains of the various colors and note the general association of color of grain to texturc.

Determine the percent of grains in the simple whose textures are hard, medium, and soft, respectively.

Size. Feeping in mind that the size of the grains of wheat differs for classes and also for varieties, obtain an idea of the sizes of large and small grains in wheat as a whole and then determine the percentages of grains in the sample which represent the large medium, and small sizes, respectively.

References: Kans. Bul. 156 and 170; Ky. Bul. 113; Cal. Bul. 181; Farmers' Bul. 237, 320, 366; B. P. I. Circ. 99.

These references are largely to experiments in breeding for qualities sought in judging. 
EXERCISE 17.

DATE.

Wheat Judging-Detailed Study.

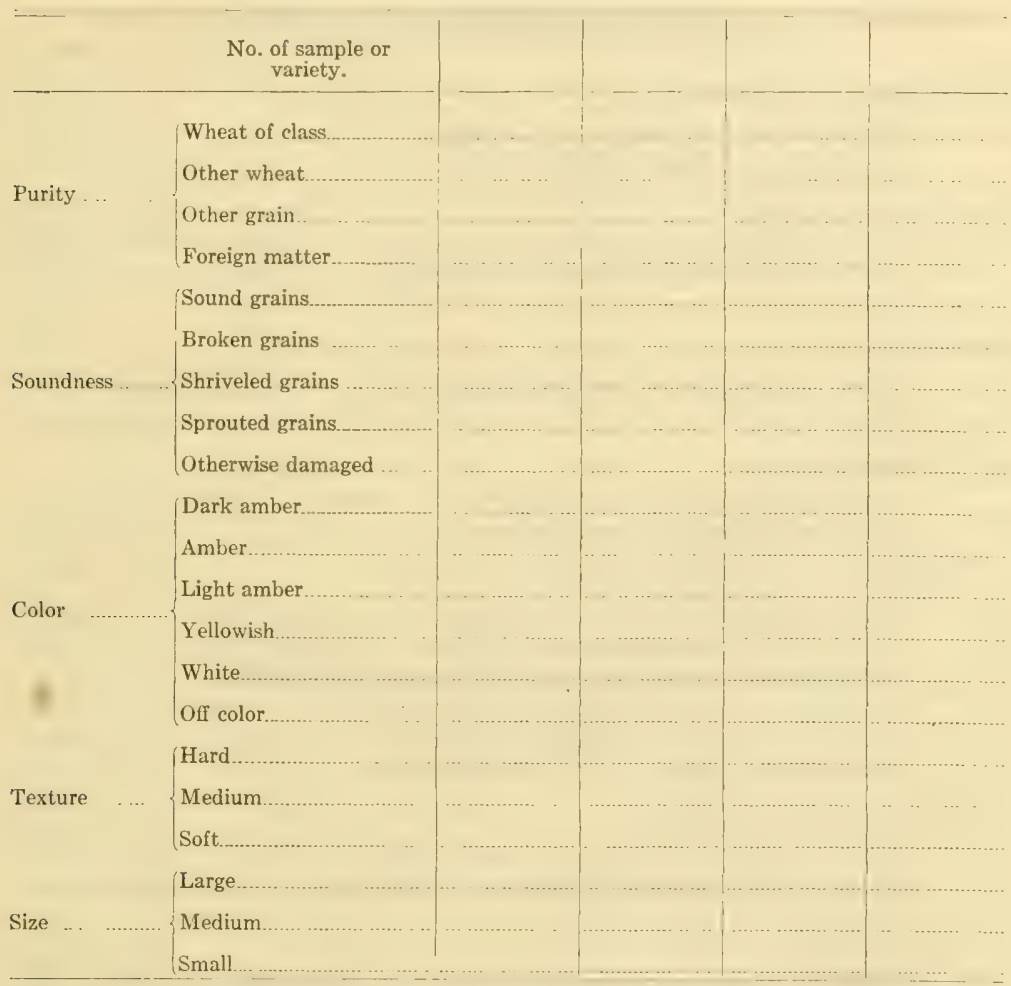

(1) What is meant by the term "texture" as applied to wheat kernels?

(2) Has texture any relation to hardness?

(3) Has texture any relation to the composition of the kernel?

(4) How may weather conditions affect the texture?

(5) Do soils have any effect upon texture and hardness of the kernels produced?

(6) Why does the miller prefer plump kernels for milling purposes?

(7) Why does the miller object to wheat that is badly bleached?

(8) Describe a good milling wheat.

(9) What is a "bin burned" or "skin burned" kernel? 
EXERCISE 18.

DATE

\section{EXPLANATION OF SCORE CARD FOR WHEAT.}

1. Weight per bushel -25 .

Wheat should weigh sixty pounds per measured bushel. Cut two points for each pound below this.

2. Soundness -20 .

There should be no sprouted, cracked, smutty, musiy, bin-burncd, or otherwise damaged grains in the sample. Cut two points for each per cent of unsound grains.

3. Purity -10 .

The sample should be free from mixture or foreign matter of any kind. Cut one point for each percent of foreign matter.

4. Plumpness - 15 .

The grains should be well filled and plump. Cut one point for each two percent of shriveled grains.

5. Uniformity in hardness and texture-15.

The berries should be uniform in hardness and texture. In a lot of 100 grains determine three classes, (1) grains hard and vitreous, (2) grains soft and starchy, (3) grains intermediate.

Cut one point for each three per cent representing class 2 and one point for each ten percent in class 3. In a fairly uniform sample two classes only may be distinguished.

6. Uniformity in color -10 .

Cut one point for each three per cent not uniform in color with the bulk of the sample. Consider "yellow berry" as a discoloration.

7. Uniformity in size -5 .

Cut one point for each four per cent of undersized grains.

References: Lyon and Montgomery, pp. 10-15; Wilson and Warburton, pp. 172-173. 
EXERCISE 18.

DATE

SCORE CARD FOR WHEAT.
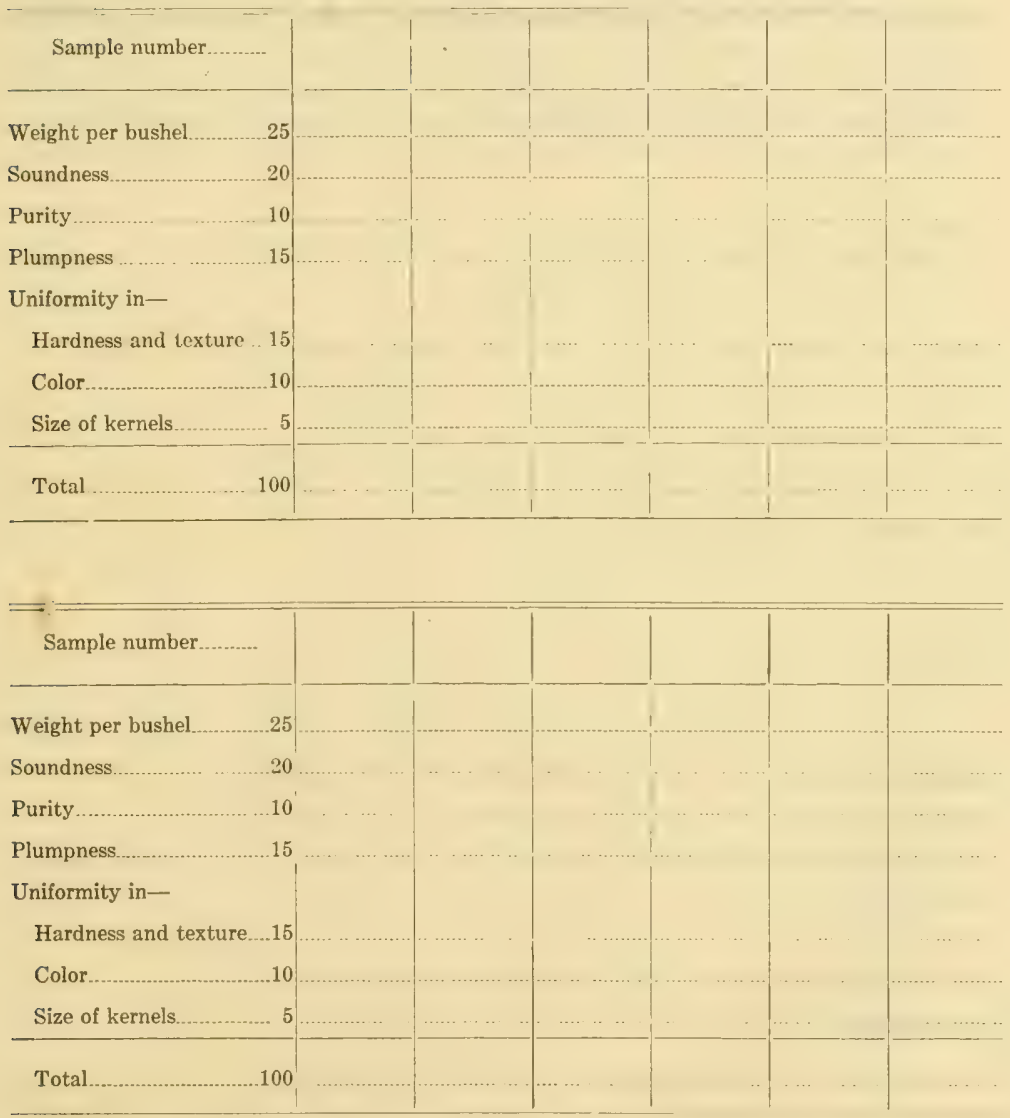

Remarks and reasons for cuts: 
EXERCISE 19.

DATE

\section{MARKET CLASSES OF WHEA'T.}

Preliminary to practice in the grading of wheat each student should make a close study of typical kernells of each of the diflerent classes. This study should fix in his mind the characteristics of each class and enable him to distinguish between them. After a close comparative study of the diflerent classes, give in the following outline a brief, concise description of each class, noting the characteristies that will be of assistance in identification.

liti Winter

Hatrl Winter

Ilarel Siprine

Siring

1)urum

l'arifie (uast

Whitw Sipring" 
Laboratory manual of Cereals and Forage Crops.

INSTRUCTOR'S NOTICES, EXPLANATIONS, ETC. 
Láioratory Manual of Cereals and Forage Crops.

INSTRUCTOR'S NOTICES, EXPLANATIONS, ETC. 
EXERCISE 20.

DATE.

OATS.

(Label all parts of each drawing.)

(1) Make a drawing of an open panicle of oats showing:

(1) Rachis

(2) Branches

(3) Pedicel

(4) Spikelets

(2) Make a drawing of a single spikelet showing:

(1) Outer glume

(2) Two oat grains.

(3) Awn (if present)

(4) Sterile flower

(3) Make a drawing of a cross section of a single oat grain showing:

(1) Flowering glume

(2) Palea

(3) Kernel

(4) Suture

(4) Make a drawing of a longitudinal section of the oat kernel showing:

(1) Covering

(2) Endosperm

(3) Germ

(5) Weight of 25 upper grains 25 lower grains

(6) What is the difference between a spike and a panicle?

(7) How many branches in the first whorl? Second?

(8) How many spikelets in all in the panicle?

(9) In what order are the whorls arranged on the rachis?

(10) Is there any variation in the length of the pedicel?

(11) Compare the outer glume of oats with the same of wheat.

(12) Compare the flowering glume and palea of oits with the same of wheri.

(13) Locate the germ in the oat kernel.

(1.1) Is length, depth, and breadth of germ so important in the oat kernel as in the kernel of the corn? Why?

(15) As the kernel is enveloped by the hull upon which end is the germ found?

(16) Does the germ of the kernel face the bosom of the grain or the bick side?

(17) Is the position of the germ on the oat kernel like that of the corn? 
(18) What is an open panicle? Compressed panicle? Side panicle?

(19) How does the oat grain differ from the wheat grain? How does the oat kernel differ from the wheat grain?

(20) Make a drawing of an oat kernel which has just started to germinate, showing:

(1) Radicle breaking from its sheath at the base of the germ

(2) Swelling of plumule

(21) In germination, which part of the embryo starts first? Note sheath over stem sprout.

(22) Make a drawing of an oat grain just newly germinated showing:

(1) Temporary roots

(2) Root hairs

(3) The stem sprout

(2:3) How many temporary roots are present?

(21) How are the leaves, paired or rolled together?

(25) From which end of the grain does the stem appear? The root?

(26) Make a drawing of a stool of oats showing:

(1) Fibrous root system

(2) A culm or so

(3) Leaf sheath

(27) (a) What is tillering or stooling?

(b) What are tillers in corn called?

(c) Upon what conditions is tillering dependent?

(d) From what points on the stem do tillers appear?

(28) (a) How many culms are in this stool?

(b) On what part of the culm are the greater number of leaves?

(c) Discuss the cause of lodging in oats.

(d) How may a fallen culm grow erect again?

(e) At what point or points on the culm dnes this growth take place?

(29) (a) Is the oat a surface or deep feeder?

(b) Does the root have a fibrous or tap root system?

(c) How deep do the roots of the oat plant extend?

(d) How far out from the base do they extend?

(e) What differences do you note between corn and oat roots?

(30) Why may similar yields be obtained upon similar ground under similar conditions and yet varying amounts of seed be sown?

References: Hunt's Cereals, pp. 280-283 ; Livingston 145-150 ; Percival; Bergen and Caldwell; Ohio Bul. 257. 
EXERCISE 21.

DATE

\section{COMPARATIVE STUDY OF OAT VARIETIES.}

\section{(Laboratory.)}

Study a number of varieties of oats according to the following outline. Fach student is movided with several panicles of the varieties to bo studied. The members of the class work in groups of two, combining data where averages are required.

Variety

I. Panicle-

1. Length (average of 5 ) (lower whorl to tip of upper spikelet)

2 . Shape (open, medium, compressed, side)

3. Number of whoris (average of 5 )

4. Number of branches in all whorls (average of 5)

II. Spikelet-

1. Number in panicle (average of 5)

2. Number of grains per spikelet

$\therefore$. Length of pedicels (average of 10)

4. Color of outer glume (white, yellow, etc.)

5. Number of sterile spikelets

III. Grain-

1. Length (long, medium, short).

2. Plumpness (plump, medium, slender)

3. Color (white, gray, yellow, brown, red black)

4. Length of awn (long, medium, short, none).

5. Per cent. of hull

1. Note distinguishing characters of the varieties studied.

2 . What factors influence the percent of hull in oats? What is the common percentage of hull?

3. What factors may influence the amount of grain on the oat panicle? 
4. What factors would govern your selection of panicles in the field for breeding or seed purposes?

5. Is there any correlation between weight and plumpness of grain? Between yield and plumpness of grain?

6. What physical characters of oat grains may be associated with a heavy weight per bushel?

7. Is there any relation between shape of panicle and yield?

References: Iowa Bul. 96; Pa. Bul. 108; Ohio Bul. 257; Nebr. Bul. 113; Minn. Bul. 81; Cornell Bul. 343; W. Va. Bul. 84; Farmers' Bul. 395 and 436; Ala. Bul. 175; Va. Bul. 168; S. D. Bul. 110.

EXERCISE 22.

DATE.

\section{FIELD STUDY OF NEWLY SOWN OAT FIELD.}

Examine the soil, remove some of the ground from the oats, and examine carefully in order to answer the following questions:

1. Is the subsoil compact or loose?

2. Is the surface soil compact or loose? Discuss a proper seed bed for oats.

3. What is the average depth of seeding?

4. Has fertilizer been used? What sort of fertilizer should be used for oats?

5. Carefully dig away the soil, uncovering the seed in the drill row for one foot. Calculate from this the number of grains per acre.

6. Name some of the factors influencing the rate of sowing.

Reference: Iowa Bul. 128; Mo. Circ. 46; Nebr. Bul. 113; Ohio Bul. 257; Farmers' Bul. 424. 
VARIE'TY S'TUDY OF OA'TS IN THE FIELD. (Four or five weeks from date of seeding.)

Variety
General appearance
No. of plants per rod
Calculated plants per acre.............
No. of culms per plant
No. of culms per acre (calculated)............

(In noting vigor, stand and general appearance, base the marking on 100 as perfect.)

Write up a report of the exercise, giving reference to the important variations that came to your attention. 
61 Laboratory manual of Cerenls and Forage Crops.

INSTRUCTOR'S NOTICES, EXPLANATIONS, ETC. 
Laboratory Manul of Cereals and Forage Crops.

INSTRUCTOR'S NOTICES, EXPLANATIONS, ETC. 
EXERCise 24.

DATE

\section{WEED SEED FOUND IN OAT SEED.}

Before taking up oat judging it is well to know something about the weed seeds commonly found in oats. Identified samples of

1. Common Black Mustard (Brassica nigra),

2. Large Smart Weed (Polygonum pennsylvanicum),

3. Yellow Foxtail (Setaria glauca),

1. Green Foxtail (Setaria viridis),

5. Greater Ragweed (Ambrosia tifida),

6. Common Sunflower (Helianthus annus),

7. Wild Hemp (Cannabis sativa),

8. Sour Dock (Rumex crispus), an : : "ry other weeds that are found in oats will be given the student with a mixed sample, from which he will select a number of each kind as a means of fixing their appearance in his mind.

After doing this for a while the identified weeds will be removed and at sample of oats containing impurities will be given the stulent. This sample the student will analyze and make a report of the same as follows:

1. Number of sample Kind of seed

2. By actual count report:

1. Percent pure seed.

2. Percent of weed seed

3. Percent of other foreign seed

4. Percent of foreign matter

i. Tabulate the following:

1. The seeds found

2. Usual rate of seeding

3. The rate for sample.

References: See exercise 43. 
EXERCISE 25.

DATE.

\section{OAT JUDGING. A DETAILED STUDY OF OATS}

Obtain 10 gram samples of good and poor grades of oats, and separate each according to the accompanying outline. (p. 68.) Weigh the foreign matter, if possible, either weigh or count the materials in the other items studied and record results in percent.

Purity.

Determine the number of oat grains in the sample that compose the oats of the class (i. e., white, red, etc.) represented by the sample. Likewise determine the amouni of impurities as represented by "other oats," "other grains," and foreign matter. Wheat, rye, barley, etc., are examples of other grain. All dirt, chaff, weed seeds, etc., atc., constitute the foreign matter. The total for purity should be 100 per cent.

Soundness.

Discard the foreign matter and other grain, and determine soundness by dividing the remainder of the sample into sound and unsound lots. Sound oats should have a bright color. Unsound oats may be dull in color, bleached, moldy, sprouted, etc. The total for soundness should be 100 percent.

Color.

Separate the sample into the different colors that can be found. The total for color should be 100 per cent.

Plumpness.

Determine the percent of grains that are plump, those that are medium in plumpness, and of those that a ${ }^{\circ}$ slender. The total for plumpness should be 100 percent.

Record the weight per bushel.

References: B. P. I. Circ. 40 and 74 (Oat bleaching); Lyon and Montgomery, pp. 61-63; Wilson and Warburton, p. 210; Duggar, p. 131. 


\section{OAT Judging-Detailed Study.}

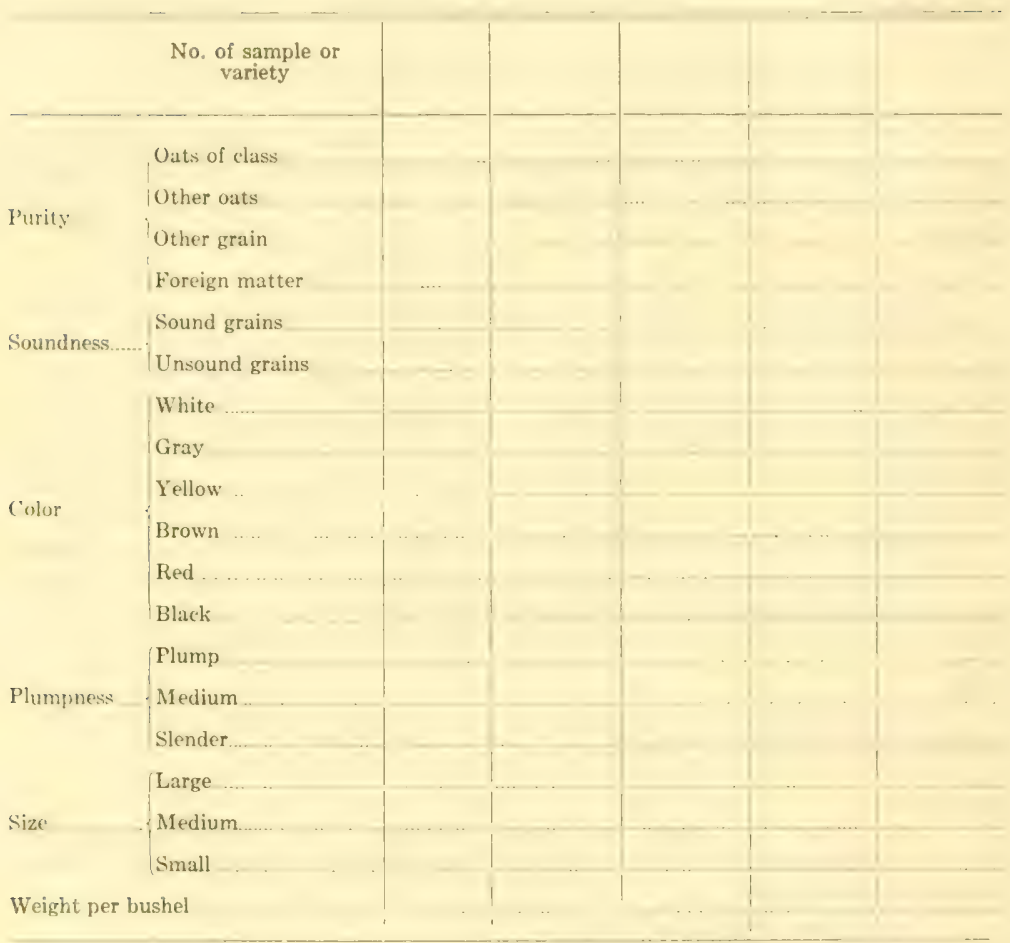




\section{SCORING OATS}

\section{EXPLANATION OF SCORE CARD FOR OATS.}

In this score card oats are judged principally from the market standpoint. It is not possible to make a score card by which an oat could be judged at the same time from both the feeder's and the miller's standpoint, and also be used to judge the grain for seed. Different points would be used in each case, and different values given them.

Weight per Bushel - 35 points.

Weight per bushel is important as a means of estimating the value of an oat for market and feeding as well, since a heavy weight indicates that the grain was well matured and the hull well filled out. In the same variety a heavy oat usually has a smaller per cent of hull. A good sample of oats should weight 32 pounds per measured bushel.

Cut four points for each pound below standard weight. For each pound above standard weight add one point to the total score.

Soundness -20 points.

The sample should be sound, dry, bright, and free from musty, smutted, spruted, or otherwise damaged grains. Cut one point for each percent of damaged grains.

Color - 15 points.

The color of the grains should be bright and uniform for the bulk of the sample.

Cut one point for each percent of discolored grains and grains not uniform in color with the bulk of the sample.

Purity -10 points.

The sample should be free from mixture, other igrain, weed seeds, straw, chaff, and any other foreign matter of any kind.

Cut one point for each percent of mixture and the same for each percent of foreign matter.

Percent of Hull -20 points.

A good oat may have as much as 30 percent of hull.

Cut two points for each percent of hull above this. For each percent below add one point to the total score. 
SCORE CARD FOR OATS.

Sample No.....
Weight per bushel
Soundness.

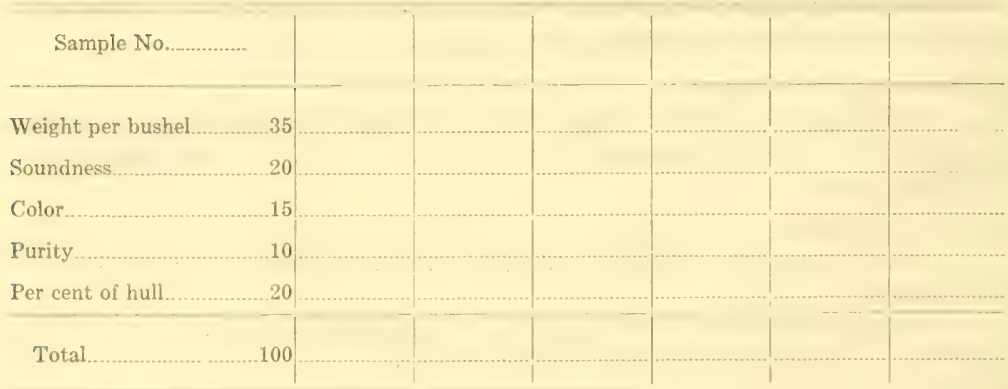

Remarks and reasons for cuts: 
EXERCISE 27.

DATE

TREATMENT OF SEED OATS FOR SMUT. THE FORMALIN TREATMENT.

Calculate the volume of formalin (40\% solution of formaldehyde gas in water) required to treat one bushel of oats, if one pint of formalin in 50 gallons of water will be sufficient to treat about 50 bushels of seed oats.

Spread the oats to be treated on a clean, tight floor, and apply the treating solution by means of a sprinkling can. During application, shovel the oats about, so that a uniform application may be given. The oats should be well moistened, but not so much that they will pack when pressed in the hands. Shovel the oats into a pile and cover them with sacks for from 2 to 4 hours. At the end of this time remove the sacks and dry the treated seed as rapidly as possible.

Write up a report, giving the life history and the economic importance of the loose smut of oats (Ustilago Avenae (Pers) Jens.). This treatment is adapted to the loose smut of oats, the stinking smut of wheat, and the covered smut of barley. In the case of each of these smuts the spores winter over on the outside of the grains.

\section{THE HOT WATER TREATMENT.}

This treatment is adapted to the loose smut of barley (the most prevalent in barley), the loose smut of wheat, and the covered smut of oats. In the case of these smuts the spores winter over inside of the grains, and so cannot be reached with the formalin.

The following rules should be carefully observed in this treatment:

1. Water should be $130^{\circ} \mathrm{F}$. to $145^{\circ} \mathrm{F}$. for oats and wheat, and $126^{\circ}$ to $129^{\circ}$ for barley.

2. Treat 10 to 15 minutes, according to temperature.

3. Warm grain before treating to insure keeping water warm.

4. Work grain up and down, lifting sack clear of water.

5. Have volume of water 8 to 10 times that of grain.

6. Do not fill sack full.

7. Drain well after treatment and spread out 2 to 3 inches deep.

8. Have on hand 2 barrels, pails, accurate thermometer, clean gunny sack, water stirrer, and clean floor or canvas on which to spread treated grain. 
Directions: In barrel No. 1 have water heated up to from $125^{\circ}$ to $130^{\prime}$ to warm the grain up before treating. This is done that the temperature of the treating water may not be lowered to a place where it will do no good. Keep the water in barrel No. 2 at a maximum temperature. This is done by having several buckets of hot water at hand all of the time. Keep water stirred.

Nake germination tests of grain used in both treatments before and after treatment to determine the effect of the treatments on the viability of the grains.

References: "Fungous Diseases of Plants," B. M. Duggar; Farmers' Bul. 250, 507; Minn. 115; Iowa Bul. 96; Utah Bul. 108; Ohio Bul. 203; Nebr. 131 ; N. D. Bul. 87 ; S. D. Bul. 109 ; B. P. I. Bul. 152 ; Ex. Sta. Work, Vol. II, No. 9 ; and N. C. Report 1908, pp. 30-36. 
74 Laboratory Manual of Cereals and Forage Crops.

INSTRUCTOR'S NOTICES, EXPLANATIONS, ETC. 
laboratory Manual of Cereals and Forage Crops.

INSTRUCTOR'S NOTICES, EXPLANATIONS, E'TC. 
ExERCISE 28.

DATE

\section{BARLEY.}

(Label all parts in each drawing.)

I. Make drawing of barley spike:

(a) Two rowed

(b) Six royed

II. Remove all the spikelets but one on a two rowed spike.

Draw a front view, showing how spikelet is attached.

(b) Draw the same view for the six rowed type, but showing three spikelets from the same node in place.

III. Draw side view of rachis with one spikelet in position:

IV. (a) Draw a spikelet of the six rowed type; (front view).

(b) Draw three spikelets of the six rowed type; (front view).

V. Make longitudinal section of spikelet showing:

Outer Glume

Flowering glume

Kernel

Palea

VI. Compare a spike of wheat with a spike of barley. Compare the outer glumes; flowering glumes; kernel; palea.

VII. Compare a spikelet of wheat with a spikelet of barley.

VIII. - (a) Explain differences of two rowed and six rowed barley.

(b) Of four rowed and six rowed.

References: Farmers' Bul. 427, 443, 518; Wilson and Warburton, pp. 212-216; Livingston, pp. 164-168. 
EXERCISE 29.

DATE.

VARIETY STUDY OF BARLEY IN THE LABORATORY

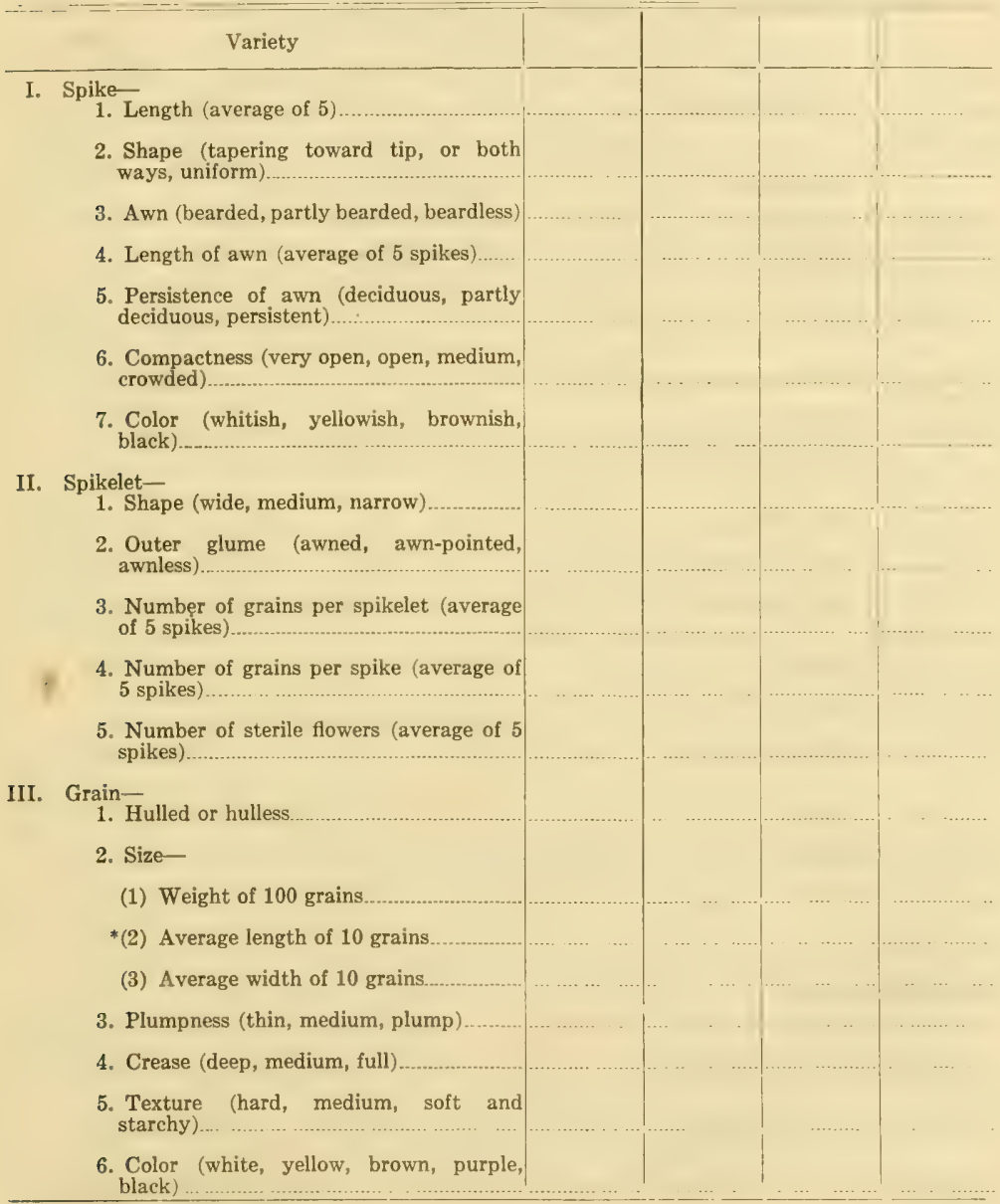

*Use coordinate paper, page 85.

References: Test of varieties, Mont. Bul. 84; Minn. Bul. 81; N. D. Bul. 75; S. D. Bul. 113; Kans. Bul. 44. 
EXERCISE 30.

DATE.

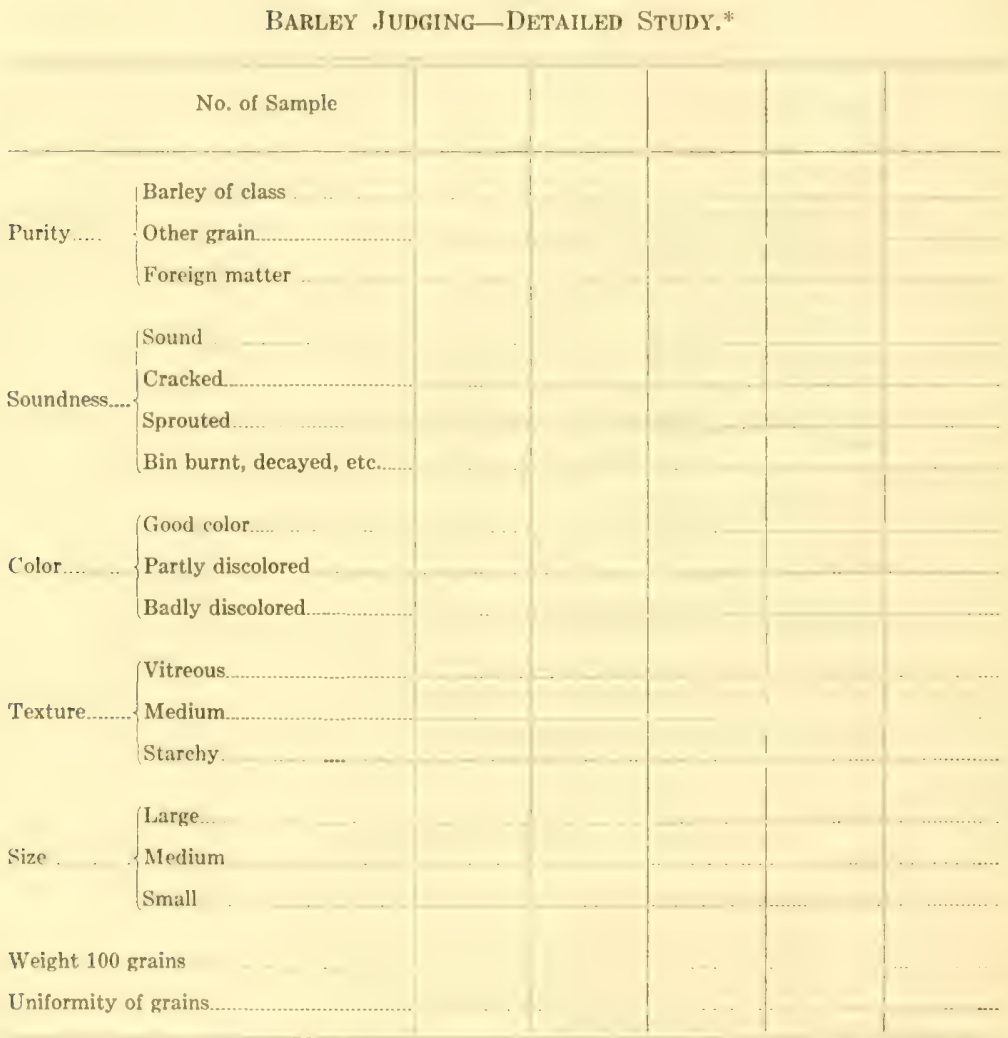

*Before beginning this exercise read carefully the notes on explanation of score card for barley. 
EXERCISE 31.

DATE

\section{JUDGING BARLEY BY MEANS OF THE SCORE CARD.}

EXPLANATION OF SCORE CARD FOR Barley.

Barley is judged from the brewer's standpoint, rather than from its feeding value, since the market price is based on its brewing quality. A different score card would be used to judge barley according to its feeding value, for the latter may be more unsound and less uniform than the former. Weight per bushel - 10 points.

Other things being the same, the barley with the heaviest weight per bushel is preferred, since weight is accompanied by a high percent of extract. Barley should weigh 48 pounds per bushel. A high weight should not be caused by excessive moisture.

Cut one point for each pound below this.

Soundness - 30 points.

The sample should be free from discolored, sprouted, bin-burned, decayed, cracked or otherwise damaged grains. It should not be musty, but have a sweet odor.

Cut one point for each unsound or damaged grain, and for mustiness according to judgment.

Foreign matter -10 points.

The sample should be free from other grains, grass, and weed seeds, as such impurities cause irregularity in germination and an unfavorable ferment.

Estimate the percent of foreign matter by weight, and cut one joint for each percent.

Uniformity in color -15 points.

Separate the sample into various classes according to color. Let the class having the largest number determine the color of the sample. Cut one point for each percent representing the other classes.

Uniformity in texture -20 points.

The texture of the sample should be uniformly hard or soft. Determine the class represented by the largest number and cut one point for each percent of grains in the other class.

Uniformity in size -10 points.

The grains should all be of the same size, as different sizes cause irregular germination. Divide the sample into large and small sizes, and cut one point for each two percent representing the smaller class.

References: Lyon and Montgomery, pp. 78-80; Wis. Bul. 212 (revised) ; B. P. I. Circ. 62. 


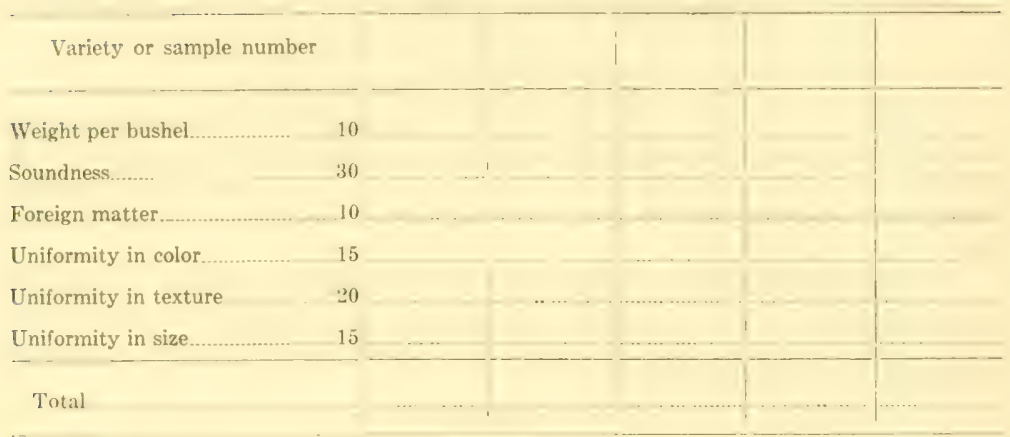

Remarks:

EXERCISE 32.

DATE.

THE GERMINATION OF BARLEY.

Place 1000 grains between well-moistened filter paper or flannel cloth and keep at temperature of $80^{\circ} \mathrm{F}$. Remove sprouted grains at end of each twenty-four hours for five days.

Tabulate results as follows:

\begin{tabular}{|c|c|c|c|c|c|c|}
\hline Sample No. & 1 & 2 & 3 & 4 & 5 & 6 \\
\hline \multicolumn{7}{|l|}{ Description } \\
\hline \multicolumn{7}{|l|}{ First day } \\
\hline \multicolumn{7}{|l|}{ Second day } \\
\hline \multicolumn{7}{|l|}{ Third day } \\
\hline \multicolumn{7}{|l|}{ Fourth day } \\
\hline Fifth day.... & & & & & & \\
\hline
\end{tabular}
mixed?

Why should two rowed and six rowed barley sold on market not be 
Laboratory Manual of Cereals and Forage Crops.

Why are broken grains harmful in market barley?

What means can the threshermen use to prevent breaking grains?

What is the chief use of barley?

What, then, should be the condition of germination?

Are the samples, good, medium, or poor for germination? 
INSTRUCTOR'S NOTICES, EXPLANATIONS, ETC. 
laboratory Manual of Cereals and Forage Crops.

INSTRUCTOR'S NOTICES, EXPLANATIONS, ETC. 
EXERCISE 33.

DATE

RYE.

(Label all parts in each drawing.)

1. Make a drawing of a rye spike.

2. Make a drawing of a spikelet.

3. Dissect a spikelet, and make a detailed drawing of each part.

4. Make a brief comparison of a rye spikelet with the same of wheat. Sicoring Rye-The color of rye should be from a sort of green to yellow. Dark brown rye is not desirable. Another thing that should be noticed is sprouting. Score on this point under color.

In noting foreign matter, score heavily against Ergot.

The weight of a bushel of rye is 56 pounds.

SCORE CARD FOR RYE.

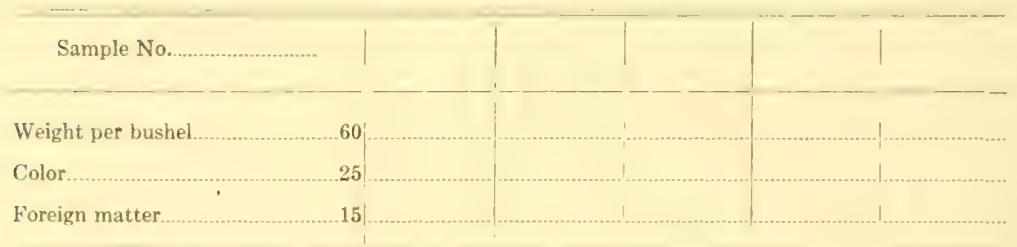

Rye varieties, Wis. Report 1902 (pp. 219-220).

EXERCISE 34.

DATE

COMPARISON OF OATS, WHEAT, BARLEY, RYE AND EMMER.

I. Make a drawing of a spikelet of oats, wheat, rye, two rowed and six rowed barley. (See note below.)

11. Mlake a drawing of the flowering glume of each of the above, including either two or six rowed barley. (See note below.)

III. Make a drawing of the flowering glume of each of the above, showing the attachment of the awn in each case. (See note below.)

IV. Make a drawing or diagram showing the relative size and location of the palea of each of the above. (See note below.)

V. Define: sessile, rachis, rachella, pedicel, spike and panicle.

VI. Make a drawing of a head of each of the above.

VII. Make a drawing of the temporary roots of germinated seeds of above.

VIII. Write a report stating chief differences noted in this study.

(Nake the drawings of the same part of each head on the same page when possible. Enlarge each drawing.) 
SCALE I/10 OF ONE INCH.

\section{1 \\ 2 \\ 3 \\ 4 \\ 5}

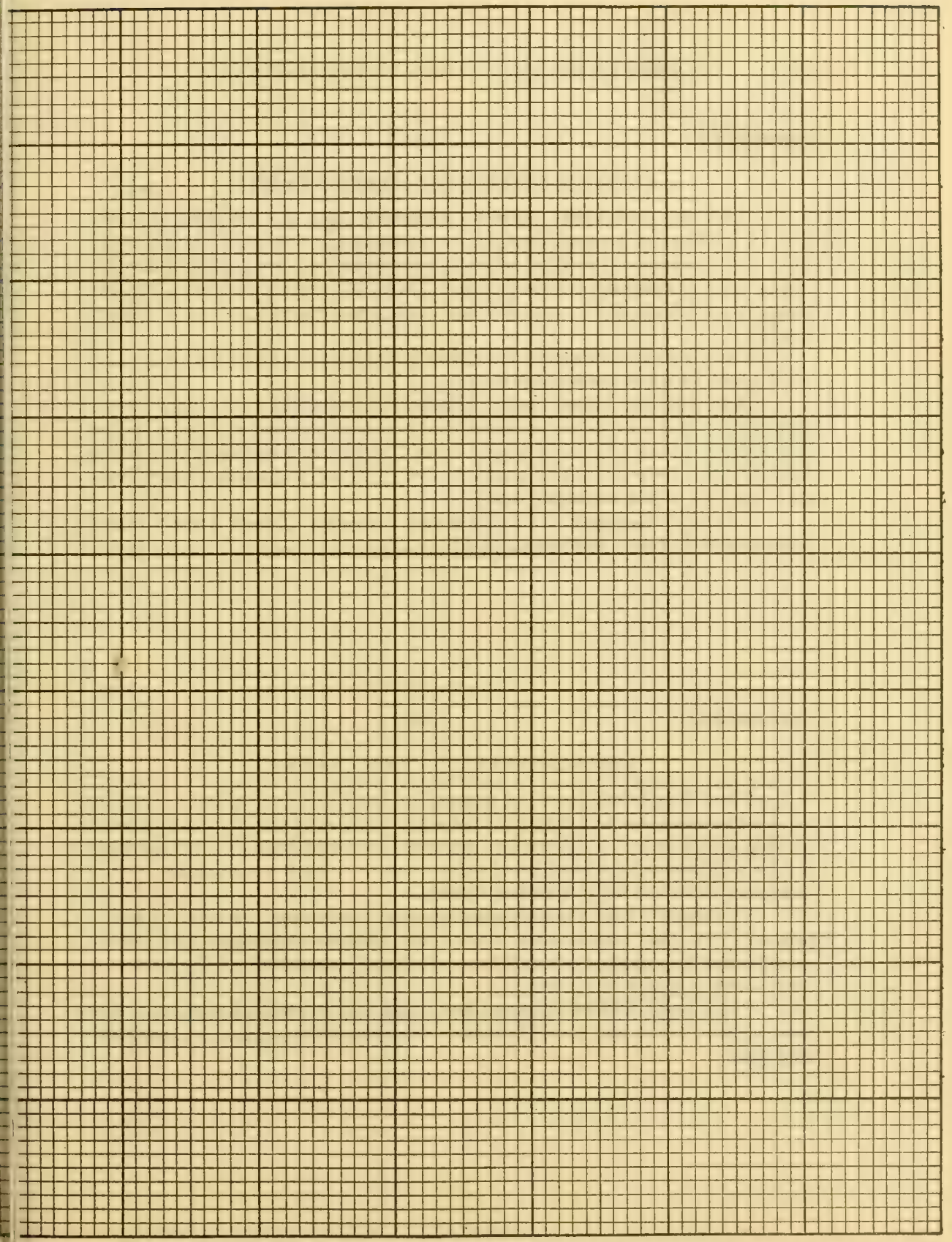


EXERCISE 35.

DATE.

KEEPING RECORD OF MARKET PRICES.

Using the co-ordinate paper on preceding page, lay off along the long side 18 equal parts representing the 18 weeks of the Semester and along the other side a convenient number of parts representing dollars and cents. By tinis means keep a graphical account of the prices of some farm crop for the semester in which this course is given, using quotations from your nearest market.

The graph should record the prices for the same day in the week thruout the time in which records are taken.

Note daily the causes for any changes in price and make note of the condition of the market for each day. (In using the word daily here, reference is made to the laboratory period only. If the student wishes to keep actual daily records, he may, but it would be better to use engineering co-ordinate paper instead of the accompanying.)

At end of Semester or on day set by instructor present a short report containing data taken and accounting for unusual rises and falls in the curve.

EXERCISE 36.

DATE

\section{DISTRIBUTION OF FARM CROPS.}

From data taken from the Reports of the U. S. Census show carefully the distribution of each of the chief fieldcrops of this country. This data should be shown on maps, \& separate map being used for each product. (These maps can be obtained by the local book store from text book concerns or by the instructor from the U. S. Weather Bureau.)

The student may use his own ingenuity in showing the relative distribution, or he may choose some one of the methods suggested, such as the use of a dot to represent a given amount of any commodity, or the area of a circle drawn within the state.

These maps will be prepared according to instructor's assignments and must be neat, clean, and carefully done. Incorporate the maps in loose leaf note book. 
INSTRUCTOR'S NOTICES, EXPLANATIONS, ETC. 
Laboratory Manual of Cereals and Forage Crops.

INSTRUCTOR'S NOTICES, EXPLANATIONS, ETC. 


\author{
GRADES OF GRAIN \\ Adopted and promulgated by the \\ GRAIN DEALERS NATIONAL ASSOCIATION
}

\title{
SAMPLE GRADES - GENERAL RULE.
}

All wheat, barley, oats, rye and corn that is in a heated condition, soluring, or too damp to be safe for warehousing, or that is badly bin-burnt, fire-burnt, tire-smolied, or badly damaged, mixed with garlic, onions, or containing live weevil, exceedingly dirty, or where different kinds of grain are badly mixed with one another, shall be classed as Sample Grade, and the inspector shall make notations as to quality and condition.

NOTICE.-The inspection departments shall, in no case, make a grade of grain above that of the poorest quality found in any lot of grain inspected, when it has evidently been plugged for the purpose of deception, or otherwise improperly loaded. Wheat which has been subjected to scouring, or clipping, or any process equivalent thereto, shall not be graded higher than a 3.

NEW.

The word "NEW" shall be inserted in each certificate of inspection of a newly harvested crop of oats until the fifteenth day of August; of rye, until the first day of September; of wheat, until the first day of November; and of barley, until the first day of November of each year.

This change shall be construed as establishing new grades for the times specified, to conform to the existing grades of grain in all particulars, except the distinctions hereby established between the new and the old crop, and shall apply to grain inspected from store for two months after the time respectively above specified.

\section{MANNER OF TESTING GRAIN WITH A TESTING KETTLE.}

Place the kettle where it cannot be jarred or shaken. Pour from a scoop, bag or pan, held two inches from the top of the kettle, into the middle of the kettle at a moderate speed until running over. Strike off in a zigzag manner with the edge of the beam held horizontally.

Recommended by the Chief Grain Inspectors National Association.

E. H. Culver.

President. 


\section{GRADES FOR COMMERCIAL CORN.}

By virtue of the authority vested in the Secretary of Agriculture by the acts of Congress of June 30, 1906 (34 Stat., 669), and of March 4 , 1913 (37 Stat., 828), to fix definite grades of grain, the following grades for corn are hereby fixed and promulgated, to take effect on July 1, 1914.

\begin{tabular}{|c|c|c|c|c|c|}
\hline \multirow[b]{2}{*}{$\begin{array}{l}\text { Grade classi- } \\
\text { fication (white, } \\
\text { yellow, and } \\
\text { mixed corn). }\end{array}$} & \multicolumn{5}{|c|}{ Maximum percentages of -} \\
\hline & Moisture & & Damaged corn & \begin{tabular}{|} 
Foreign \\
material, \\
including \\
dirt, cob, \\
other \\
grains, \\
finely, \\
broken \\
corn, etc.
\end{tabular} & $\begin{array}{c}\text { "Cracked" } \\
\text { corn, not } \\
\text { including } \\
\text { finely } \\
\text { broken } \\
\text { corn. (See } \\
\text { General } \\
\text { Rule No. } \\
\text { 9.) }\end{array}$ \\
\hline $\begin{array}{l}\text { No. } 1 \\
\text { No. } 2 \\
\text { No. } 3 \\
\text { No. } 4 \\
\text { No. } 5 \\
\text { No. } 6 \\
\text { "Sample" }\end{array}$ & $\begin{array}{c}14.0 \\
15.5 \\
17.5 \\
19.5 \\
21.5 \\
23.0 \\
\text { See Gene }\end{array}$ & $\left.\begin{array}{r}2 \\
4 \\
6 \\
8 \\
10 \\
15 \\
\text { eeral }\end{array}\right\}$ & 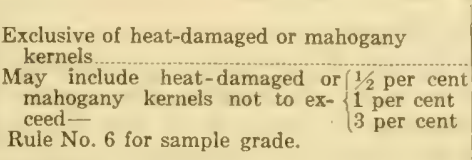 & $\begin{cases}1 & 1 \\
1 & 1 \\
1 & 2 \\
2 \\
3 \\
5\end{cases}$ & $\begin{array}{l}2 \\
3 \\
4 \\
4 \\
5 \\
7\end{array}$ \\
\hline
\end{tabular}

\section{GENERAL RULES.}

(1) The corn in grades No. 1 to No. 5, inclusive, must be sweet.

(2) White corn, all grades, shall be at least 98 per cent white.

(3) Yellow corn, all grades, shall be at least 95 per cent yellow.

(4) Mixed corn, all grades, shall include corn of various colors not coming within the limits for color as provided for under white or yellow corn.

(5) In addition to the various limits indicated, No. 6 corn may be musty, sour, and may also include corn of inferior quality, such as immature and badly blistered.

(6) All corn that does not meet the requirements of either of the six numerical grades by reason of an excessive percentage of moisture, damaged kernels, foreign matter, or "cracked" corn, or corn that is hot, heat damaged, fire burnt, infested with live weevils, or otherwise of distinctly low quality shall be classed as sample grade.

(7) In No. 6 and sample grade, reasons for so grading shall be stated on the inspector's certificate.

(8) Finely broken corn shall include all broken particles of corn that will pass through a perforated metal sieve with round holes nine sixty-fourths of an inch in diameter.

(9) "Cracked" corn shall include all coarsely broken pieces of kernels that will pass through a perforated metal sieve with round holes one-quarter of an inch in diameter, except that the finely broken corn, as provided for under Rule No. 8 , shall not be considered as "cracked" corn.

(10) It is understood that the damaged corn; the foreign material, including pieces of cob, dirt, finely broken corn, other grains, etc.; and the coarsely broken or "cracked" corn, as provided for under the various grades, shall be such as occur naturally in corn when handled under good commercial conditions.

(11) Moisture percentages, as provided for in these grade specifications, shall conform to results obtained by the standard method and tester, as described in Circular No. 72 , Bureau of Plant Industry, U. S. Department of Agriculture. 


\section{GRADES OF WHEAT.}

White WiNTER WhEAT.

No. 1 White Winter Wheat.

Shall include all varieties of pure soft white winter wheat, sound, plump, dry, sweet and clean, and weigh not less than $58 \mathrm{lbs}$. to the measured bushel.

No. 2 White Winter Wheat.

Shall include all varieties of soft white winter wheat, dry, sound and clean, and shall not contain more than 8 per cent. of soft red winter wheat, and weigh not less than $56 \mathrm{lbs}$. to the measured bushel.

Y\%. 3 White Winter Wheat.

Shall include all varieties of soft white winter wheat. It may contain 5 per cent. of damaged grains other than skin-burnt wheat. and may contain 10 per cent. of soft red winter wheat, and weigh not less than $53 \mathrm{lbs}$. to the measured bushel.

No. 4 White Winter Wheat.

Shall include all varieties of soft white winter wheat not fit for a higher grade in consequence of being poor quality, damp, musty or dirty, and shall not contain more than 10 per cent. of soft red winter wheat, and weigh not less than $50 \mathrm{lbs}$. to the measured bushel.

\section{RED Winter Wheat.}

No. 1 Red Winter Wheat.

Shall be pure soft red winter wheat of both light and dark colors, sound, sweet, plump and well cleaned, and weigh not less than $60 \mathrm{lbs}$. to the measured bushel.

No. 2 Red Winter Wheat.

Shall be soft red winter wheat of both light and dark colors, sound, sweet and clean, shall not contain more than 5 per cent. of white winter wheat, and weigh not less than $58 \mathrm{lbs}$. to the measured bushel. 
No. 3 Red Winter Wheat.

Shall be sound, soft red winter wheat not clean or plump enough for No. 2, shall not contain more than 8 per cent. of white winter wheat, and weigh not less than 55 lbs. to the measured bushel.

No. 4 Red Winter Wheat.

Shall be soft red winter wheat, shall contain not more than 8 per cent. of white winter wheat. It may be damp, musty or dirty, but must be cool, and weigh not less than $50 \mathrm{lbs}$. to the measured bushel.

\section{HARD WINTER WHEAT.}

No. 1 Hard Winter Wheat.

Shall include all varieties of pure, hard winter wheat, sound, plump, dry, sweet and well cleaned and weigh not less than $61 \mathrm{lbs}$. to the measured bushel.

No. 2 Hard Winter Wheat.

Shall include all varieties of hard winter wheat of both light and dark colors, dry, sound, sweet and clean, and weigh not less than $59 \mathrm{lbs}$. to the measured bushel.

No. 3 Hard Winter Wheat.

Shall include all varieties of hard winter wheat of both light and dark colors, not clean or plump enough for No. 2, and weigh not less than $56 \mathrm{lbs}$. to the measured bushel.

No. 4 Hard Winter Wheat.

Shall include all varieties of hard winter wheat of both light and dark colors. It may be damp, musty or dirty, and weigh not less than $50 \mathrm{lbs}$. to the measured bushel.

\section{NORTHERN SPRING WHEAT.}

No. 1 Hard Spring Wheat.

Shall be sound, bright, sweet, clean, and consist of over 50 per cent of the hard Scotch Fife, and weigh not less than $58 \mathrm{lbs}$. to the measured bushel. 
No. 1 Northern Spring Wheat.

Must be Northern grown spring wheat, sound, clean, and of good milling quality and must contain not less than 50 per cent of the hard varieties of spring wheat, and weigh not less than $57 \mathrm{lbs}$. to the measured bushel.

No. 2 Northern Spring Wheat.

Shall be Northern grown spring wheat, not clean enough or sound enough for No. 1 and must contain not less than 50 per cent of the hard varieties of spring wheat and must weigh not less than $56 \mathrm{lbs}$. to the measured bushel.

\section{No. 3 Northern Spring Wheat.}

Shall be composed of inferior shrunken Northern grown spring wheat, and weigh not less than $54 \mathrm{lbs}$. to the measured bushel, and must contain not less than 50 per cent of the hard varieties of spring wheat.

\section{No. 4 Northern Spring Wheat.}

Shall include all inferior Northern grown spring wheat that is badly shrunken or damaged and must contain not less than 50 per cent of the hard varieties of spring wheat, and shall weigh not less than $49 \mathrm{lbs}$. to the measured bushel.

\section{SPRING WHEAT}

No. 1 Spring Wheat.

Shall be sound, plump and well cleaned, and weigh not less than $59 \mathrm{lbs}$. to the measured bushel.

No. 2 Spring Wheat.

Shall be sound, clean, of a good milling quality and weigh not less than $571 / 2 \mathrm{lbs}$. to the measured bushel.

\section{No. S Spring Wheat.}

Shall include all inferior, shrunken or dirty spring wheat, and weigh not less than $53 \mathrm{lbs}$. to the measured bushel. 
No. 4 Spring Wheat.

Shall include all spring wheat damp, musty, grown, badly bleached, or from any cause which renders it unfit for No. 3 and weigh not less than $49 \mathrm{lbs}$. to the measured bushel.

\section{WHITE SPRING WHEAT.}

White Spring Wheat.

The grades of Nos. 1, 2, 3 and 4 White Spring Wheat shall correspond with the grades of Nos. 1, 2, 3 and 4 Spring Wheat, except that they shall be of the white variety.

\section{Durum [Macaroni] Wheat.}

No. 1 Durum Wheat.

Shall be bright, sound, dry, well cleaned and be composed of durum, commonly known as macaroni wheat, and weigh not less than $60 \mathrm{lbs}$. to the measured bushel.

No. 2 Durum Wheat.

Shall be dry, clean, and of good milling quality. It shall include all durum wheat that for any reason is not suitable for No. 1 durum, and weigh not less than $58 \mathrm{lbs}$. to the measured bushel.

No. 3 Durum Wheat.

Shall include all durum wheat bleached, shrunken, or for any cause unfit for No. 2, and weigh not less than $55 \mathrm{lbs}$. to the measured bushel.

No. 4 Durum Wheat.

Shall include all durum wheat that is badly bleached or for any cause unfit for No. 3 , and weigh not less than $50 \mathrm{lbs}$. to the measurerl bushel.

\section{Pacific Coast Wheat.}

No. 1 Pacific Coast Red Wheat.

Shall be dry, sound, clean and free from smut and weigh not less than $59 \mathrm{lbs}$. to the measured bushel. 
No. 2 Pacific Coast Red Wheat.

Shall be dry, sound, clean and only slightly tainted with smut and alkali, and weigh not less than $58 \mathrm{lbs}$. to the measured bushel.

No. 3 Pacific Coast Red Wheat.

Shall include all other Pacific Coast red wheat. It may be smutty or musty, or from any other reason unfit for flouring purposes, and weigh not less than $54 \mathrm{lbs}$. to the measured bushel.

NOTE:

Pacific Coast White Wheat shall be graded according to the rules for Pacific Coast Red Wheat. In case of a mixture of Pacific Coast wheat with our home grown wheat, red or white, such mixture shal be graded "Pacific Coast Mixed Wheat."

NOTE:

The grades of Pacific White and Pacific Red Wheat are to include all such wheats as are grown in the extreme Northwest and on the Pacific slope from either Spring or Winter seeding.

\section{MiXed WheAT.}

Mixel. Wheat.

In case of an appreciable mixture of hard and soft wheat, red and white wheat (except as provided in the rule of red winter, white winter and northern spring wheat), durum, and spring wheat any of them with each other, it shall be graded according to the quality thereof, and the kind of wheat predominating, shall be classed as No. $1,2,3$ and 4 mixed wheat, and the inspector shall make notation describing its character.

\section{GRADES OF OATS.}

\section{White OATS.}

No. 1 White Oats.

Shall be white, dry, sweet, sound, bright, clean, free from other grain and weigh not less than $32 \mathrm{lbs}$. to the measured bushel. 
No. 2 White Oats.

Shall be 95 per cent white, dry, sweet, shall contain not more than 1 per cent of dirt and 1 per cent of other grain, and weigh not less than $29 \mathrm{lbs}$. to the measured bushel.

Standard White Oats.

Shall be 92 per cent white, dry, sweet, shall not contain more than 2 per cent of dirt and 2 per cent of other grain, and weigi not less than $28 \mathrm{lbs}$. to the measured bushel.

No. 3 White Oats.

Shall be sweet, 90 per cent white, shall not contain more than 3 per cent of dirt and 5 per cent of other grain, and weigh not less than $24 \mathrm{lbs}$. to the measured bushel.

No. 4 White Oats.

Shall be 90 per cent white, may be damp, damaged, musty or very dirty.

NOTICE:

Yellow Oats shall not be graded better than No. 3 white oats.

\section{MIXED OATS.}

No. 1 Mixed Oats.

Shall be oats of various colors, dry, sweet, sound, bright, clean, free from other grain and weigh not less than $32 \mathrm{lbs}$. to the measured bushel.

No. 2 Mixed Oats.

Shall be oats of various colors, dry, sweet, shall not contain more than 2 per cent of dirt and 2 per cent of other grain, and weigh not less than $28 \mathrm{lbs}$. to the measured bushel.

No. 3 Mixed Oats.

Shall be sweet oats of various colors, shall not contain more than 3 per cent of dirt and 5 per cent of other grain, and weigh not less than $24 \mathrm{lbs}$. to the measured bushel. 
No. \& Mixed Oats. dirty.

Shall be oats of various colors, damp, damaged, musty or very

\section{RED OR LUST PROOF OATS.}

No. 1 Red Outs or Rust Proof.

Shall be pure red, sound, bright, sweet, clean and free from other grain and weigh not less than $32 \mathrm{lbs}$. to the measured bushel.

No. 2 Red Oats or Rust Proof.

Shall be seven-eighths red, sweet, dry, and shall not contain more than two per cent dirt or foreign matter, and weigh $30 \mathrm{lbs}$. to the measured bushel.

Wi. : Red Oats or Rust Proof.

Shall be sweet, seven-eighths red, shall not contain more than five por cent dirt or foreign matter and weigh not less than $24 \mathrm{lbs}$. to the measured bushel.

No. \& Red Oats or Rust Proof.

Shall be seven-eighths red, may be damp, musty, or very dirty.

\section{White Clipped OAts.}

No. 1 White Clipped Oats.

Shall be white, clean, dry, sweet, sound, bright, free from other grain, and weigh not less than $35 \mathrm{lbs}$. to the measured bushel.

No. 2 White Clipped Oats.

Shall be 95 per cent white, dry, sweet, shall not contain more than 2 per cent of dirt or foreign matter and weigh not less than 32 lbs. to the measured bushel.

No. 3 White Clipped Oats.

Shall be sweet, 90 per cent white, shall not contain more than 5 ner cent of dirt or foreign matter, and weigh not less than 30 lbs. to the measured bushel. 
No. 4 White Clipped Oats.

Shall be 90 per cent white, damp, damaged, musty or dirty, and weigh not less than $30 \mathrm{lbs}$. to the measured bushel.

\section{Mixed Clipped OATS.}

No. 1 Mixed Clipped Oats.

Shall be oats of various colors, dry, sweet, sound, bright, clean, free from other grain, and weigh not less than $35 \mathrm{lbs}$. to the measured bushel.

No. 2 Mixed Clipped Oats.

Shall be oats of various colors, dry, sweet, shall not contain more than 2 per cent of dirt or foreign matter, and weigh not less than $32 \mathrm{lbs}$, to the measured bushel.

No. \& Mixed Clipped Oats.

Shall be sweet oats of various colors, shall not contain more than 5 per cent of dirt or foreign matter, and weigh not less than $30 \mathrm{lbs}$. to the measured bushel.

No. 4 Mixed Clipped Oats.

Shall be oats of various colors, damp, damaged, musty or dirty and weigh not less than $30 \mathrm{lbs}$. to the measured bushel.

NOTE :

Inspectors are authorized when requested by shippers, to give weight per bushel instead of grade on Clipped White Oats and Clipped Mixed Oats from private elevators.

\section{Purified OATS.}

Purified Oats.

All oats that have been chemically treated or purified, shall be classed as purified oats, and inspectors shall give the test weight on each car or parcel, that may be so inspected. 


\section{GRADES OF BARLEY.}

(Note.-These Barley Rules have been adopted by the Barley Association of the United States.)

No. 1 Barley.

Shall be sound, plump, bright, clean and free from other grain, and, not scoured nor clipped, shall weigh not less than 48 lbs. to the measured bushel.

No. 2 Barley.

Shall be sound, of healthy color (bright or straw color), reasonably clear and reasonably free from other grains and seeds, and not scoured nor clipped, shall weigh not less than 46 los. to the measured bushel.

No. 3 Barley.

Shall include slightly shrunken or otherwise slightly damaged barley, not good enough for No. 2, and, not scoured nor clipped, shall weigh not less than $44 \mathrm{lbs}$. to the measured bushel.

No. 4 Barley.

Shall include barley fit for malting purposes, not good enough for No. 3.

No. 1 Feed Barley.

Shall test not less than $40 \mathrm{lbs}$. to the measured bushel, shall be cool and reasonably free from other grain and seeds, and not good enough for No. 4, and may include barley with a strong ground smell, or a slightly musty or bin smell.

Rejected Barley.

Shall include all barley testing under $40 \mathrm{lbs}$. to the measured bushel or barley which is badly musty or badly damaged, and not good enough to grade "feed" barley, except that barley which has been chemically treated shall not be graded at all.

Bay Brewing Barley.

The grades of Nos. 1, 2 and 3 Bay Brewing Barley shall conform in all respects to the grades of Nos, 1, 2 and 3 barley, except that they shall be of the Bay Brewing variety, grown in the far west and on the Pacific Coast. 


\section{Chevalier Barley.}

The grades of Nos. 1, 2 and 3 Chevalier barley shall conform in all respects to the grades of Nos. 1, 2 and 3 barley, except that they shall be of the Chevalier variety grown in the far west and on the Pacific Coast.

Bay Brewing Mixed Barley.

In case of admixture of Bay Brewing barley with barley of other varieties, it shall be graded according to the quality thereof and classed as 1-2-3 Bay Brewing Mixed Barley.

\section{Chevalier Mixed Barley}

In case of admixture of Chevalier barley with barley of other varieties, it shall be graded according to the quality thereof and classed as 1-2-3 Chevalier Mixed Barley.

\section{WINTER BARLEY.}

No. 1 Winter Barley.

Shall be plump, bright, sound and clean, free from other grain, and weigh not less than $48 \mathrm{lbs}$. to the measured bushel.

No. 2 Winter Barley.

Shall be sound, plump, may be stained, shall contain not more than 3 per cent of foreign matter, and weigh not less than $46 \mathrm{lbs}$. to the measured bushel.

No. 3 Winter Barley.

Shall include all shrunken, stained and dirty barley, shall contain not more than 5 per cent of foreign matter, and weigh not less than $44 \mathrm{lbs}$. to the measured bushel.

No. 4 Winter Barley.

Shall include all barley not fit for a higher grade in consequence of being poor quality, damp, musty or dirty; shall contain not more than 10 per cent of foreign matter and weigh not less than $40 \mathrm{lbs}$. to the measured bushel. 
No. 1 Rye.

Shall be dry, sound, plump, sweet and well cleaned and shall weigh not less than $57 \mathrm{lbs}$. to the measured bushel.

No. 2 Rye.

Shall be dry, sound and contain not more than 1 per cent of other grain or foreign matter, and weigh not less than $55 \mathrm{lbs}$. to the measured bushel.

No. 3 Rye.

Shall include inferior rye not unsound, but from any other cause not good enough for No. 2, and weigh not less than 53 lbs. to the measured bushel.

No. 4 Rye.

May be damp, musty or dirty, and weigh not less than $50 \mathrm{lbs}$. to the measured bushel. 
laboratory Manual of Cereals and Forage Crops.

EXERCISE 37.

DATE

REPORT ON GRADES OF GRAIN.

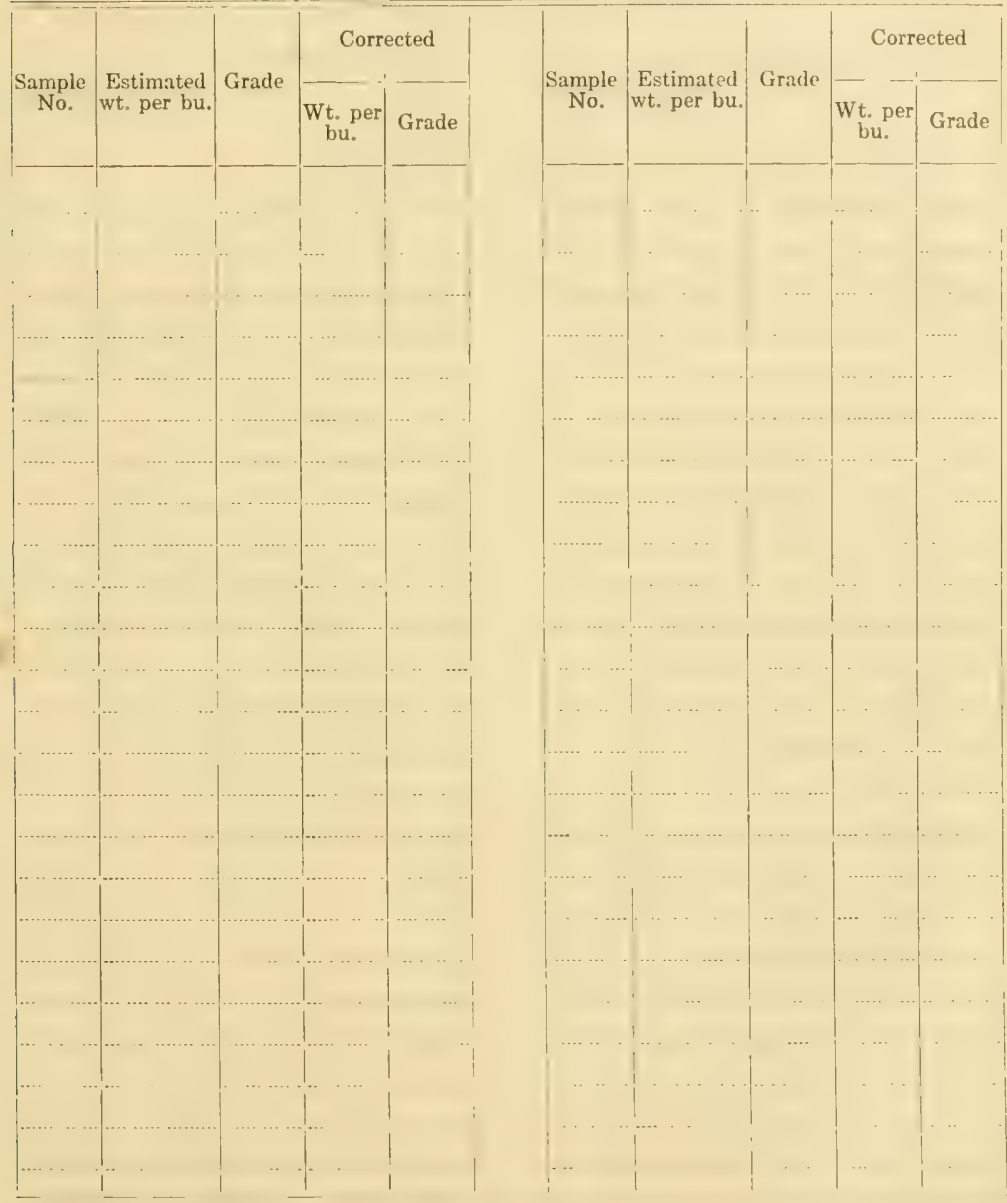


EXERCISE 38.

DATE

REPORT ON GRADES OF GRAIN.

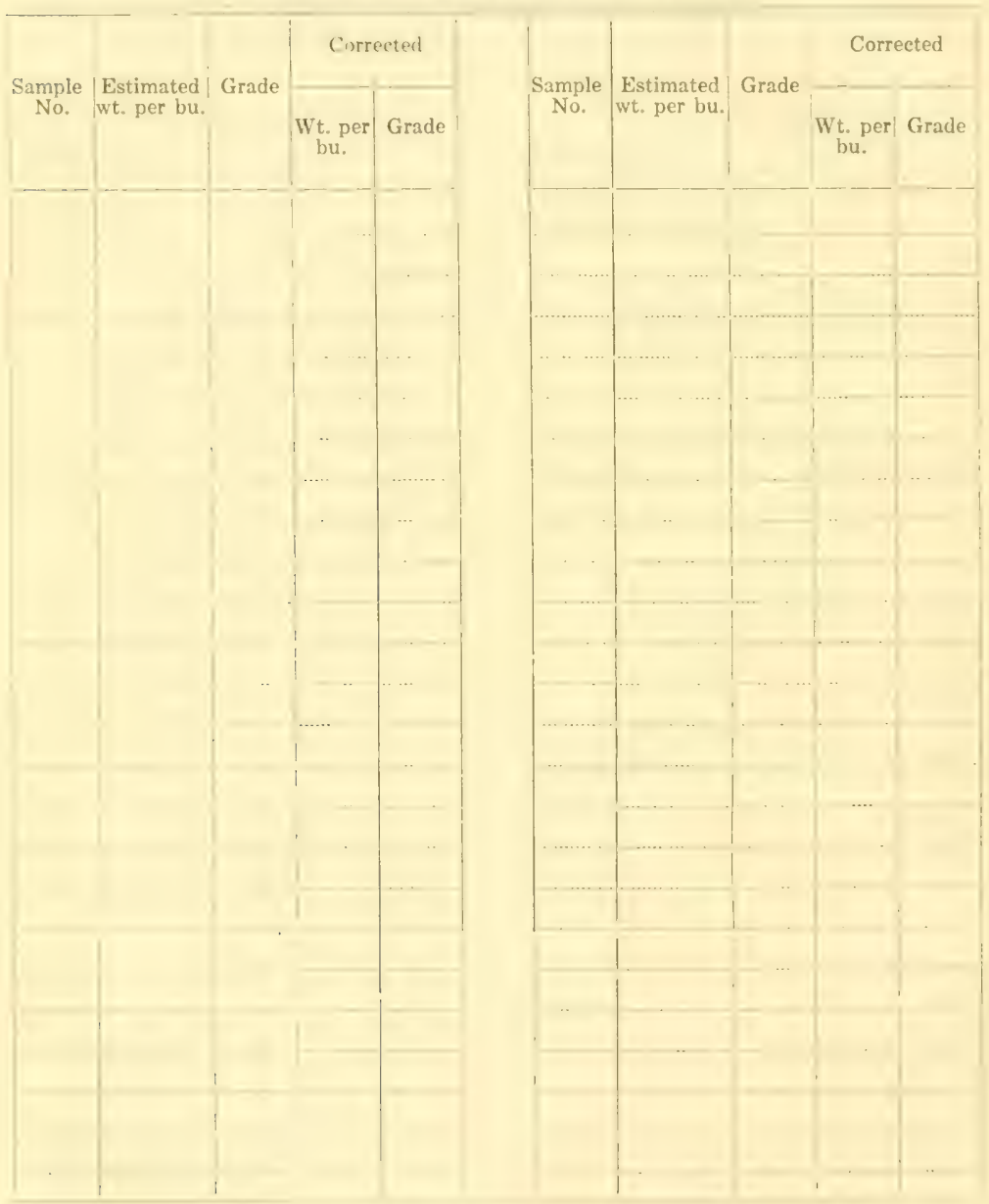


laboratory Manual of Cereals and Forage Crops.

EXERCISE 39.

DATE.

REPORT ON GRADING OF GRAINS.

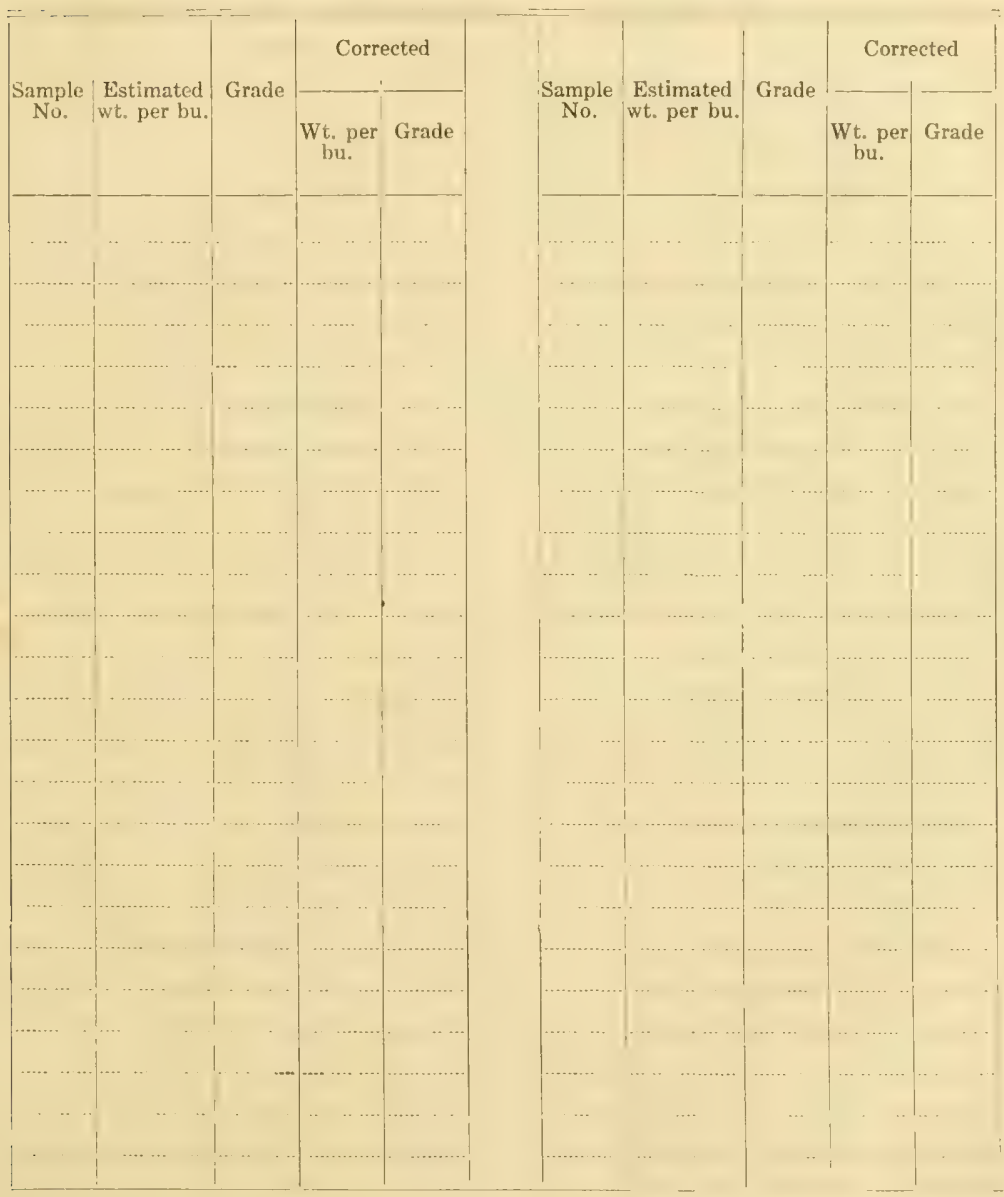


106 - Laboratory Manual of Cereals and Forage Crops. INSTRUCTOR'S NOTICES, EXPLANATIONS, ETC. 
laboratory Manual of Cereals and Forage Crops.

INSTRUCTOR'S NOTICES, EXPLANATIONS, ETC. 
EXERCISE 40.

DATE

\section{STUDY OF LEGUME INOCULATION.}

The purpose of this exercise is to demonstrate in the laboratory the value of pure cultures and soil cultures and to give the student some idea of the methods and value of inoculation.

Sufficient pots must be provided for making the tests both with and without lime, of the various commercial cultures, government cultures, soil culture, and check of no culture. The pots should be arranged in systematic order so that the limed and unlimed pot of each culture appears as a pair in the series. Six-inch flower pois or glass jars with hole near the bottom may be used. These pots should be filled to within 1 or 2 inches of the top with clean sterile white sand.

Inoculate the seeds or sand according to directions accompanying the cultures. In case of soil inoculation add to the pot of sand about 2 or 3 ounces of the soil obtained from a field in which the legume (alfalfa, clover, soybean, etc.) to he used has been successfully grown, or else mix up some of the soil with two or three times its volume of water, allow to stand, and then use $10 \mathrm{cc}$. of the supernatant liquid to each seed planted putting seed and water in the same place in the sand so as to insure bacteria being well in contact with the seed.

A nutrient solution with the nitrogen compound left out must be used to keep plant growing. This can be prepared by mixing up in separate bottles the following:

Bottle No. 1. Twenty-five grams Magnesium sulfate and 2500 cc. water.

Bottle No. 2. Twenty-five grams acid Potas. phosphate and $2500 \mathrm{cc}$. water.

Bottle No. 3. Twelve grams Potassium chloride and $250 \mathrm{cc}$. water.

Bottle No. 4. One-tenth gram Ferric chloride and $250 \mathrm{cc}$. water.

(The water should be ammonia free.)

In applying the nutrient solution to the pots $10 \mathrm{cc}$. of each of the first three and $1 \mathrm{cc}$. of the fourth solution are mixed thoroughly with $1000 \mathrm{cc}$. of pure ammonia free water and all or nearly all applied to a pot, allowing any surplus to run out through drain at bottom of pot.

The first application is made at time of planting, the second about 
three weeks later, the third two weeks later and the others at week intervals thereafter.

At end of 8 or 10 weeks, carefully remove plants from sand, weigh, make approximate estimate of number of nodules present, tabulate results and draw conclusions in a short report of the work.

References: $\quad$ B. P. I. Bul. 150 ; B. P. I. Circ. 71. 
EXERCISE 41.

DATE

\section{LEGUMINOSAE (PEA FAMLLY).}

1. Make a sketch of leaf of bean or peas showing:
1. Petiole
2. Stipule
3. Leaflet
4. Tendril (if present)

2. Make a driwing of a dissected flower showing in their relative positions the following:
1. Lateral petal
2. Standard petal
3. Keel petal
4. Sepals
5. Stamens noting that they are diadelphous
6. Pistil

3. Make an enlarged drawing of pistil showing:
1. Ovary
2. Style
3. Stigma

1. Make an enlarged drawing of the stamens of the pea showing the arrangement of the filaments and anthers.

5. Are the leaves simple or compound?

Are stipules present?

What part of the leaf is modified to form tendrils?

What kind of inflorescence is this?

How many petals?

How many sepals?

How many stamens in the flower? Are all filaments united?

6. Sketch a soaked bean showing:
1. Testa
2. Hilum
3. Micropyle

7. Make a drawing of a germinated bean (early stage) showing:

1. Hypocotyl

2. Plumule

3. Cotyledons 
8. Make a drawing of a later stage showing last named parts and permanent leaves and root.

?. Are the halves (cotyledons) of the bean united in any way?

Where is the reserve food of the bean stored?

What finally becomes of the cotyledons?

What parts found in a bean grow most rapidly?

Reference: Farmers' Bul. 408. 
EXERCISE 42.

DATE.

\section{LABORATORY STUDY OF PEAS AND BEANS.}

This exercise is arranged to familiarize the student with the appearance and characteristics of field beans and peas, cow peas, and soy beans. Several of the common varieties of each are provided for study and comparison. loth the dried plants with pods and the threshed grain shruld be examined in securing information necessary to fill out the outline.

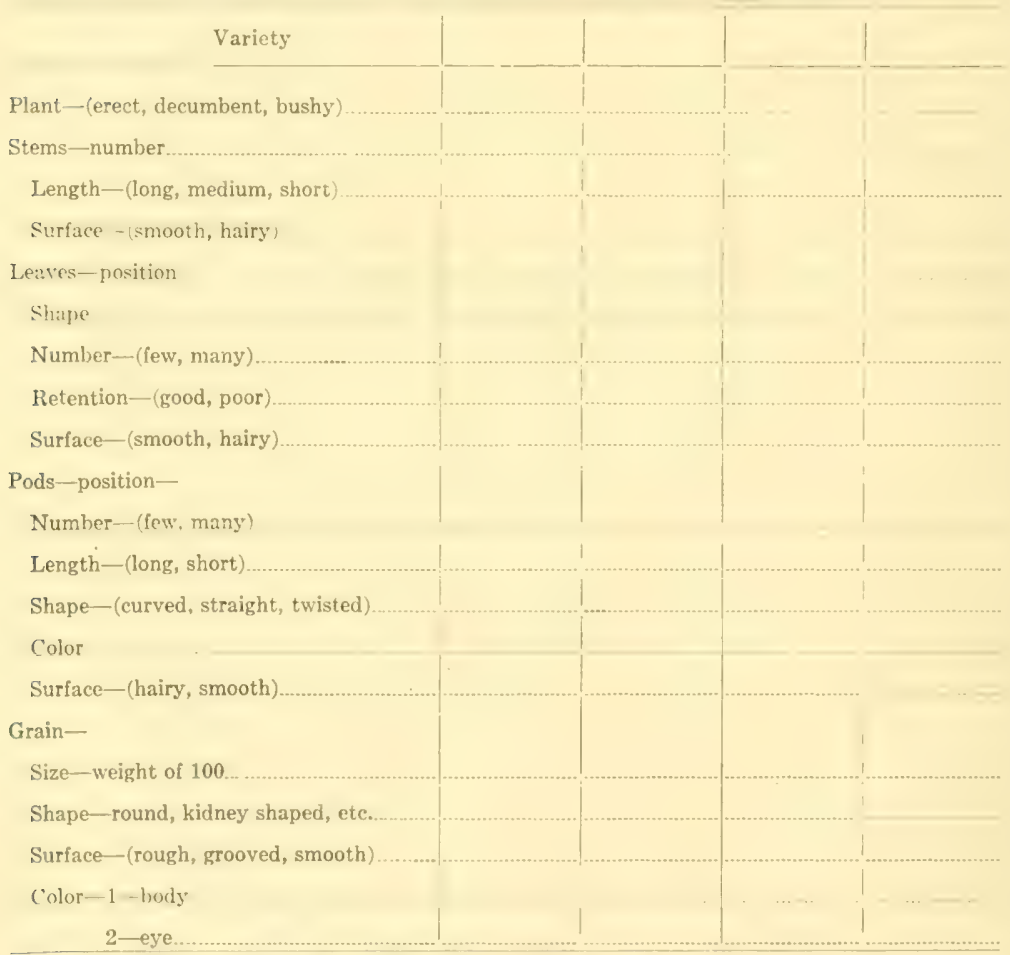

References: N. J. Bul. 250; Va. Bul. 168; Cornell Bul. 210; Farmers' Bul. 289, :318, :32; B. P. I. Circ. 121; I)el. Bul. 81; Ind. Bul. 172; Ohio Circ. 78; B. P. I. Bul. 98, 102, 197, 229; Journal of Agr. Research, Vol. II, No. 1, p. 33 ; Wis. Bul. 236; Tenn. Bul. 82 ; U. S. Dep. Bul. 119. 
EXERCISE 43.

DATE.

\section{STUDY OF WEED SEEDS IN FORAGE AND GRASS SEEDS.}

Before taking up the study of economical seeds it is well to study in the same manner as in Exercise 24, the seeds of weeds bad in grass and clover seeds. The seeds of Oxeye daisy, Burdock, Canada thistle, Quack grass, Sour dock, Wild mustard, Wild parsnip, Cheat, and probably a few other very bad weeds should be given to the class for study with a mixed sample of the same for separation somewhat after same plan as shown in Exercise 46 on the identification of legume seeds. In all exercises following identify weed seeds learned in this exercisc and in Exercise 24.

References: Ada Georgia-Assigned topies; Farm Weeds, Canadian Department of Agriculture; Ky. Bul. 18?; Ohio Bul. 175; B. P. I. Circ. 73; Md. Bul. 155; Farmers' Bul. 382, 428, 660; Minn. Bul. 129. 
C'ommon name

Sientifie name

() riģrin native or introduced

If introduced, from whenes?

Where commonly found?

Seeds found in what commercial seeds?

Character of weed-noxious, poisonous, etc.

Annual, biemnial or peremnial

Flower:

\section{Color}

Shape (wheel, bell, funnel, tubular)

Inflorescence (raceme, umbel, spike, head, panicle) terminal or axillary.

Stem:

Habit of growth (erect, decumbent, spreading, trailing)

Shape (round, triangular, rectangular)

Condition (rough, hairy, bristly, oily, sticky, smooth) Leaves:

Simple or compound

Parallel or notted reined.

Shape (linear, lanceolate, oblong, elliptical, oval, ovate, circular, wedge shapeel, heart shaped

Color: Upper side

Lower side

Condition (smooth, rough, bairy, prickly)

Arrangement topposite, alternate, whorl-:

Root:

Fihrous, conic:al, nayiform or fusiform

Habit (vertical, horizontal or both)

Fruit or seed:

Fleshy, stone or dry.

Dehiscent or indehisernt

Smooth or rough

Color or markings

Shape

Method of reproduction

Method of dissemination

- Methend of eradication

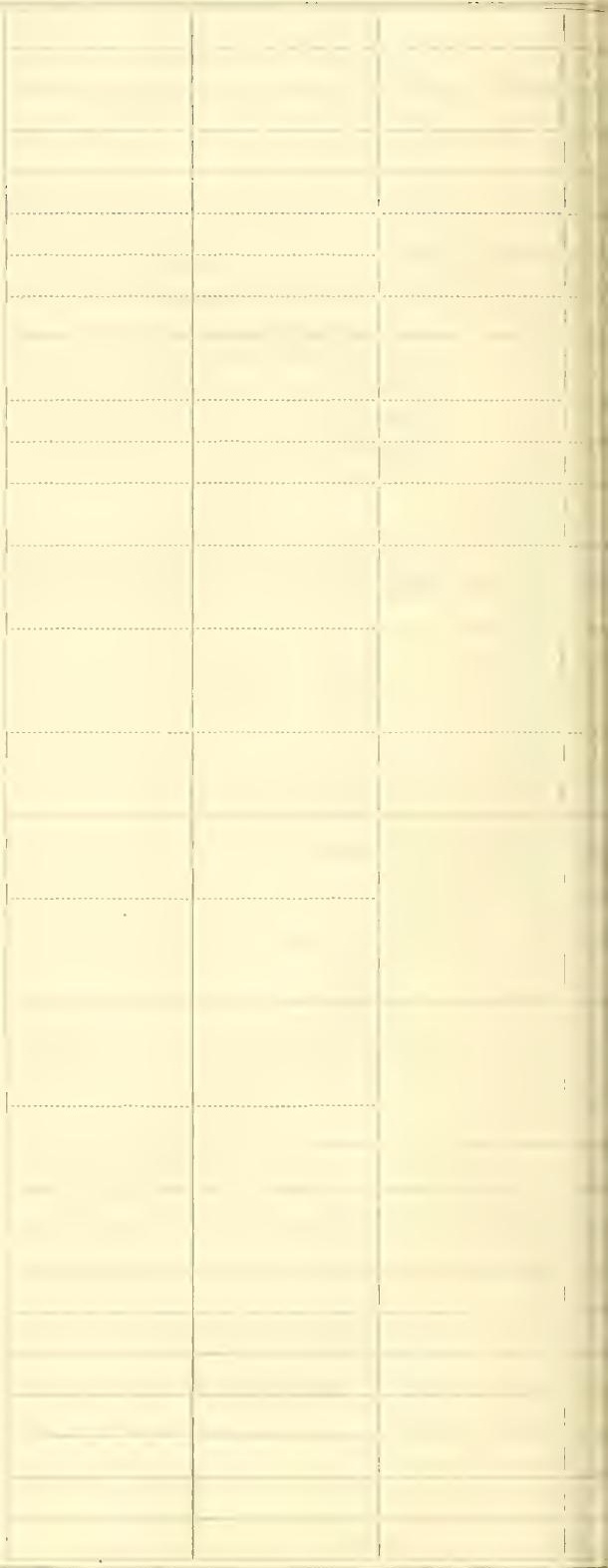


DATE.

D PLANTS.

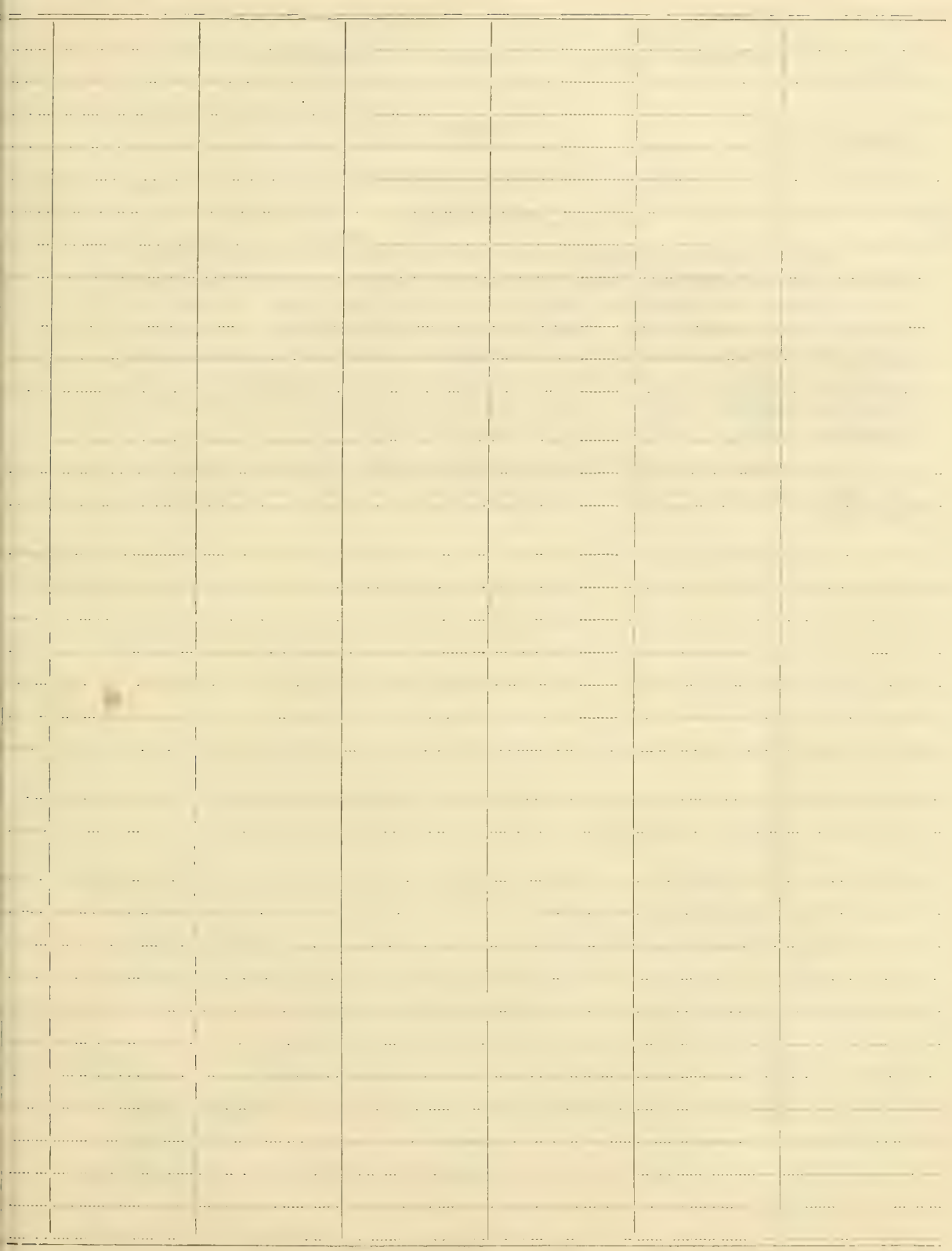


EXERCISE 45.

DATE

\section{STUDY OF LEGUME SEEDS. \\ (Clovers, Alfalfa, Etc.)}

Make a careful drawing of one of each of the different kinds of seeds supplied for the exercise. When there is more than one characieristic shape for the seed of any one legume, make a drawing of each type. Enlarge the drawing six or seven times. Label all parts in each drawing. After completing the drawings, write up a full description of each kind of seed, giving special attention to any characteristics that are helpful in identification. The following characters should be noted carefully: Size, shape, color, prominence of radicle, length of radicle, and prominence of hilum.

References: Farmers' Bul. 123, 260, 382, 428, 485; Minn. Sta. Bul. 127; Mich. Sta. Bul. 260; Ohio Sta. Bul. 142 and 175 ; Nev. Bul. 17 ; B. P. I. Bul. 111. 


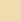


INSTRUCTOR'S NOTICES, EXPLANATIONS, ETC. 
Laboratory manual of Cereals and Forage Crops.

INSTRUCTOR'S NOTICES, EXPLANATIONS, ETC. 
EXERCISE 46.

DATE.

\section{IDENTIFICATION OF LEGUME SEEDS.}

The small vial supplied contains a mixture of small seeded legume seeds Logether with other foreign matter. Pun whe thind of the seed from the viat on a shect of scratch paper, and separate from the mixture all of the red clover seed. Then remove the alfalfa seed into another group and so on, so that when the separation is completed all of the seeds of one kind will be in one pile and all of another kind in another pile, etc.

Suggested Plan for Maiking Separation.

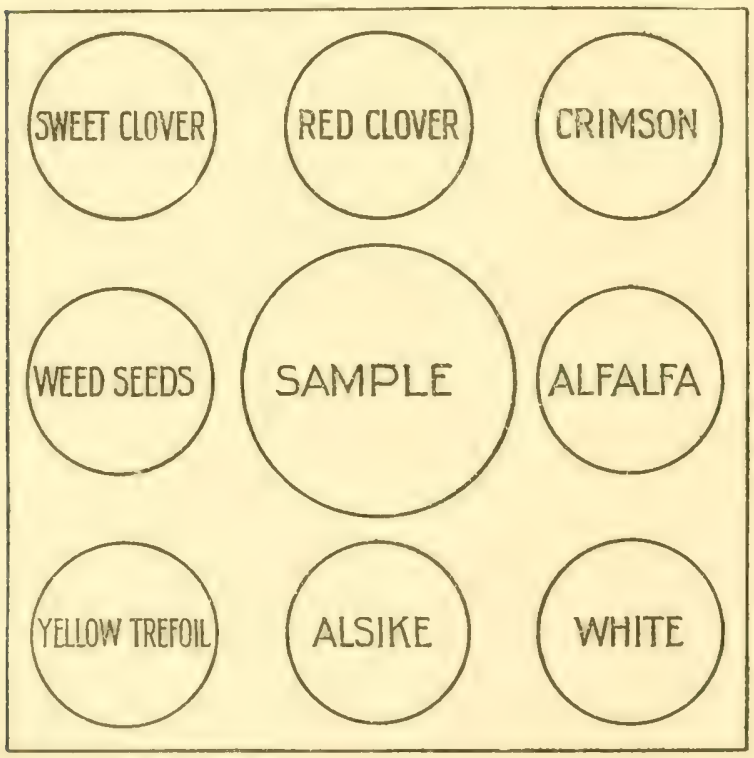


EXERCISE 47.

DATE

PURITY TEST FOR COMMERCIAL SEEDS.

The vial supplied contains a commercial sample of seed. The kind of seed is labeled on the vial. Make a determination for purity in the following manner. Accurately weigh up two grains of seed from the sample, pour out upon a piece of scratch paper as in exercise 46, and separate in as many groups as there are kinds of seeds present. Blasted, shriveled or otherwise injured seeds are considered pure seed. Tabulate the results in the outline.

Sample of. seed

Weight of sample used.

Number of Sample.

Weight of pure seed

*Weight of weed seed

Weight of other foreign seeds

Weight of inert matter

Total Weight

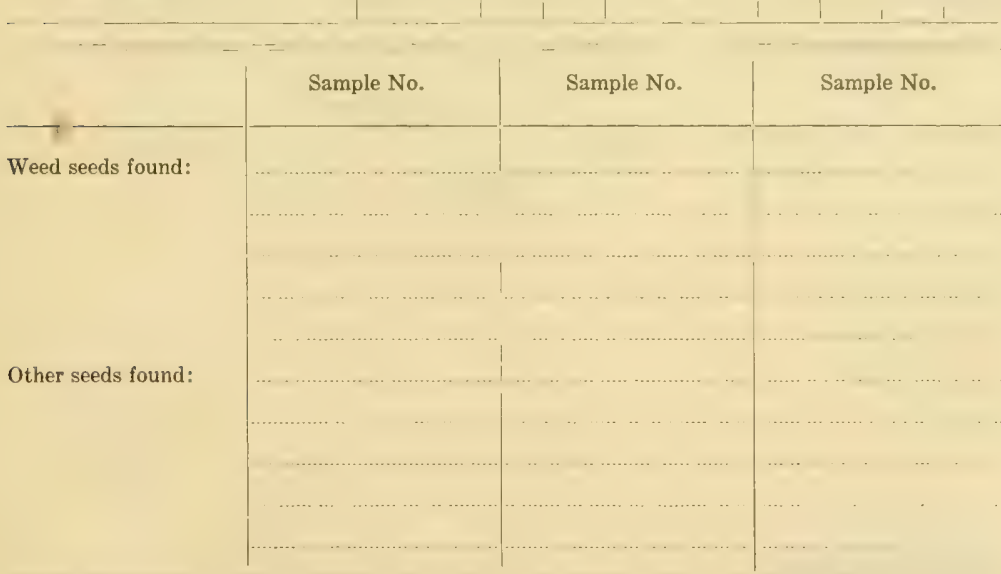

*When weed seeds or foreign matter are present in very small amounts, they need not be weighed, but may be expressed by number (as determined by counting), or as a trace. The per cent of pure seeds, if over $99 \%$, can be indicated as $99+$.

Bul. 148.

References: Mich. Bul. 212; Ariz. Bul. 54; Mass. Bul. 121; Ky. 
EXERCISE 48.

DATE.

\section{GERMINATION TEST OF LEGUME SEEDS.}

Count out one hundred seeds from the pure sample and place in the germinator. It should be remembered that shriveled, blasted or otherwi: injured seeds are considered as pure. In counting out the seeds, for the grerminating test, they should be taken without regard to their appearance. Run the test in duplicate.

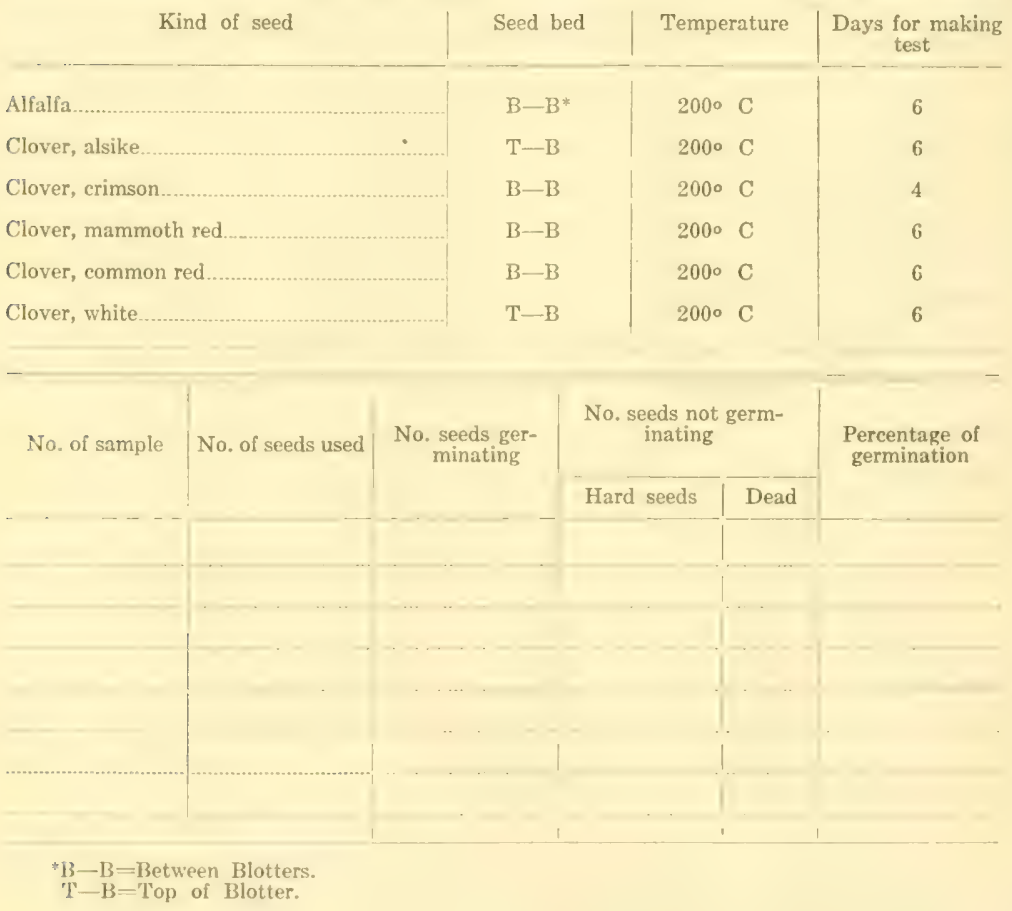


(1) What are the common impurities found in Alfalfa seed? Red Clover? Sweet Clover? Alsike?

(2) What is the standard of purity for commercial alfalfa seed? Red clover?

(3) If alfalfa seed of standard purity is worth $\$ 12.00$ per bushel, what is the actual value of a bushel of alfalfa seed of $82 \%$ purity?

(1) In the purchase of impure seed, is the loss in money value the only consideration?

(5) From the data obtained in Exercise 38, determine the cost of the weed seed and inert matter, if the commercial seed is quoted at $\$ 10.00$ per bushel.

(6) Why is a representative sample for testing necessary for a reliable test?

(7) Explain how you would select a representative sample from a bag of seed.

(8) What are "hard seeds"? What consideration would you give them in reporting a test?

(9) Locate the areas in United States supplying the various legume seeds.

(10) Are any of the legume seeds imported? How extensively and from what countries?

References: Ky. Bul. 148; Cornell Bul. 312; Farmers' Bul. 428. 


\section{Iaboratory manual of Cereals and forage Crops.}

EXERCISE 49.

LABORATORY STUDY OF LE: (Study of dried

Common name

Scientific name.

Annual, biennial, perennial

Place mostly grown

Soil adaptations...

Stems:

Length:

Size: coarse, medium, fine

Shape: round, square.

Surface: smooth, hairy

Branches: none, few, many.

Stoloniferous: very, medium, not

Position (in field): erect, decumbent, spreading, trailing.

Leaves:

Arrangement: spiral, two-rowed

Number: abundant, medium, not abundant

Shape: palmately or pennately foliolate

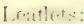

Numbier:

Sllape:

surlian: smeuth, haim

Edges: serrated, smooth

Persistence: persistent, lacking persistence

Stipules: attached to petioles, free

Inflorescence:

Natural color of petals

Position: end of leaf bearing stem or branch, in axil of leaf.

Kind: raceme, umbel, capilitum

Fruit:

Seed borne in pods, in capsules

Pod:

Shape: flat and elongated, spiral

Surface: smooth, hairy

(inlur:

Roots:

Diameter one inch below crown

Forkid, not forlacil

Tubereles: large, small, rounded, irregular 
DATE

\section{MINOUS FORAGE CROPS. ture plants.)}


INSTRUCTOR'S NOTICES, EXPLANATIONS, ETC. 
Laboratory Manual of Cereals and Forage Crops.

INSTRUCTOR'S NOTICES, EXPLANATIONS, ETC. 
Exercise 50.

FIELD S'TUDY OF LEGC

(Adapted for last

('ummon name

Scientific name

Annual, biennial, perennial...

Place mostly grown.

Thriftiness: vigorous, medium, weak

No. of plants per sq. ft. for full stand..

Stems:

Position: erect, decumbent, spreading, trailing.

Height:

Shape: round, square.

Surface: smooth, hairy

Stooling: stoloniferous, not

Branches: none, few, many

Coarseness: coarse, medium, fine.

Leaves:

Arrangement: spiral, two-ruwerl

Number: abundant, medium, not abundant

Shape: palmate, pemate

Leaflets:

Number:

Shape:

Surface: smooth, hairy...

Edges: smooth, serrated.

Color: shate of green

Stipules: attached to petioles, free

Inflorescence (if present):

Position: end of leaf bearing stem or branch, in axil of leaf.

hind: raceme, umbel, eapilitum

Nake a funal report of the legumes studied, giving the distinguishing characters and including What are the most common variations that serve as distinguishing characters among the leg What vegetative characters determine the value of a legume for hay?

Make a final report of the exercise, giving the distinguishing characters of the legumes studi 
EXERCISE 51.

DATE

\section{STUDY OF GRASS SEEDS.}

Make a careful drawing of one of each of the different kinds of grass seeds supplied for the exercise. When there is more than one characteristic shape for the seeds of any one grass, make a drawing of each type. Enlarge the drawing six or seven times. Label all parts in each drawing. After completing the drawings write up a full description of each kind of seed, giving special attention to any characters that are helpful in identification. The following characters should be carefully noted: Size, shape, color and length of flowering glume (when present) ; the characteristics of the rachilla and palea, and any other important characters useful for identification. The purpose of this exercise is to familiarize the student with the characteristics of the various grass seeds, which knowledge will be necessary in making separations and in conducting the purity test.

References: Assigned topics in A Text Book of Grasses-Hitcheock.

EXERCISE 52.

DATE

\section{IDENTIFICATION OF GRASS SEEDS.}

The small vial supplied contains a mixture of grass seeds together with other foreign matter. Pour a part of the seed from the vial upon a piece of seratch paper and separate it as in Exercise 46 . This is a continnation of Exercise 51 and is desirable for the purpose of gaining further skill in the identification of grass seeds. 
EXERCISE 53.

DATE.

\section{PURITY TEST OF GRASS SEEDS.}

The vial supplied contains a commercial sample of grass seed. Determine the purity in the following manner: Accurately weigh up one gram of seed from the sample. Pour out upon a piece of paper as in Exercise 47, and separate into as many groups as there are kinds of seeds present. Identify foreign seeds. Tabulate the results in the outline.

Sample of
Sample Number
Weight of pure seed.
*Weight of other foreign seeds..
*Weight of inert matter
Total weight ...............

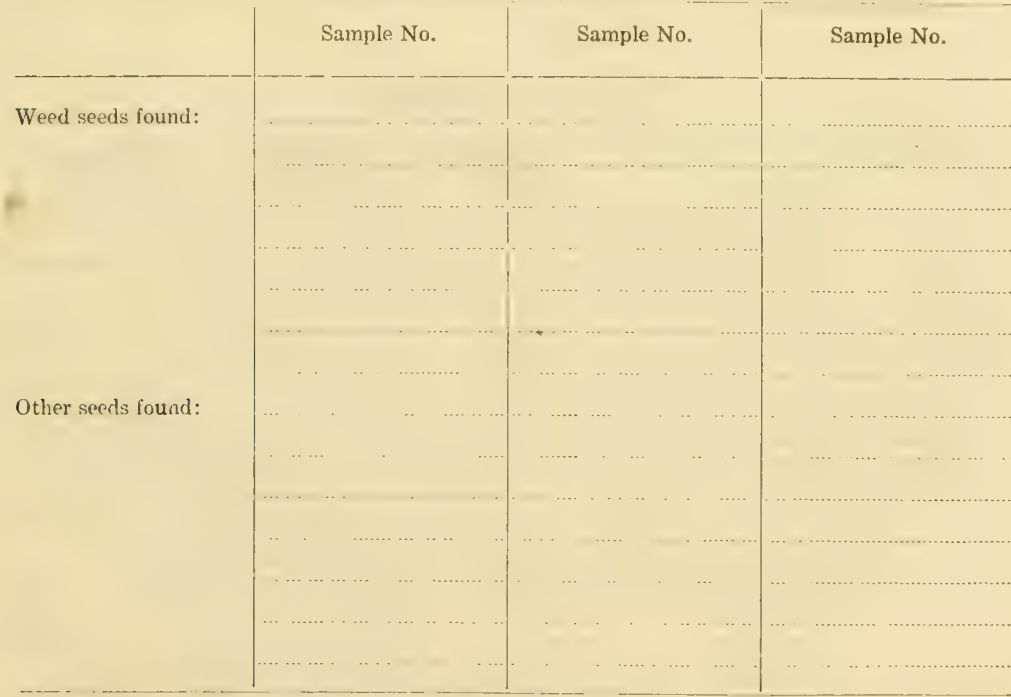

"When present in small amounts, may be indicated by number or by "a trace."

Referenees: Ohio Circ. 106; Mich. Circ. 20; Ala. Bul. 100; Farmers' Bul. 248, 300; U. S. Department Bul. 201; Office of Ex. Sta. Bul. 115; Meadows and Pastures-Wing. 
EXERCISF 54.

DATE

\section{GERMINATION TEST OF GRASS SEEDS.}

Count out one hundred seeds from the pure sample separated in Exercise 53. It should be remembered that blasted, shriveled and otherwise injured seeds are considered as pure seed. In counting out the seeds for the rromination test, they should be taken without regard to appearance. Run the test in duplicate.

\begin{tabular}{|c|c|c|c|}
\hline Kind of seed & Seed bed & Temperature & $\begin{array}{l}\text { Length of time } \\
\text { to complete } \\
\text { test }\end{array}$ \\
\hline $\begin{array}{l}\text { Bermuda Grass } \\
\text { Brome Grass } \\
\text { Blue Grass } \\
\text { Meadow Feseue } \\
\text { Orchard Grass.................... } \\
\text { Red Top } \\
\text { Rye Grass } \\
\text { TImothy }\end{array}$ & $\begin{array}{l}\mathrm{T}-\mathrm{B}^{*} \\
\mathrm{~B}-\mathrm{B} \\
\mathrm{T}-\mathrm{B} \\
\mathrm{B}-\mathrm{B} \\
\mathrm{B}-\mathrm{B} \\
\mathrm{T}-\mathrm{B} \\
\mathrm{B}-\mathrm{B} \\
\mathrm{T}-\mathrm{B}\end{array}$ & $\begin{array}{l}20-35^{\circ} \mathrm{C} . \\
20-30^{\circ} \mathrm{C} . \\
20-30^{\circ} \mathrm{C} . \\
30-30^{\circ} \mathrm{C} . \\
20-30^{\circ} \mathrm{C} . \\
20-30^{\circ} \mathrm{C} . \\
20-30^{\circ} \mathrm{C} . \\
20-30^{\circ} \mathrm{C} .\end{array}$ & $\begin{array}{r}21 \text { days } \\
10 \text { " } \\
28 \text { " } \\
10 \text { " } \\
14 \text { " } \\
8 \text { “ } \\
14 \text { " }\end{array}$ \\
\hline
\end{tabular}

* See Exercise 48.

\section{TABUlation of REsUlts.}

No. of sample No. of seeds used $\mid$ No. of seeds ger- $\begin{gathered}\text { No. seeds not } \\ \text { Germinating }\end{gathered} \mid \begin{gathered}\text { Percentage of } \\ \text { germination }\end{gathered}$


(1) What are the common impurities of the following grasses:- Kentucky Blue Grass, Orchard Grass, Red Top. Timothy and Brome Grass?

(2) How may the impurities indicate the source of seed. Give several examples.

(3) Which of the above grass seeds are imported in large amounts? From what countries?

(4) Does the United States export grass seeds? What kinds and to what countries?

(5) The seeds of what grasses are likely to be low in vitality? Can you give any reasons for the general lack of vitality?

(6) Calculate the actual value of the samples you have tested, if pure seed of perfect vitality is selling at prevailing market quotations.

References: Ver. Bul. 170; Ky. 148; Minn. Ex. Bul. 24.

EXERCISE 55.

DATE

\section{COLLECTING AND MOUNTING OF LEGUMES AND GRASSES.}

Collect from the grass garden or from the fields a typical specimen of each of the grasses and legumes studied in the preceding exercises. Preare the specimens for mounting by drying in the herbarium press. After pressing and drying mount each specimen on cardboard mounts which are furnished. Correctly label with common and scientific name, the date of collection, and the name of the collector. When possible, attach to the mount several seed pods together with a number of seeds of the specimen. Seeds and seed pods of some of them may be secured from the laboratory.

Or instead of mounting as suggested above use the pasteboard boxes with glass fronts and cotton background. These boxes may be obtained from supply houses at small cost and the mount when finished allows of much handling and ready examination. This sort of mount is well adapted to specimens that can not be pressed, such as grain heads.

The instructor will make assignments of work but the student would find it profitable and worth while to make as complete collection of seeds, plants and so on as possible.

Reference: Farmers' Bul. 586. 
134 Laboratory manula of Cerenls and forage Crops.

INSTRUCTOR'S NOTICES, EXPLANA'TIONS, E'T'C. 
Laboratory Manual of Cereals and Forage Crops.

INSTRUCTOR'S NOTICES, EXPLANATIONS, ETC. 
IXERCISE 56.

FIELD STUDY OI

(Adapted for last

(i)mument mamm

Scientific name.

Place mostly grown

T'hriftiness: vigorous, medium, weal:

Habit of growth:

Stooling: very stoloniferous, medium, not

Diameter of plants (average of 10 plants)

No. of plants per square foot for full stand.

Roots:

Color: white, brown, red

Culms:

Depth, deep or shallow-medium

Number per plant (average 10 plants)

Height-inches (average 10 plants)

Position: erect, decumbent at base, decumbent.......

Size: coarse, medium, slender

Shape: round, elliptical, lenticular...

('olor:

Filiuge:

Ihiculame: atmuslant, medium, scanty

Distribution: basal foliage, abundant, culm foliage abundant...

Leaf sheath: smooth, downy, scabrous, split to node, partly split,

I. eaf blade:

$$
\text { rluard }
$$

Length-average of 5 .

Width-average of 5 .

Position: erect, ascending, drooping.

Midrib: prominent, medium, indistinct.

Surface: smooth, downy, rough

Color: shade of green.

Adapted for: pasture, hay, both, lawn, etr.

Intlorescence (if present):

Shape: panicle, open and spreading, compressed, spike like

Lemith ivirage of 5

No. of flowers per spikelet

Colur:

Make a final report of the grasses studied, noting variations that may serve as points of distinction.

REFERENCE:

Ohio Bul. 225. 
RENNIAL GRASSES.

ay or first of June.) 
INSTRUCTOR'S NO'TICES, EXPLANATIONS, E'TC. 
Laboratory Manual of Cereals and Forage Crops.

INSTRUCTOR'S NOTICES, EXPLANATIONS, ETC. 
EXERCISE 57.

DATE.

STUDY OF MILLETS AND SORGHUMS.

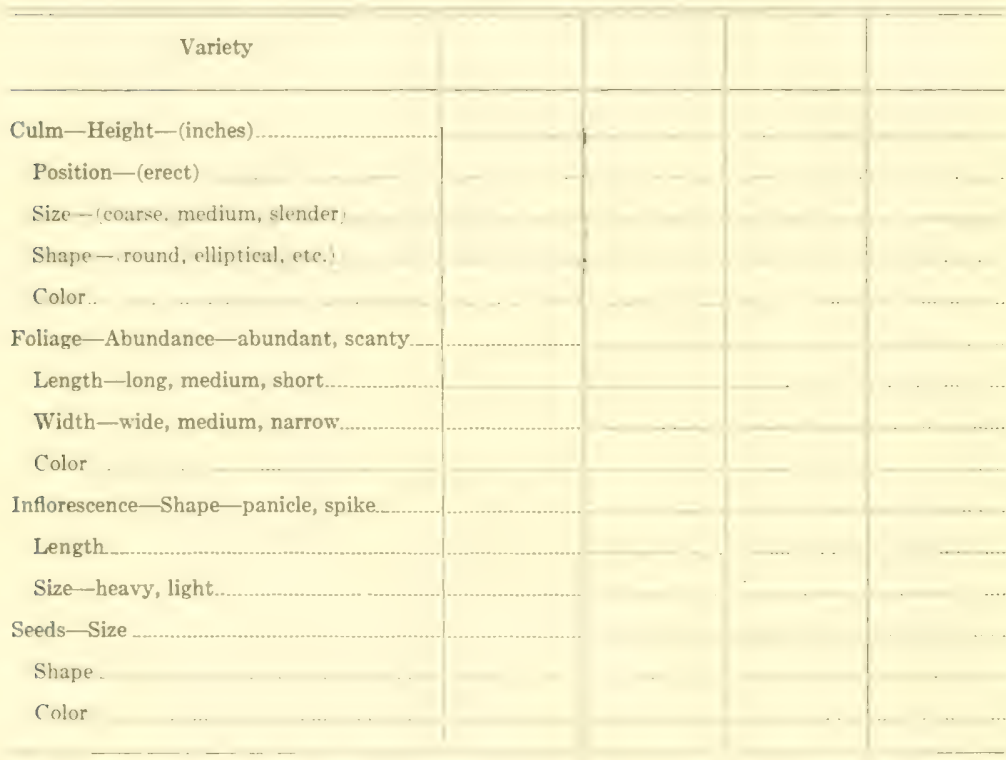

\section{REFERENCES:}

Ariz. Bull. 54.

S. D. Bul. 135.

Ohio Bul. 269.

N. J. Bul. $250^{\circ}$.

B. P. I. Bul. 175, 203.
Mich. Bul. 117.

Va. Bul. 168.

Fla. Bul. 92.
Idaho Bul. 24.

Kans. Bull. 123

S. C. Bul. 88 . 

142 Laboratory Manual of Cereals and Forage Crops.

INSTRUCTOR'S NOTICES, EXPLANATIONS, ETC. 
laboratory Manual of Cereals and forage Crops.

INSTRUCTOR'S NOTICES, EXPLANATIONS, ETC. 
EXERCISE; 58.

A VARIETY STL

This work may be done by using old potatoes for tuber description outline throughout the growing season.

Group potatoes after study according to scheme of Stuart, U. S. D.

Variety

Tuber:

$\therefore+\cdots$

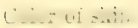

Markings (splashed with color, rough, smooth)

Markings of tlesh.

Size.

Eyes (deep, medium, shallow)

Sprouts:

Base color

1. $\therefore \therefore \ldots+\cdots+r+\cdots n$

$1, \cdots f \times \cdots, 1+\cdots, 1, t$

$T_{i}-(\cdots, \cdots$

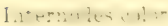

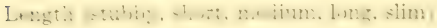
Eve:

(cole:

Dumbur fore, rulliwn, many

Depth (deep, medium, shallow)

Bud eye cluster (deep, medium, shallow)

Vines:

Size (small, medium, large)

Color of stem

Habit of growth (compact, spreading, short, long, erect, decumbent).

Leaves:

Size (small, medium, large)

Color (light green, green, med. dark green, dark)

Color (light green, green, med. dark green, dark green|)

Flowers:

Number (many, medium, few)

( $:-$

Time to mature...

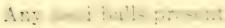


EXERCISE 59.

DATE.

\section{SCORING POTATOES.} potatoes:

The following points should be carefully noted in judging and scoring

1. Trueness to type-Conforming to variety characteristics in variety classes, and to prevailing type in general classes.

2. Uniformity of exhibit-Uniform in shape, length and circumference.

3. Shape-Should be round, oval or long, conforming to the typical shape of the class to which they belong. They should be smooth, free from depressions and protuberances.

4. Color-True to variety, fresh and without sunburn.

5. A split potato should show no hollows. The centers should be small and not watery. The cortical layer should be thick. The flesh should be firm of texture, clear in color, free from dark rings or discolorations of any kind.

6. Skin-Should be smooth or russeted, without blemish and thin.

7. Eyes-Few in number according to variety characteristics, shallow, and cover little surface.

Size-Should be uniform and according to variety. Extremely large or small potatoes are undesirable.

Judge plates of five, pecks, and half bushels.

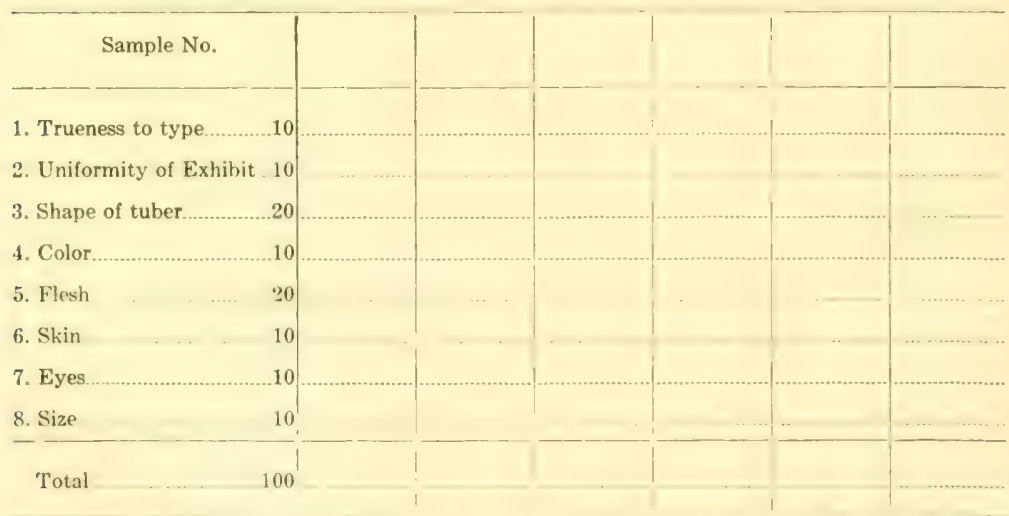

References: Fraser, pp. 70-90; Guilford and Grubb, pp. 311-318; Farmers' Bul. 533; B. P. I. Circ. 93, 113. 


\section{APPENDIX.}

\section{QUANTITy TO SOW PER ACRE AND THE Leg.LL Weight PER Bushel of VARI- ous FARM CROP SEEDS.}

Name of Seed

Alfalfa

Beans (feld)

Beans (field) large

Blue Grass.

Brome Grass

Broom Corn

Buckwheat

Bur Clover

Clover Alsike

Clover, Crimson

Clover, Mammoth

Clover, Lespedeza

Clover, Red.

Clover, Sweet

Clover, White.

Corn, Dent

Corn, Pop.

Corn, Sweet

Cowpeas

Field Pea (small)

Field Pea (large)

Flax (for seed)

Flax (for fiber)

Hemp.

Hungarian Grass

Johnson Grass

Kaffir (for grain)

Kaffir (for fodder).

Lupine

\section{Y'angel}

Meadow Fescue

Millet

Milo.

Oat grass, tall

Oats

Orchard Grass

Potatoes (Irish)

Rape (drilled)

Rape (broadcast)

Red Top

Rye.

Rye Grass

Sorghum (forage)

Soybean (drilled)

Soybean (broadcast)

Sugar Beets.

Timothy.

Vetch

Wheat.
Amount per Acre

15 to $25 \mathrm{lb}$.

8 to $10 \mathrm{pk}$

2 to 4 pk.

$41 / 2$ to $6 \mathrm{pk}$

20 to $40 \mathrm{lb}$.

12 to $15 \mathrm{lbs}$.

2 to 4 plss.

3 to 5 plss.

10 to $15 \mathrm{lbs}$

8 to $15 \mathrm{lbs}$.

10 to 15 lbs.

10 to $15 \mathrm{lbs}$.

10 to $15 \mathrm{lbs}$...

8 to 12 liss.

8 to $12 \mathrm{lbs}$.

4 to $8 \mathrm{lbs}$.

5 to $10 \mathrm{lbs}$.

2 to $4 \mathrm{lbs}$.

3 to $6 \mathrm{lb}$.

3 to 6 pks.

2 to 3 bu.

3 to $31 / 2 \mathrm{bu}$

2 to $3 \mathrm{pk}$...

$11 / 2$ to $2 \mathrm{bu}$.

$31 \frac{1}{2}$ to $41 / 2 \mathrm{pk}$.

1 to 2 pks.

1 to $11 / 2$ bu.

5 to 10 lbs.

40 to 80 lbs.

$11 / 2$ to $2 \mathrm{bu}$.

5 to $10 \mathrm{lbs}$...

25 to $35 \mathrm{lbs}$.

1 to $3 \mathrm{pk}$.

4 to $8 \mathrm{lb}$....

25 to $30 \mathrm{lbs}$.

2 to 3 bu.

12 to $15 \mathrm{lb}$.

12 to $25 \mathrm{bu}$.

2 to 4 lbs.

4 to 8 lbs.

10 to $20 \mathrm{lbs}$.

3 to 4 pks.

2 to 3 hu.

$11 / 2$ to 2 bu.

2 to 3 pks.

1 to $11 / 2 \mathrm{bu}$.

15 to $25 \mathrm{lbs}$.

15 to $25 \mathrm{lbs}$.

1 to $11 / 2 \mathrm{bu}$.

3 to 9 pks.
Legal Weight per Bu.

Pounds

60

48

60

60

14

14

56

48

60

60

60

60

60

60

60

56

56

56

60

60

60

56

56

50

56

56

56

-

24

50

56

10

32

14

60

50

50

14

56

14

56

60

60

45

60

60 




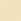





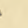

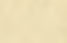




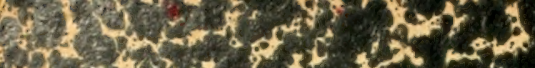

$\left.x^{2}\right]^{7}=0$

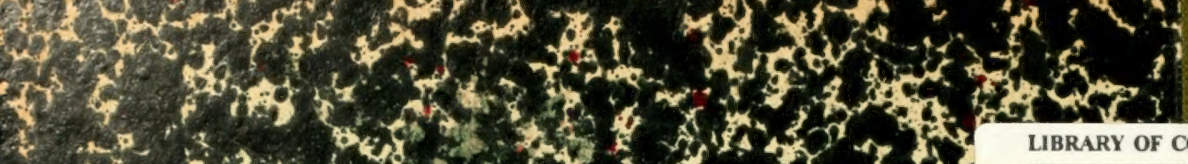

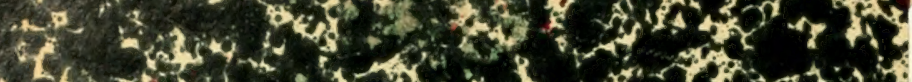

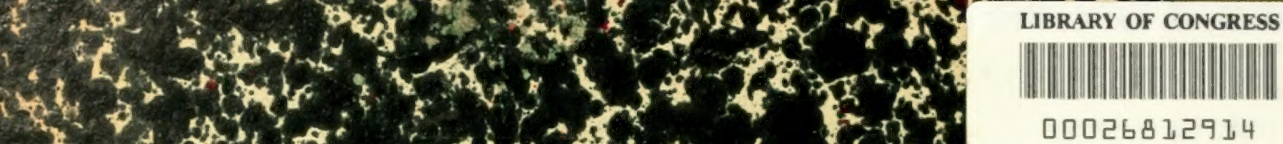

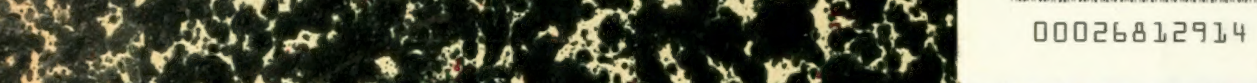
6.

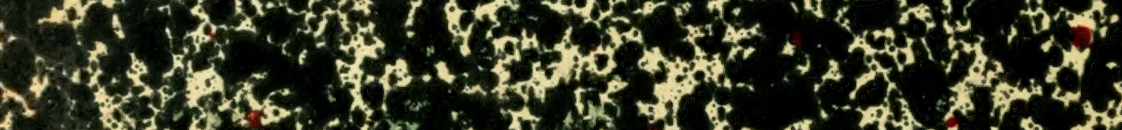

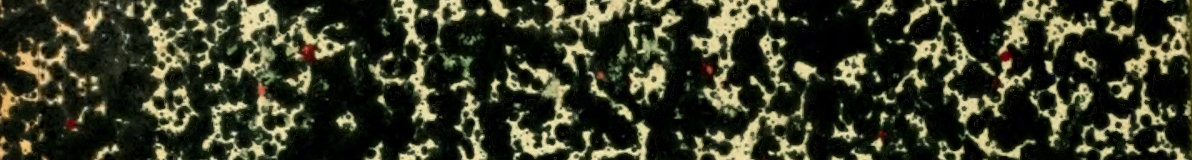

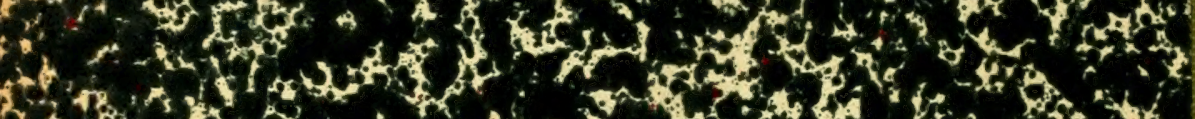
(1)

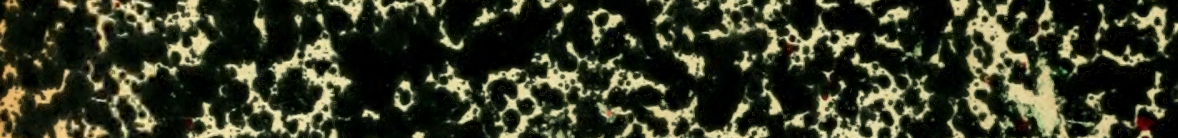

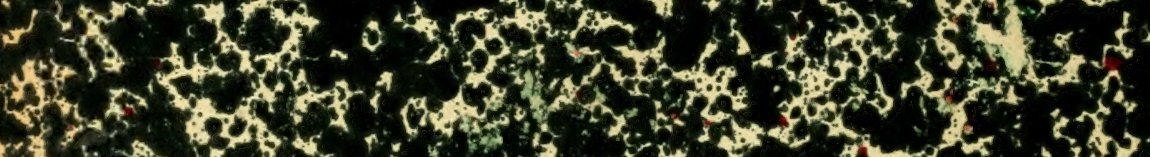

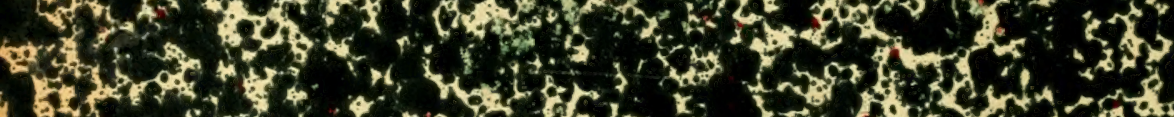

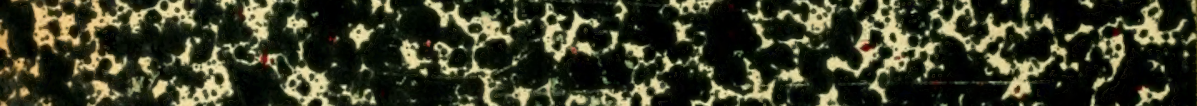

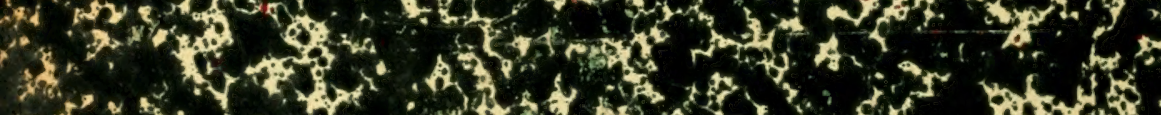

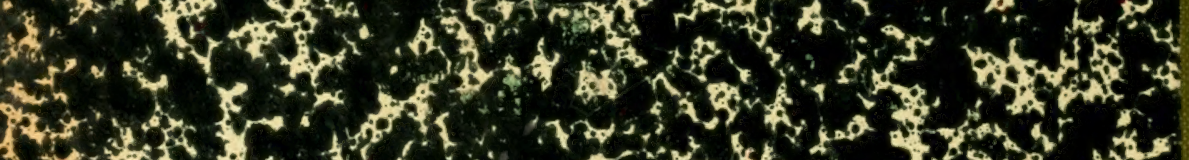

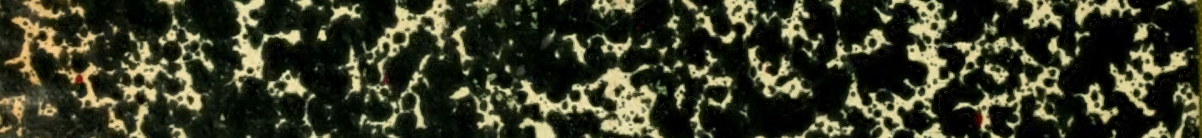

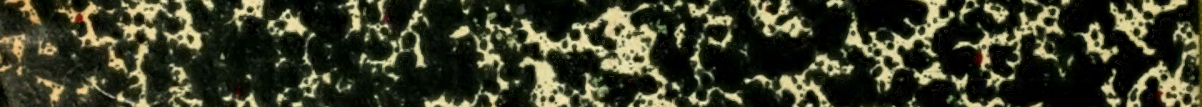
3)

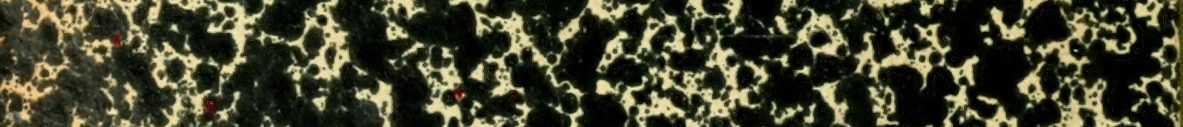

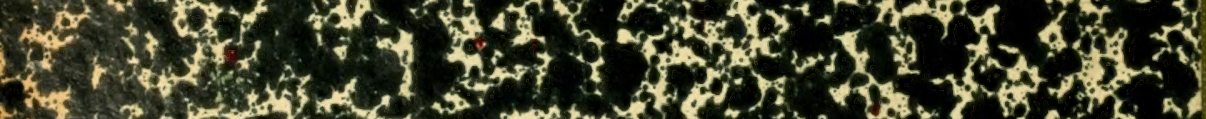

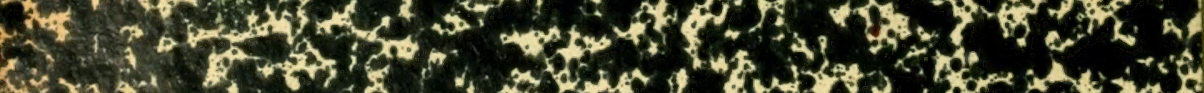

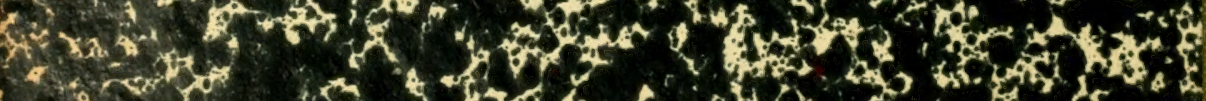

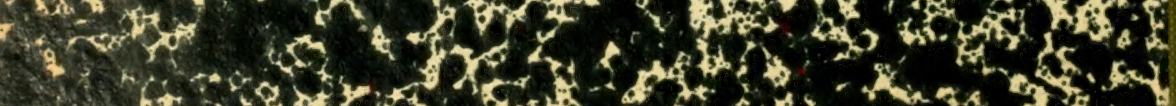

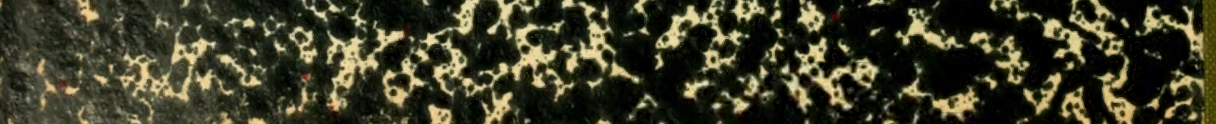

